Characterisation of chicken OX40 and OX40L

von

Stephanie Hanna Katharina Scherer 
Inaugural-Dissertation zur Erlangung der Doktorwürde der Tierärztlichen Fakultät

der Ludwig-Maximilians-Universität München

\section{Characterisation of chicken OX40 and OX40L}

von Stephanie Hanna Katharina Scherer

aus Baunach bei Bamberg

München 2018 

Aus dem Veterinärwissenschaftlichen Department der Tierärztlichen Fakultät der Ludwig-Maximilians-Universität München

Lehrstuhl für Physiologie

Arbeit angefertigt unter der Leitung von

Univ.-Prof. Dr. Thomas Göbel 



\section{Gedruckt mit Genehmigung der Tierärztlichen Fakultät der Ludwig-Maximilians-Universität München}

Dekan:

Berichterstatter: Univ.-Prof. Dr. Thomas Göbel

Korreferenten:

Univ.-Prof. Dr. Bernhard Aigner

Prof. Dr. Herbert Kaltner

Univ.-Prof. Dr. Rüdiger Wanke

Tag der Promotion: 27. Juli 2018 

Meinen Eltern und Großeltern 



\section{Contents}

$\begin{array}{lr}\text { List of Figures } & 11\end{array}$

$\begin{array}{ll}\text { Abbreviations } & 13\end{array}$

1 Introduction $\quad 17$

2 Fundamentals $r$

$2.1 \mathrm{~T}$ cell activation $\ldots \ldots \ldots \ldots \ldots \ldots$

2.1.1 The activation of $\mathrm{T}$ cells requires the presence of several signals 19

2.1.2 Costimulatory signals transmitted via members of the immunoglobulin superfamily . . . . . . . . . . . . 22

2.1.3 Costimulatory signals transmitted via members of the cytokine receptor family . . . . . . . . . . . . 23

2.1.4 Costimulatory signals transmitted via members of the tumour necrosis factor receptor superfamily . . . . . . . . . 24

2.2 The tumour necrosis factor receptor superfamily $\ldots \ldots$. . . . . . 26

2.2.1 The structure of tumour necrosis factor receptors . . . . . 26

2.2.2 Functional classification of TNFRSF members . . . . . . 28

2.3 The tumour necrosis factor superfamily . . . . . . . . . . . . . 29

2.3.1 The structure of tumour necrosis factor ligands . . . . . . . . 29

2.3.2 Classification of TNFSF members according to their structural properties . . . . . . . . . . . . . . 31

2.4 Receptor-ligand interactions . . . . . . . . . . . . . . . . . . 32

2.5 Signalling pathways . . . . . . . . . . . . . . . . 35

2.5.1 Signalling cascade of OX40 within the T cell . . . . . . . 35

2.5 .2 Reverse signalling $\ldots \ldots \ldots \ldots$. . . . . . . . . 37

2.6 The OX40-OX40L costimulatory system . . . . . . . . . . 38

2.6.1 Expression profile of OX40 . . . . . . . . . . . 38

2.6.2 Expression profile of OX40L . . . . . . . . . . . . . 39

2.6.3 Functions of the OX40-OX40L system during an immune response . . . . . . . . . . . . . . . . 39 
$\begin{array}{llr}4 & \text { Publication } & 47\end{array}$

$\begin{array}{lll}5 & \text { Discussion } & 59\end{array}$

5.1 Costimulatory signals in T cell activation in chickens . . . . . . . . 59

5.2 Genomic identification of chicken OX40 and OX40L . . . . . 60

5.3 Phylogenetic and structural analyses of OX40 and OX40L . . . . . 61

5.4 Dimerisation of recombinant soluble OX40 and OX40L variants . . . 64

5.5 Interaction of chicken OX40 and OX40L . . . . . . . . . . . 64

5.6 Staining of chicken cells with recombinant OX40-Fc . . . . . . 66

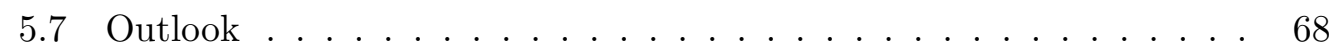

$\begin{array}{lll}6 & \text { Summary } & 71\end{array}$

$\begin{array}{lll}7 & \text { Zusammenfassung } & 73\end{array}$

$\begin{array}{llr}8 & \text { References } & \mathbf{7 5}\end{array}$

9 Danksagung $\quad 95$ 


\section{List of Figures}

1 Costimulatory signals allow for $\mathrm{T}$ cell activation . . . . . . . . . . 20

2 The lack of costimulatory signals inhibits $\mathrm{T}$ cell activation . . . . . 20

3 The superfamilies of costimulatory molecules . . . . . . . . . . 21

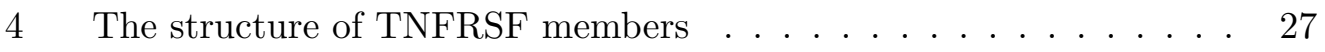

5 The structure of TNFSF members . . . . . . . . . . . 30

6 The $3: 3$ interaction between OX40 and OX40L monomers . . . . . 32

$7 \quad$ A model of receptor preassembly and receptor-ligand interaction . . 34

8 Signalling pathways of OX40 upon OX40L interaction . . . . . . 36

$9 \quad$ Effects of OX40 signals for T cells . . . . . . . . . . . . . 40

10 Effects of reverse signalling via OX40L for OX40L-expressing cells . 42 



\section{Abbreviations}

$\begin{array}{ll}\text { 4-1BBL } & \text { 4-1BB ligand } \\ \text { APC } & \text { Antigen presenting cell } \\ \text { BAFF } & \text { B cell activating factor belonging to the TNF family } \\ \text { BAFFR } & \text { B cell activating factor receptor } \\ \text { Bcl-2 } & \text { B cell lymphoma } 2 \\ \text { BCL2A1 } & \text { Bcl2-related protein A1 } \\ \text { Bcl-XL } & \text { B cell lymphoma-extra large } \\ \text { BCMA } & \text { B cell maturation antigen } \\ \text { CCL5 } & \text { C-C chemokine ligand } 5 \\ \text { CD } & \text { Cluster of differentiation } \\ \text { CD4 } & \text { CD4 positive } \\ \text { CD8 } & \text { CD8 positive } \\ \text { CD27L } & \text { CD27 ligand } \\ \text { CD30L } & \text { CD30 ligand } \\ \text { CD40L } & \text { CD40 ligand } \\ \text { cDNA } & \text { Complementary DNA } \\ \text { ConA } & \text { Concanavalin A } \\ \text { CRD } & \text { Cysteine rich domain } \\ \text { CTLA-4 } & \text { Cytotoxic T lymphocyte-associated protein 4 } \\ \text { CXCR5 } & \text { C-X-C motif chemokine receptor } 5 \\ \text { DC } & \text { Dendritic cell } \\ \text { DcR3 } & \text { Decoy receptor } 3 \\ \text { DD } & \text { Death domain } \\ \text { DR3 } & \text { Death receptor } 3 \\ \text { EDA } & \text { Ectodysplasin A } \\ \text { ELISA } & \text { Enzyme-linked immunosorbent assay } \\ \text { FasL } & \text { Fas ligand } \\ \text { FoxP3 } & \text { Fragment crystallisable } \\ & \end{array}$




\begin{tabular}{|c|c|}
\hline GITR & Glucocorticoid-induced TNFR-related protein \\
\hline GITRL & GlTR ligand \\
\hline gp34 & Glycoprotein 34 \\
\hline GvHD & Graft versus host disease \\
\hline HVEM & Herpesvirus entry mediator \\
\hline HVEML & HVEM ligand \\
\hline ICOS & Inducible $\mathrm{T}$ cell costimulator \\
\hline ICOSL & ICOS ligand \\
\hline $\mathrm{IFN} \gamma_{\gamma}$ & Interferon $\gamma$ \\
\hline IGSF & Immunoglobulin superfamily \\
\hline IL & Interleukin \\
\hline IL-2R & Interleukin 2 receptor \\
\hline LFA-3 & Lymphocyte function-associated antigen 3 \\
\hline $\mathrm{MHC}$ & Major histocompatibility complex \\
\hline mRNA & Messenger RNA \\
\hline NFAT & Nuclear factor of activated $\mathrm{T}$ cells \\
\hline $\mathrm{NF} \varkappa \mathrm{B}$ & Nuclear factor $x$-light-chain-enhancer of activated B cells \\
\hline NK & Natural killer cell \\
\hline NKT & Natural killer T cell \\
\hline OPG & Osteoprotegerin \\
\hline $\mathrm{OX} 40-\mathrm{Fc}^{+}$ & OX40-Fc positive \\
\hline OX40L & OX40 ligand \\
\hline PBL & Peripheral blood lymphocyte \\
\hline PBMC & Peripheral blood mononuclear cell \\
\hline PI3-K & Phosphatidylinositol 3-kinase \\
\hline PKB & Protein kinase B \\
\hline PLAD & Pre-ligand-binding assembly domain \\
\hline PRDX6 & Peroxiredoxin 6 \\
\hline qPCR & Quantitative polymerase chain reaction \\
\hline RANK & Receptor activator of nuclear factor $x \mathrm{~B}$ \\
\hline
\end{tabular}


RANKL RANK ligand

RANTES Regulated on activation normal T cell expressed and secreted

SDF4

Stromal cell derived factor 4

SMART

Simple modular architecture research tool

TACI

Transmembrane activator and calcium modulating ligand interactor

TCR

$\mathrm{T}$ cell receptor

TCR $1^{+} \quad$ TCR1 positive

TCR2 ${ }^{+} \quad$ TCR2 positive

TCR3 $^{+} \quad$ TCR3 positive

Tfh Follicular helper T cell

TGF- $\beta \quad$ Transforming growth factor $\beta$

Th T helper cell

THD TNF homology domain

TNC Tenascin C

TNF Tumour necrosis factor

$\mathrm{TNF} \alpha \quad$ Tumour necrosis factor $\alpha$

TNF $\beta \quad$ Tumour necrosis factor $\beta$

TNF-R1 TNF receptor 1

TNF-R2 TNF receptor 2

TNFRSF Tumour necrosis factor receptor superfamily

TNFSF Tumour necrosis factor superfamily

TRAF TNF receptor-associated factor

TRAIL TNF-related apoptosis-inducing ligand

TRAIL-R3 TNF-related apoptosis-inducing ligand receptor 3

TRAIL-R4 TNF-related apoptosis-inducing ligand receptor 4

Treg Regulatory $\mathrm{T}$ cell

TSLP Thymic stromal lymphopoietin

V Variable chain

XEDAR X-linked ectodysplasin-A2 receptor 



\section{Introduction}

Immunological research mainly focusses on the immune response to infections and the pathogenesis of different diseases in humans based on the application of human cells or mouse models. Besides humans and rodents, chickens represent the species whose immune system is studied best [1]. In fact, the understanding of several basic immunological mechanisms dates back to studies with chickens. Pivotal processes like $\mathrm{B}$ cell and $\mathrm{T}$ cell development or the function of interferons, were first discovered and described in chickens [2-4]. Only later, this knowledge was transferred to the mammalian immune system. This transfer of knowledge was possible, since the main components and mechanisms of host defence are conserved among birds and mammals, even though the two lineages split approximately 310 million years ago [5].

Like mammals, chickens exhibit a potent innate immune system comprising humoral (e.g. defensines) as well as cellular components (e.g. Natural Killer (NK) cells and macrophages) [6-8]. Additionally, chickens possess a highly developed adaptive immune system, including immunological memory. Analogously to mammals, antibodies and lymphocytes constitute the two major (humoral and cell-mediated) branches of the adaptive immune system in chickens [9, 10]. Antibodies, which are produced by B lymphocytes, specifically target extracellular antigen, whereas $\mathrm{T}$ lymphocytes constitute the cellular axis of the adaptive immune system. T lymphocytes can be further divided into different subsets, which are crucially involved in the process of host defence. In terms of effector functions, T cells can be generally classified into three main groups. Cytotoxic $\mathrm{T}$ lymphocytes recognise intracellular pathogens as well as tumour cells and eliminate them to regain homeostasis. They characteristically exhibit the Cluster of Differentiation (CD) 8 co-receptor on their cell surface $\left(\mathrm{CD}^{+}\right)$. T helper (Th) cells, bearing the $\mathrm{CD} 4$ co-receptor $\left(\mathrm{CD} 4^{+}\right)$, support B cells and cells of the innate immune system in fulfilling their tasks. Finally, regulatory $\mathrm{T}$ cells (Treg) terminate the immune response and help to restore homeostasis. On the basis of their $\mathrm{T}$ cell receptor (TCR), $\mathrm{T}$ cells can be divided into $\alpha \beta$ and $\gamma \delta \mathrm{T}$ cells $[11,12]$. While the functions of $\alpha \beta \mathrm{T}$ cells are well studied in chickens and mammals, the knowledge about $\gamma \delta \mathrm{T}$ cells in both lineages remains scarce.

Even though the general mechanisms of the formation of an immune response in chickens are similar to those in mammals, chickens exhibit specialities, which distin- 
guish them from the mammalian species. The existence of the Bursa of Fabricius, i.e. the location of $\mathrm{B}$ cell development, the presence of a special type of granulocytes called heterophils or the absence of lymph nodes, neutrophils and classical eosinophils only constitute the most evident differences between mammals and chickens [6]. Additionally, chickens are equipped with an altered set of cytokines and receptors [6] and exhibit a significantly higher number of $\gamma \delta \mathrm{T}$ cells [13].

In the past, the specialities of the embryonic development of chickens and of its immune system notably contributed to the understanding of immunological processes in mammals. Nowadays, the economic impact of poultry as a leading meat source (regarding the feed conversion rate) [14] and its epidemiological role in spreading zoonotic infections (e.g. Campylobacter, Salmonella and Influenza) [15], emphasise the importance of investigating chicken immune responses. A profound understanding thereof may notably contribute to maintain human and animal welfare by ensuring low loss rearing and by limiting the risk of zoonoses. 


\section{Fundamentals}

\subsection{T cell activation}

The activation of naïve $\mathrm{T}$ cells and their differentiation into effector, regulatory or memory $\mathrm{T}$ cells is a crucial step in the formation of an effective host defence against pathogens of diverse origin and in regaining homeostasis. With the help of Antigen Presenting Cells (APC), T cells encounter the antigen in secondary lymphoid organs: APC pick up antigen at the sites of infection, migrate to secondary lymphoid tissues, process and present the antigen to the $\mathrm{T}$ cells. Only $\mathrm{T}$ cells are activated, whose TCR specifically recognises discrete epitopes of the antigen. Thereupon, they clonally expand, differentiate into effector cells and help to activate $\mathrm{B}$ cells or migrate to the sites of infection $[16,17]$. Recognition of the antigen by the TCR and consecutive activation of antigen-specific T cells is a complex process combining different signals.

\subsubsection{The activation of $T$ cells requires the presence of several signals}

Recognition of the processed antigen in the Major Histocompatibility Complex I or II (MHC I or II) molecules by a suitable specific TCR represents the first step towards the formation of a specific $\mathrm{T}$ cell immune response to fight the invading antigen. The contact between APC and T cells via the TCR-MHC complex, including the CD4 and CD8 co-receptor molecules, is therefore also referred to as signal one [18]. It constitutes the basis for $\mathrm{T}$ cell stimulation, but it is, by itself, not sufficient to yield a full activation state in terms of cell proliferation, differentiation, effector functions, cytokine production and longevity [19]. To attain a sustained and effective $\mathrm{T}$ cell response, the processing of additional signals is pivotal. These signals are transduced via a variety of receptors and enhance the extent of the evolving host defence $[16,17,19,20]$. Besides, the necessity of costimulatory signals to generate a functional $\mathrm{T}$ cell response also serves as a control system to prevent unintended autoimmune reactions directed against self-antigens. Since costimulatory ligands on APC are only expressed upon infection, T cells are usually solely activated by mature APC presenting the processed antigen as well as costimulatory molecules (e.g. B7.1 and B7.2) [16, 20, 21]. If no secondary signals accompany TCR triggering, $\mathrm{T}$ cells adopt an inactive, unresponsive state called anergy, undergo apoptosis in 


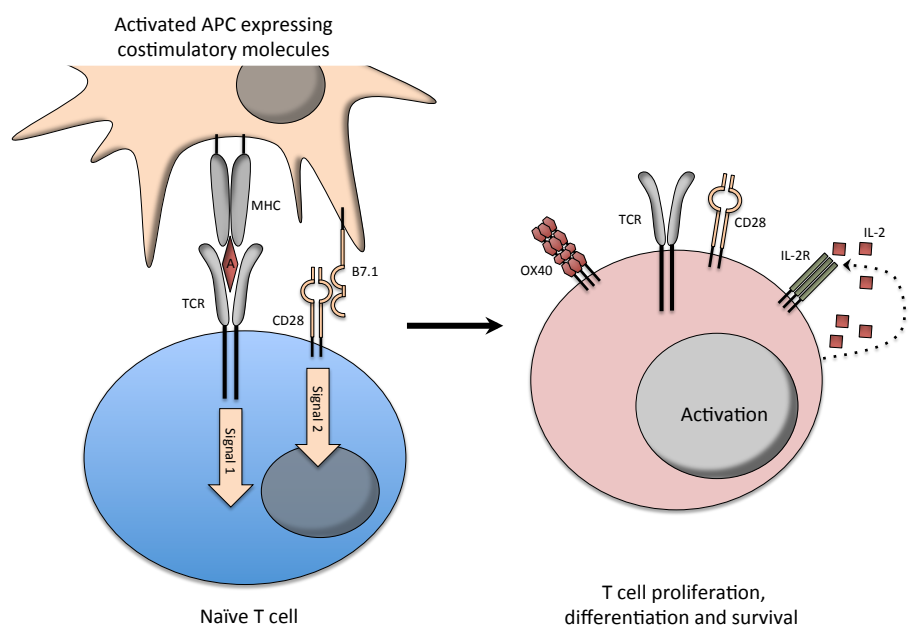

Figure 1: Costimulatory signals allow for $\mathrm{T}$ cell activation.

An activated, matured APC presents the antigen (A) as well as costimulatory molecules (e.g. B7.1) on its cell surface, thus allowing for the signal transduction by the TCR complex (signal one) and by costimulatory receptors, e.g. CD28 (signal two). The cooperation of both signals subsequently promotes $\mathrm{T}$ cell proliferation, differentiation and cell survival, which are further maintained and enhanced by the upregulation of additional costimulatory molecules like OX40 and IL-2R.

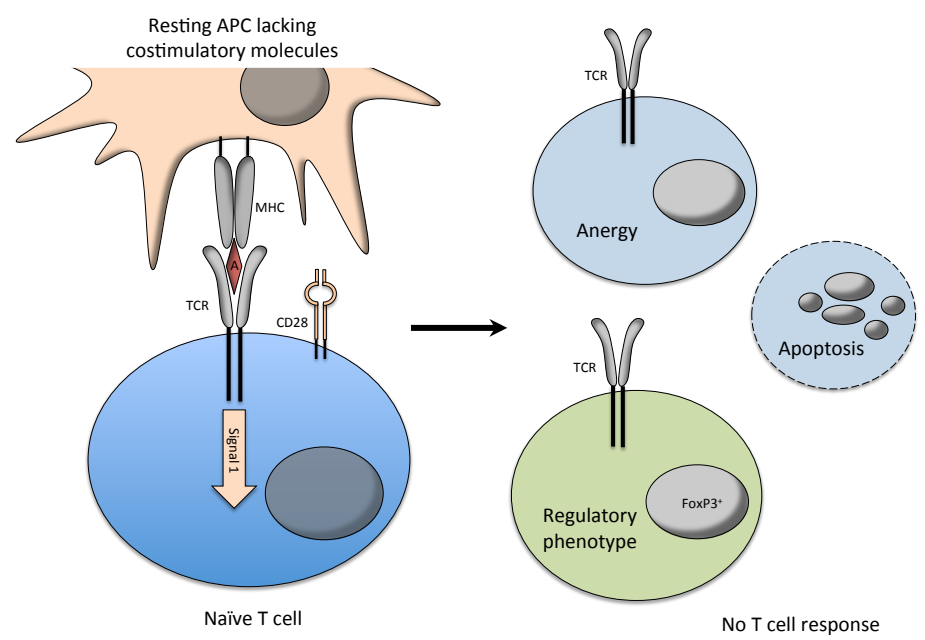

Figure 2: The lack of costimulatory signals inhibits $\mathbf{T}$ cell activation.

A resting APC, lacking any costimulatory molecules, solely presents the antigenic peptide (A) in its MHC molecule. As no costimulatory signals accompany TCR triggering upon antigen encounter, the naïve $\mathrm{T}$ cell undergoes apoptosis, adopts a regulatory phenotype (exhibiting the transcription factor FoxP3, FoxP3 ${ }^{+}$) or an unresponsive state called anergy. 
form of clonal deletion or differentiate into Treg [16, 17]. Figure 1 and 2 depict the two possible fates of $\mathrm{T}$ cells recognising an antigen, either with or without secondary signals.

The classic accessory molecules on $\mathrm{T}$ cells, which provide this signal two, can be found, to a varying degree, on mammalian as well as on chicken $\alpha \beta$ and $\gamma \delta \mathrm{T}$ cells $[10,19,22,23]$. They belong to three superfamilies, which are illustrated in Figure 3: the Immunoglobulin Superfamily (IGSF), the family of cytokine receptors and the Tumour Necrosis Factor Receptor Superfamily (TNFRSF, also referred to as TNF receptors) [24]. The most prominent members of these families and their involvement in the process of $\mathrm{T}$ cell activation will be described in the following.

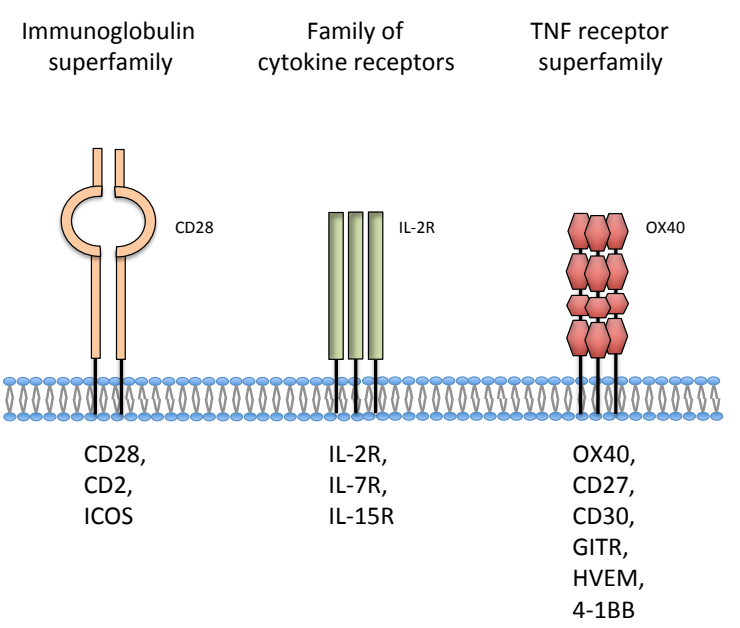

Figure 3: The superfamilies of costimulatory molecules.

Examples of the typical costimulatory molecules, which are involved in T cell activation. They belong to three superfamilies: the immunoglobulin superfamily, the family of cytokine receptors and the tumour necrosis factor receptor superfamily. 


\subsubsection{Costimulatory signals transmitted via members of the immuno- globulin superfamily}

The immunoglobulin superfamily comprises different costimulatory molecules, adopting important roles in T cell stimulation. All representatives of the IGSF exhibit a conserved structural feature in their extracellular domain, namely immunoglobulinlike domains whose number varies among different family members.

The CD2 receptor on $\mathrm{T}$ cells, for instance, interacts with its ligand Lymphocyte Function-associated Antigen 3 (LFA-3, also called CD58) on APC to improve the cellular interaction between APC and T cells by stabilising intercellular contact and maintaining the ideal spacing for TCR-ligand interactions [19, 25]. Additionally, CD2 stimulation cooperates with TCR triggering in activating intracellular signalling cascades leading to differentiation, proliferation and effector functions [26].

While CD2 is already expressed by resting T cells [27], Inducible T cell Costimulator (ICOS), i.e. another costimulatory member of the IGSF, is considerably upregulated when $\alpha \beta$ and $\gamma \delta \mathrm{T}$ cells are activated [28]. The binding of its ligand ICOSL (also known as B7-H2) on APC positively influences $\alpha \beta \mathrm{T}$ cell responses, especially the formation of follicular helper $\mathrm{T}$ ( Tfh) cells and of different $\mathrm{T}$ helper subsets (Th1, 2, 17) [29]. ICOS probably induces similar intracellular pathways as the most prominent member of the immunoglobulin superfamily, CD28. Hence, it complements the effects of CD28 on proliferation, cytokine production and survival $[29]$.

Studies characterising the involvement of CD28 in T cell activation long dominated the investigations of costimulatory requirements for $\mathrm{T}$ cell responses. The CD28 receptor is constitutively expressed on virtually all murine, on all chicken and on a great majority of human $\alpha \beta \mathrm{T}$ cells [30-32]. Additionally, it is reported to be present on a subset of resting $\gamma \delta \mathrm{T}$ cells in humans and chickens and is upregulated on activated murine and avian $\gamma \delta$ T cells [33-35]. Its ligands B7.1 (CD80) and B7.2 (CD86) are expressed on activated APC. CD28 is crucially involved in the initial process of T cell stimulation. Signals via CD28 e.g. support the expression of the anti-apoptotic factor B cell lymphoma-extra Large $\left(\mathrm{Bcl}-\mathrm{x}_{\mathrm{L}}\right)$ [36], promote the transcription of the growth factor Interleukin (IL)-2 [37] or stabilise messenger RNA (mRNA) of Tumour Necrosis Factor $\alpha(\mathrm{TNF} \alpha)$, Interferon $\gamma(\mathrm{IFN} \gamma)$ or IL-2 [38]. Thereby, CD28 triggering constitutes the basis for $\mathrm{T}$ cell proliferation, differentia- 
tion and survival. While the CD28 signalling initialises $\mathrm{T}$ cell activation through the mechanisms named above, other molecules notably contribute to the generation and maintenance of an effective $\mathrm{T}$ cell response.

\subsubsection{Costimulatory signals transmitted via members of the cytokine receptor family}

The interleukins IL-2, IL-7 and IL-15 are required for the homeostasis and development of lymphocytes, concerning $\alpha \beta$ as well as $\gamma \delta \mathrm{T}$ cell subsets [20, 22]. Upon $\mathrm{T}$ cell activation via antigen encounter, these cytokines and their respective receptors are upregulated and are involved in the expansion of the antigen-specific subsets of T cells [39].

Besides IL-2, IL-7 and IL-15, which provide signal two, additional interleukins, for instance IL-4, IL-12 and IL-23, further affect T cell responses upon inflammation. During the process of $\mathrm{T}$ cell stimulation, the latter promote the differentiation of activated $\mathrm{T}$ cells into different $\mathrm{T}$ cell phenotypes [17]. Therefore, they are also referred to as signal three, as they define the evolving effector T cell subsets [17].

Since IL-2 and IL-12 were used in this study to stimulate chicken splenocytes in vitro, the role of IL-2 and IL-12 in the process of T cell activation is briefly discussed in the following.

IL-2 and its receptor (IL-2R) exert pleiotropic effects on a great variety of cells, comprising e.g. B cells, NK cells and oligodendroglial cells [40-42]. Besides its widespread implication in the generation of an immune response, the most prominent function of IL-2 is its role as a major T cell growth factor for $\alpha \beta$ as well as $\gamma \delta \mathrm{T}$ cells $[43,44]$. The IL-2R is a heterotrimer comprising three subunits, namely IL-2R $\alpha$ (also known as CD25) [45], IL-2R $\beta$ (also shared by the IL-15R) [46] and IL-2R $\curlyvee$ (also shared by the receptors IL-7R and IL-15R) [47]. While resting T cells do not significantly express the functional IL-2R nor produce IL-2, both molecules are strongly upregulated upon TCR triggering. By promoting cell cycle progression, IL-2R signals favour $\mathrm{T}$ cell proliferation and differentiation in an autocrine or paracrine manner [48]. The extent and period of $\mathrm{T}$ cell activation is thereby restricted by the amount of secreted IL-2 and surface-expressed IL-2R. It promotes the differentiation of activated $\mathrm{CD} 4^{+}$cells into Th1 and Th2 subsets by either inducing growth factors necessary for Th1 development (IL-12R $\beta 2$ chain and the transcription factor T-bet) [49] or those for Th2 development (IL-4 and IL-4R $\alpha$ chain) [50, 51]. 
Furthermore, IL-2 is involved in priming $\mathrm{CD}^{+} \mathrm{T}$ cells during initial infections for expansion of $\mathrm{CD}^{+}$memory $\mathrm{T}$ cells upon secondary antigen encounter [52]. Additionally, IL-2R signalling is also reported to exhibit regulating and restraining properties in vivo, as it restricts Th17 differentiation, for instance [53]. With its crucial role in the development of Treg [54] and supporting the activation-induced cell death of repeatedly stimulated T cells [55], IL-2 prevents the evolution of autoimmunity and ensures homeostasis after an immune response.

Besides IL-2, IL-12 also displays a wide range of effects observable in innate as well as in adaptive immune responses. It acts as signal three to drive $\mathrm{T}$ cell differentiation during the activation process. IL-12 is a cytokine, predominantly secreted by phagocytic cells upon bacterial and parasitic infections and by activated APC [48]. Its corresponding receptor IL-12R can mainly be detected on NK cells, on activated $\mathrm{CD}^{+}$and $\mathrm{CD} 8^{+} \mathrm{T}$ cells and on murine $\gamma \delta \mathrm{T}$ cells $[56,57]$. The receptor is composed of two subunits, IL- $12 \mathrm{R} \beta 1$ and IL-12R $\beta 2$, where the expression of the signalling component IL-12R $\beta 2$ is more limited, arguing for a mechanism to regulate IL-12 effects $[58,59]$. As mentioned above, IL-2 as well as IFN $\gamma$ can promote the upregulation of IL-12R $\beta 2[49,60]$. They allow for the proliferation and differentiation of specialised $\mathrm{T}$ cell subsets by a positive feedback mechanism: with upregulation of IL-12R and binding by IL-12, activated $\mathrm{T}$ cells increase the production of IFN $\gamma$ and IL-2. In an autocrine way, the latter promote the upregulation of IL-12R, sensitising the cells for IL-12. Via this positive feedback loop, activated T cells themselves add to create the necessary environment to differentiate into Th1 cells [48]. Signals via IL-12R therefore constitute the main impulse for the generation of an effective Th1 response [61].

\subsubsection{Costimulatory signals transmitted via members of the tumour necrosis factor receptor superfamily}

Only recently, the third group of costimulatory molecules, namely members of the Tumour Necrosis Factor Receptor Superfamily (TNFRSF), together with their ligands (Tumour Necrosis Factor Superfamily, TNFSF, also referred to as TNF ligands), emerged as a key player in providing secondary signals essential for the generation of a potent $\mathrm{T}$ cell response. The costimulatory receptors 4-1BB, CD27, CD30, Glucocorticoid-Induced TNFR-Related protein (GITR), Herpesvirus Entry Mediator (HVEM) and OX40, together with their respective ligands (4-1BB/4-1BBL, 
CD27/CD27L, CD30/CD30L, GITR/GITRL, HVEM/HVEML, OX40/OX40L), are pivotal for the preservation of $\mathrm{T}$ cell activation following the initial costimulatory effects of the CD28-B7 system [62]. The mutual relation among the different costimulatory TNFRSF members and their relation to CD28 in the complex process of $\mathrm{T}$ cell activation is not yet fully understood. It remains unclear whether each receptor has an indispensable function for the generation of a fully effective $\mathrm{T}$ cell response or if some of them share a certain redundancy in their effects [24]. Past studies indicate that their impacts appear at different times during stimulation, thus permitting to sustain the activation process [24]. While CD27 is constitutively expressed on T cells [17] and its signalling probably supports the primary clonal expansion, OX40 and 4-1BB are induced in later activation states to ensure the longevity of the $\mathrm{T}$ cell response by supplying anti-apoptotic signals [24, 63]. For OX40 and CD27 it was already shown by Akiba et al. [64] that their costimulatory effects on T cells operate independently of CD28 signals in vitro, but that their expression is promoted by CD28 involvement $[63,65]$ and that they cannot supersede its contributions to the initial activation process [63]. 


\subsection{The tumour necrosis factor receptor superfamily}

The costimulatory members of the TNFRSF, which are described above, constitute only one functional branch of the whole superfamily. Up to now, 29 genes for TNF receptors were detected in the human genome. In mice, three additional genes were described encoding for receptors lacking human homologues [66]. The TNF receptors coordinate the immune reaction against malignant cells and pathogens from the onset of the response to its controlled elimination and thus notably add to host defence and homeostasis. They are involved in mobilising effector cells, sustaining their longevity, recruiting stromal cells by creating an inflammatory milieu, but also in promoting activation-induced cell death to restore the initial state [67].

\subsubsection{The structure of tumour necrosis factor receptors}

Despite these partly antithetic functions, the TNF receptors share a common topology causal for their way of interacting with their respective ligands. The great majority of these receptors can be categorised as type I transmembrane proteins, exhibiting an extracellular $\mathrm{N}$ terminus with a signal peptide and an intracellular $\mathrm{C}$ terminus [68]. Some members, however, differ from this rule as they possess no signal peptide (e.g. B cell Activating Factor Receptor, BAFFR, B Cell Maturation Antigen, BCMA and X-linked Ectodysplasin-A2 Receptor, XEDAR), only exist as soluble forms (Osteoprotegerin, OPG and Decoy Receptor 3, DcR3) or reveal another mechanism for anchoring in the membrane (TNF-Related Apoptosis-Inducing Ligand Receptor 3, TRAIL-R3) [68]. Several of the transmembrane receptors also occur as soluble forms after being proteolytically cleaved from the cell surface (e.g. Tumour Necrosis Factor Receptor 1 and 2 (TNF-R1 and TNF-R2), CD27, CD30 and $\mathrm{CD} 40$ ) or by removal of the transmembrane region via alternative splicing (e.g. 4 -1BB) $[69,70]$. These soluble variants are probably able to regulate the activity of their designated ligands [68].

The extracellular domain of the receptors is characterised by Cysteine Rich Domains (CRD), which typically consist of six cysteine residues forming a distinct repetitive pattern [71]. The disulphide bonds, formed by these cysteines, generate a topological framework, which is supplemented by a varying number of additional amino acids. This diversity within the CRD sequences allows for specific interactions with their destined ligands [72]. According to the number of cysteines and the 
topology of disulphide bridges, the CRD can be further categorised into different submodules: the letters describe the fold of the subunits and the digits indicate the number of disulphide bridges [73]. The combination of submodules within the CRD varies among different receptor molecules.

At first, five submodules, namely A1, A2, B1, B2 and C2 were established by Naismith and Sprang [73], but with the ongoing characterisation of structural properties, new subunits D2, X2 and $\mathrm{N}$ were added to the existing modules [68, 74]. As the search for additional family members and the investigation of already known members still proceeds and yields even improved structural models, new subunits may be introduced [75].

The number of CRD in the ectodomain varies between the different members of the receptor family, ranging from only an incomplete CRD in the BAFFR, three complete and one truncated CRD in the OX40 receptor to six CRD in the CD30 molecule [76]. Due to these CRD, the extracellular domain of the receptors possesses a stretched shape, which is important for ligand binding [77]. Figure 4 illustrates the typical structure of a TNF receptor family member using the example of chicken OX40. Additionally, the N-terminal region of several receptors (e.g. TNF-R1, TNF-R2 and CD40) was reported to contain a so-called Pre-Ligand-binding Assem-

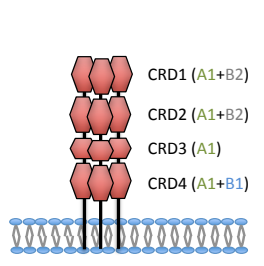

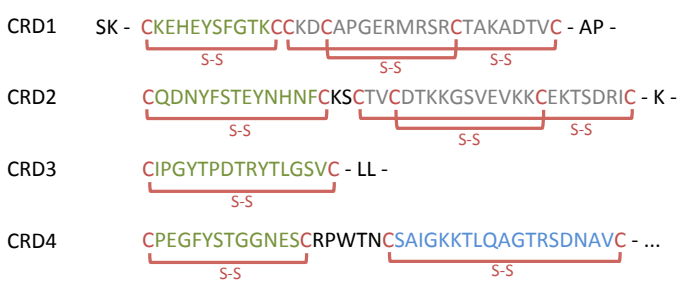

Figure 4: The structure of TNFRSF members.

A, The model of chicken OX40 receptor trimer illustrates the characteristic feature of the extracellular domain of the members of the TNFRSF. Each OX40 monomer exhibits four CRD, represented by red hexagons. CRD1, 2 and 4 are composed of two subunits (indicated in brackets, in the colour scheme of (B)), whereas the CRD3 solely consists of one subunit. B, The amino acid sequence of chicken OX40 extracellular domain displays the CRD1-4 as indicated, following the analysis of human OX40 by Willoughby et al. [78]. The residues forming the different subunits (A1, B1, B2) are coloured: A1 green, B1 blue, B2 grey. The cysteine residues and the disulphide bridges (S-S) are marked in red. The dots indicate the C-terminal sequence of the OX40 stalk region, its transmembrane and intracellular domain. 
bly Domain (PLAD) [79]. It enables the preassembling of the receptor molecules on the cell surface prior to the interaction with their respective ligands [79]. The functional implications of receptor preassembly are specified in section 2.4.

\subsubsection{Functional classification of TNFRSF members}

The cytoplasmic region and the intracellular signalling pathway allow for the functional classification of TNFRSF members into three groups [80].

Decoy receptors lack an operative intracellular domain and are thus thought to restrain interaction with functional receptors (e.g. DcR3 for Fas Ligand, FasL) [81]. Besides the typical decoy receptors (DcR3, OPG, TRAIL-R3 and TNF-Related Apoptosis-Inducing Ligand Receptor 4, TRAIL-R4), also the soluble variants of TNFRSF, originating from proteolytic cleavage, can act as decoy receptors [82]. A second group of receptors exhibits an intracellular, so called Death Domain (DD) promoting apoptosis upon interaction with the respective ligands. Examples for DD containing receptors are Fas, Death Receptor 3 (DR3) or TNF-R1, which can mobilise caspase cascades causing changes in the nucleus, membranes and cytoskeleton, which are typical of apoptosis [67].

As a third group, receptors like TNF-R2, OX40 or 4-1BB comprise an intracellular motif allowing for the interaction with TNF Receptor-Associated Factors (TRAF) [83]. These adaptor molecules are part of an intracellular signalling pathway primarily promoting cell activation, differentiation and survival. This signalling cascade will be further described in section 2.5 using the example of the OX40 molecule. 


\subsection{The tumour necrosis factor superfamily}

The eponym of this ligand family, $\mathrm{TNF} \alpha$, was first described in the 1960ies as a factor, which was produced upon endotoxin treatment in mice and which was able to induce apoptosis of tumour cells [84]. Since then, the number of identified molecules, which were related to $\mathrm{TNF} \alpha$, steadily increased. Due to the structural homologies to their most prominent member, a number of 19 cytokines [82] are classified as the tumour necrosis factor superfamily in humans. Forming functional systems with their respective receptors, TNFSF members are involved in a wide variety of processes. They participate in the formation and regulation of various tissues, like the neuronal and lymphoid systems, the skin or the mammary gland [76]. In addition, they contribute to the generation and elimination of immune responses upon antigen encounter.

\subsubsection{The structure of tumour necrosis factor ligands}

Like the superfamily of receptors, TNF ligands share a certain homology of about 15-20\% and, more importantly, a common topology, which impacts their functionality [85]. The TNFSF members are type II transmembrane proteins with an intracellular N terminus and a C-terminal extracellular region with a TNF Homology Domain (THD) [76]. The THD sequence comprises a conserved scaffold of aromatic and hydrophobic amino acids, which allows for non-covalent trimerisation of three THD domains forming a condensed, bell-like molecule (Figure 5A and B) [86]. As illustrated in Figure 5C, for the TNF $\alpha$ molecule, a THD exhibits a so called jelly roll topology. It is composed of two $\beta$-sheets, which form an antiparallel $\beta$-sandwich. Each sheet, in turn, consists of five antiparallel $\beta$-strands (indicated with letters) [86]. The inner sheet establishes contact to the other two THD protomers, while the outer sheet constitutes the exterior of the trimeric protein [86]. Consequently, each ligand homotrimer possesses three receptor-binding sites located in a groove, which is formed by two adjoining THD [76].

Numerous ligands exert their functions as membrane-bound molecules. Nevertheless, several TNFSF members occur as soluble variants, after being cleaved from the cell surface by different proteases [68]. Obviously, solubilisation of these ligands can alter their impact compared to the effects performed by their cell-bound forms. On the one hand, solubilisation can be necessary to expand their range of action, 
as it is reported for the ligand Ectodysplasin A (EDA) [87, 88]. On the other hand, cleavage from the cell surface can also diminish their effectiveness, as e.g. apoptotic effects of soluble FasL are reported to be reduced compared to its surface-bound form [89].
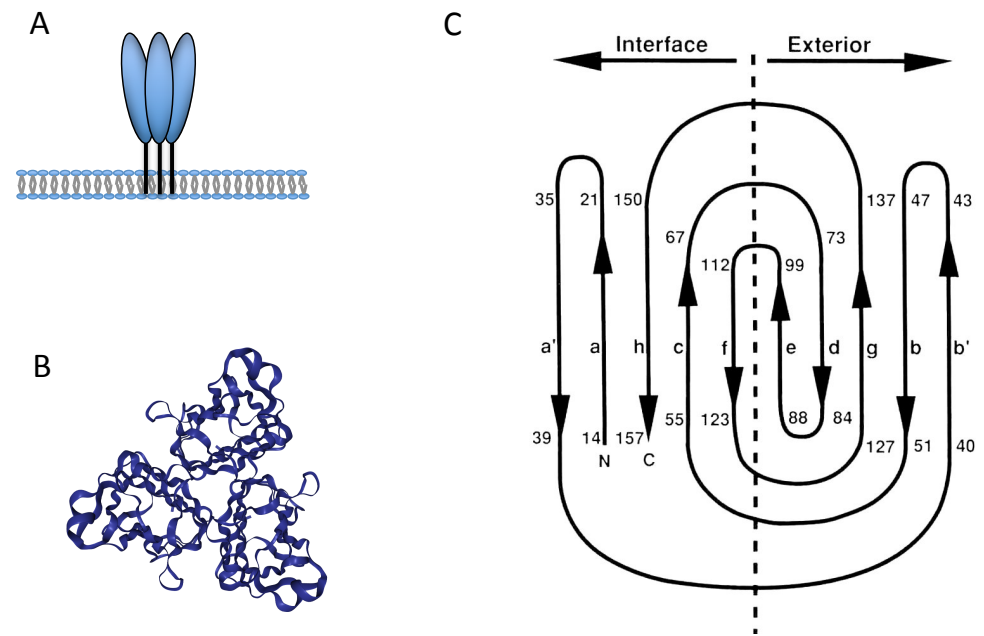

Figure 5: The structure of TNFSF members.

A, The model of an OX40L trimer illustrates the characteristic bell shape of TNF ligands. B, The top view of the crystal structure of mouse OX40L trimer. C, Model of the jelly roll topology of the TNF $\alpha$ molecule illustrating the basic structure of the THD in TNF ligands [86]. The THD consists of two antiparallel $\beta$-sheets, which are divided by the dashed line in the diagram (the inner sheet on the left, the external sheet on the right). Each $\beta$-sheet, in turn, comprises five $\beta$-strands (labelled a-h according to their sequential arrangement within the primary sequence); a' and b' are loops of the $\mathrm{b}$ strand. They form short strands, which adjoin the strands a and $\mathrm{b}$. B: The Crystal Structure of the Costimulatory OX40-OX40L Complex [90], item 2HEW from RCSB PDB [91, 92], created with NGL viewer [93, 94], style: cartoon. C: Reproduced from: The structure of tumor necrosis factor-alpha at 2.6 A resolution. Implications for receptor binding [86]. 


\subsubsection{Classification of TNFSF members according to their structural properties}

Although TNF ligands generally share the formation of homotrimers exhibiting a bell-like shape, they can be classified into three categories according to their structural properties: the conventional, the EF-disulphide and the divergent group [90]. The conventional group of ligands comprises e.g. the molecules CD40 Ligand (CD40L), FasL and TNF $\alpha$, and is well defined, as crystal structures were generated for several of its members [86, 95]. Analyses revealed that this conventional group exhibits elongated loops between the antiparallel $\beta$-strands CD, DF and DE, which are responsible for its typical pyramidal conformation. Moreover, members of this group share a conserved hydrophobic residue within the DE loop, arguing for a conserved way of receptor interaction [90].

The members of the EF-disulphide group, e.g. B cell Activating Factor belonging to the TNF Family (BAFF) and EDA, were likewise characterised via crystallography $[96,97]$. The analyses exhibited the eponymous disulphide bond between strands $\mathrm{E}$ and $\mathrm{F}$ as their distinctive feature [90]. In addition, crystal structures revealed the absence of the hydrophobic residue, which is pivotal for receptor interaction and conserved within the conventional group. Furthermore, the structures displayed shortened CD and EF loops causing a more spheroidal conformation [90]. The third group with its members OX40L, 4-1BBL, CD27L, CD30L and GITRL, was denominated divergent group as the amino acid sequences show only low homology within the subgroup, but also to the other two subgroups [90]. The molecule OX40L is a typical representative of the divergent group as it shares only 10-15\% sequence identity with other TNFSF members [90]. 


\subsection{Receptor-ligand interactions}

In general, TNFSF members form homotrimers and are reported to interact with their respective receptors in a 3:3 ratio, as depicted in Figure 6 for OX40 and OX40L. Three elongated receptor molecules bind in parallel in the three grooves of the ligand homotrimer, each formed by two ligand protomers [72]. This was first demonstrated for the ligand TNF $\beta$ and its receptor TNF-R1 by Banner et al. in 1993 [77] and confirmed for other members of the TNF superfamily, e.g. for OX40L and its receptor OX40 [90]. Even though molecular domains of receptors and ligands, which participate in the mutual interaction, vary among the different receptor-ligand pairs, the $3: 3$ concept of receptor-ligand interaction seems to be conserved within the TNF superfamily [68]. The involvement of varying molecular regions in the binding between different receptors and their cognate ligands gives rise to the specificity of these interactions [68]. Probably due to this specific recognition process, some TNF family members were reported to solely bind one partner in mammals, for instance OX40 and OX40L, GITR and GITRL or CD30 and CD30L [98]. Nevertheless, several ligands are known to interact with different receptors, thus rendering the impacts of the TNF superfamily more complex and flexible [72, 98]. Irrespective of the nature of the interacting receptor-ligand pair, Vanamee and Faustmann [82] suggest a model explaining the condition prior to the process of mutual binding. It further describes the mechanism of interaction itself and its correlation with intracellular
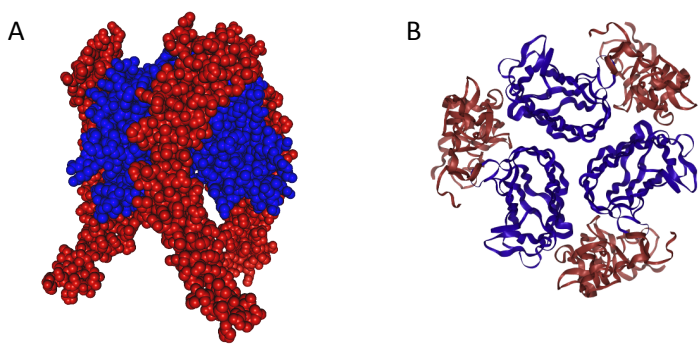

Figure 6: The 3:3 interaction between OX40 and OX40L monomers.

$\mathbf{A}$, The side view of the crystal structure of human OX40 trimer (red) bound to human OX40L trimer (blue). B, Crystal structure of the human OX40-OX40Lcomplex viewed from the membrane of the ligand-expressing cell.

A and B: The Crystal Structure of the Costimulatory OX40-OX40L Complex [90], item 2HEV from RCSB PDB [91, 92], created with NGL viewer [93, 94], style: A: spacefill, B: cartoon. 
signalling. Due to the PLAD domain within the $\mathrm{N}$ terminus of TNF receptors, free receptor monomers can form dimers $[79,99]$. These dimers were found in a parallel or an antiparallel orientation [100], as illustrated in Figure 7A. Within parallel receptor dimers, sites for ligand-interaction are uncovered, because monomers are collocated in a back-to-back manner $[82,100]$. In contrast, antiparallel dimers, formed by CRD1 and CRD2, hide fractions of the ligand-binding site. The conformation of the antiparallel molecules prevents interactions with the ligand and thus represents the passive state of the receptors $[82,100]$. Both potential receptor dimers are assumed to organise as a hexagonal mesh on the cell surface (Fig. 7B). Three receptor monomers adjoin at the junctions of the hexagons to form ligandbinding sites preserving the 3:3 stoichiometry. A receptor dimer is composed of two receptor monomers from two collocated ligand-binding sites [82]. The preassembly of receptor molecules is necessary for subsequent ligand interaction and efficient intracellular signalling [101]. It facilitates the formation of a hexagonal network of the associated intracellular signalling proteins [102]. Since the model of antiparallel receptor dimers better agrees with the configuration of cytoplasmic signalling components, this mode of dimerisation is more likely to reflect the actual state before ligand interaction (Fig. 7C) [82]. Upon ligand binding, antiparallel receptor dimers dissolve. The monomers undergo a conformational change to orientate perpendicularly to the cell membrane, transmitting intracellular signals and yet preserving the hexagonal geometry. In this process, the transmembrane regions of receptors likewise trimerise and allow for the merging of the intracellular domains [82]. This, in turn, ensures their interaction with the network of hexagonally organised adaptor proteins of the signalling cascade [103]. 
A

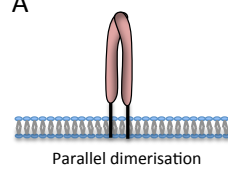

B

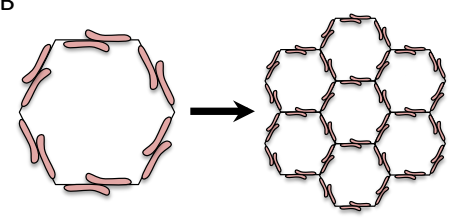

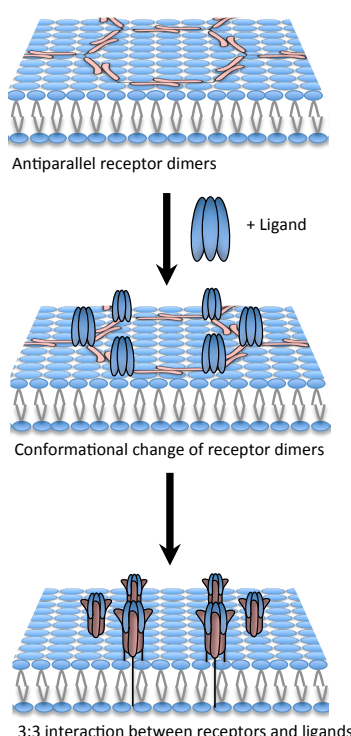

Figure 7: A model of receptor preassembly and receptor-ligand interaction.

A, The two possible modes of receptor (light red) dimerisation (parallel and antiparallel) on the cell surface prior to ligand encounter. While parallel receptor dimers expose their ligand-binding sites, the latter are hidden in antiparallel dimers. B, Both types of receptor dimers can form hexagonal networks on the cell surface, which is illustrated for antiparallel receptors. C, Prior to ligand binding, the receptors (light red) preassemble as antiparallel dimers, forming a hexagonal network on the cell surface. Upon contact with the ligand (blue), receptor dimers abandon their resting state and undergo conformational changes. These changes within the receptor molecules allow for ligand binding in a 3:3 stoichiometry and enable subsequent signalling events [82]. 


\subsection{Signalling pathways}

OX40 and other members of the TNF receptor family, which are involved in the process of $\mathrm{T}$ cell costimulation, belong to the TRAF-interacting receptors. Thus, the OX40 molecule constitutes an excellent example of a costimulatory receptor sustaining $\mathrm{T}$ cell activation. The signalling pathways underlying its costimulatory effects in $\mathrm{T}$ cells and the phenomenon of reverse signalling within the ligand-expressing cells will be described in the following sections.

\subsubsection{Signalling cascade of OX40 within the $\mathrm{T}$ cell}

OX40 molecules are not constitutively expressed on T cells, but they are upregulated after the TCR was triggered. Therefore, it is difficult to examine the OX40 downstream pathways and their effects irrespectively of effects caused by TCR signalling itself [78]. Most studies hence delineate the effects of OX40 signalling following TCR stimulation and indicate its contributions to the generation of the $\mathrm{T}$ cell response. Figure 8 summarises the main components of OX40 signalling. After binding of OX40L to its receptor OX40, different signalling cascades within the $\mathrm{T}$ cell have been described, which allow for clonal expansion, longevity and cytokine production. The intracellular domain of OX40 molecules exhibits a QEE motif [104], which permits the interaction with TRAF as major mediators in downstream signalling events [105]. To date, six different TRAF are characterised in mammals [83]. Different TNF receptors use a diverse set of these adaptor proteins for signalling, where TRAF2 seems to be an essential component for all costimulatory molecules [106]. TRAF1-3, 5 and 6 were reported to mediate signal transduction within the OX40OX40L system in vivo $[82,107,108]$. TRAF2 and 5 adaptor molecules induce the Nuclear Factor $x$-light-chain-enhancer of activated B cells (NF- $x$ B) pathway, whereas TRAF3 probably restrains this signalling cascade [108].

Via both the canonical NF- $x \mathrm{~B} 1$ and the non-canonical NF- $x \mathrm{~B} 2$ pathway, OX40 signalling stimulates the expression of anti-apoptotic proteins and survival factors like B cell lymphoma 2 (Bcl-2), Bcl- $x_{L}$ and Bcl2-related protein A1 (BCL2A1) [63, 109, 110].

Furthermore, OX40 costimulation was reported to support the signalling cascades mediated by the TCR, primarily by sustaining the activation of Phosphatidylinositol 3-Kinase (PI3-K) and Protein Kinase B (PKB) and other intermediates involved 
in this pathway: via increased expression of survivin, combined TCR and OX40 signals enable the cell cycle progression from G1 to $\mathrm{S}$ phase, thus promoting $\mathrm{T}$ cell mitosis $[111,112]$.

Moreover, OX40 and TCR signals cooperate in activating Nuclear Factor of Activated $\mathrm{T}$ cells (NFAT), which allows for the production of cytokines like IL-2, IL-4 and IL-5, depending on the existing cell polarisation. The evolving cytokine milieu thereby causes the subsequent differentiation into different $\mathrm{T}$ cell effector subsets and their maintenance $[113,114]$.

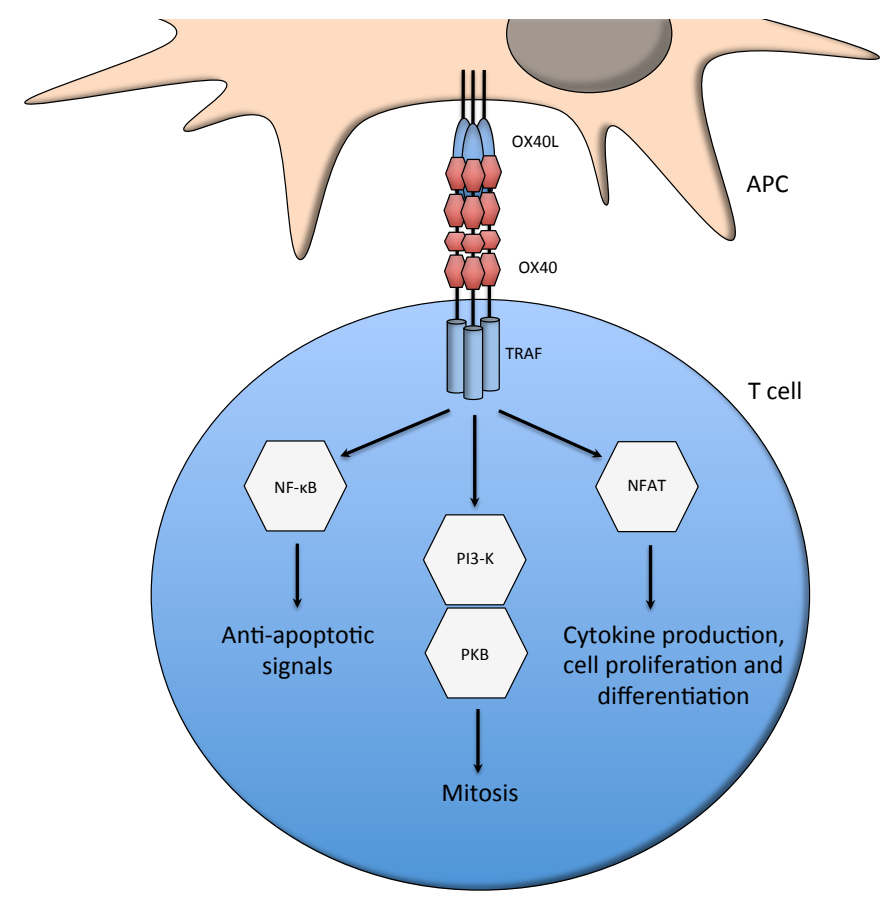

Figure 8: Signalling pathways of OX40 upon OX40L interaction.

Upon interaction with OX40L on APC, the cytoplasmic domains of OX40 molecules interact with the TRAF adaptor proteins to transduce signals via three main pathways. Activation of the NF $x \mathrm{~B}$ pathway primarily results in the generation of antiapoptotic signals, whereas activation of PI3-K and PKB mainly drives cell division. The activation of the NFAT pathway promotes cytokine production, which in turn supports cell proliferation and differentiation. 


\subsubsection{Reverse signalling}

As reflected in the remarks above, most studies investigating the cytoplasmic processes of OX40-OX40L system, dealt with the signalling events in the OX40-expressing cells and their functional implications for the $\mathrm{T}$ cell response. By now, it is well established that upon OX40-OX40L interaction, the intracellular signalling is not restricted to the receptor-bearing cell, but can also be observed within the OX40L-expressing cells $[115,116]$. This bidirectional communication, also called reverse signalling, is reported for different members of the TNF superfamily like TNF $\alpha$, OX40L, CD30L, CD40L, and FasL [117, 118].

Detailed information of intracellular signalling pathways of the TNFSF members is not yet available, but the structural properties of the intracellular domains of TNF ligands suggest certain mechanisms. Homology analyses of the cytoplasmic domains of different TNF ligands revealed only poor levels of identity, arguing for the utilisation of diverse signalling pathways instead of a conserved cascade within the superfamily [119]. Additionally, the cytoplasmic regions of these ligands exhibit no enzymatic functions, which indicates that cytoplasmic signals are delivered via adaptor proteins [117]. However, the latter still have to be identified and characterised.

Even though the mechanism of reverse signalling, its intracellular components and their interaction need to be further investigated, the diverse effects of bidirectional signalling of different TNFSF members have already been described [117] and are summarised in the following, for OX40L-bearing cells in section 2.6.3.

In general, the phenomenon of reverse signalling allows for adjusting and shaping an ongoing immune response. Both cells, expressing receptor or ligand, mutually impact their functions upon cell-to-cell contact, rendering the system more complex and also significantly more tunable [117]. 


\subsection{The OX40-OX40L costimulatory system}

The OX40 receptor, also referred to as TNFRSF member 4 (TNFRSF4), CD134 or ACT35 [120] was identified in 1987 by an antibody called MRC Ox-40, recognising a molecule on activated CD4 ${ }^{+}$cells in rats [121]. Its ligand OX40L (TNFSF4, CD252, glycoprotein 34, gp34) [122] was already described in 1985 as the protein gp34, which was expressed by a $\mathrm{T}$ cell line derived from transformation with human $\mathrm{T}$ cell leukemia virus type-I [123]. Baum et al. [124] finally identified the former gp34 molecule as OX40L. OX40 and OX40L notably impact the generation of an effective immune response upon antigen encounter. Their prominent and far-reaching role in host defence is reflected by their widespread expression profile.

\subsubsection{Expression profile of OX40}

In human and mouse, naïve T cells lack the expression of OX40, but they upregulate the receptor twelve hours up to five to six days after antigen encounter and TCR triggering $[63,115,125]$. The following activated $\mathrm{T}$ cell subsets express OX40 on their cell surface: $\mathrm{CD} 4^{+} \mathrm{T}$ cells $[125,126], \mathrm{CD} 8^{+} \mathrm{T}$ cells [127], as well as Treg and different T helper subpopulations (Th1, Th2, Th9 and Th17 cells) [110, 115, 128]. Effector and probably also memory $\mathrm{T}$ cells with former contact to an antigen, can quickly upregulate the molecule upon secondary antigen encounter [114]. In vivo, activated T cells bearing OX40 can be detected in the paracortex of lymph nodes and in the periarteriolar lymphoid sheaths of the spleen upon immunisation with protein antigen $[129,130]$. Moreover, OX40-expressing T cells were visualised upon inflammation during several diseases, e.g. during tumour growth [131], Graft versus Host Disease (GvHD) [132, 133] or during immunologically associated diseases of the gastrointestinal tract [134]. Additionally, OX40 was detected on neutrophils [135], NK cells [136] and Natural Killer T (NKT) cells [137] at lower densities.

Different parameters such as the type of antigen, its persistence, the involved $\mathrm{T}$ cell population and the emerging cytokine milieu affect the level and the period of OX40 expression [138]. Furthermore, cytokines like TNF $\alpha$, IL-1 and IL-4 as well as signalling through other secondary costimulatory molecules as IL-2R and CD28, favour an optimal and sustained expression of OX40 [115, 128]. 


\subsubsection{Expression profile of OX40L}

The expression of the OX40L molecule in humans and mice is primarily associated with different types of APC, namely Dendritic Cells (DC) [139], B cells [140], macrophages [141] and Langerhans cells [142]. Upregulation of the ligand is stimulated by different factors like signalling via the B cell receptor, Toll-like receptors or the CD40 molecule and accordingly by soluble factors as IL-18, Thymic Stromal Lymphopoietin (TSLP), IFN $\gamma$ or prostaglandin E2 [115, 143-146]. Besides its expression on APC, OX40L was also detected on a broader range of cell types, e.g. on mast cells [147, 148], NK cells [149], on smooth muscle cells [150] and on endothelial cells [151]. In addition, activated $\mathrm{CD} 4^{+}$and $\mathrm{CD} 8^{+}$cells were reported to express OX40L, arguing for an alternative way to sustain $\mathrm{T}$ cell responses via $\mathrm{T}$ cell- $\mathrm{T}$ cell interactions in addition to APC contact [152].

OX40L expression was also detected in association with various diseases, e.g. during chronic infections [153] or at inflammatory sites during autoimmune reactions [154].

\subsubsection{Functions of the OX40-OX40L system during an immune response}

Among the costimulatory TNFRSF members involved in the activation process of $\mathrm{T}$ cells, the OX40-OX40L system is regarded as a key mediator ensuring the longevity of a $\mathrm{T}$ cell response by enhancing the proliferation of diverse $\mathrm{T}$ cell subsets upon different stimuli [155]. However, the activating and proliferating effects of the OX40-OX40L system only become operative in later activation stages, following initial activation signals via the CD28-B7 system [63].

OX40 and OX40L knockout mice, as well as agonistic and antagonistic antibodies assisted to investigate the impacts of the OX40-OX40L system in mammals. The receptor-ligand pair was first demonstrated to support primary and secondary CD4 ${ }^{+}$ $\mathrm{T}$ cell responses as well as the development of immunological memory [114, 130, 156]. As described in section 2.5, OX40 triggering mediates several anti-apoptotic signals and thereby notably adds to the proliferation and survival of $\mathrm{T}$ cell populations. The costimulatory effects of OX40 signalling in the T cell are summarised in Figure 9. To preserve the activation state, OX40 signalling induces the upregulation of IL-2R $\alpha$ chain [157] and the production of IL-2 as an autocrine stimulus [114]. It further promotes the expression of the OX40L molecule on activated T cells to provide costimulatory signals to other $\mathrm{T}$ cells for maintaining the activation state indepen- 
dently of APC involvement $[116,152,158]$. Besides, experiments report that OX40 costimulation also adds to the adhesion of $\mathrm{T}$ cells to OX40L-expressing endothelial cells and that it is involved in $\mathrm{T}$ cell migration to germinal centres and to inflammatory sites by the upregulation of molecules like C-X-C motif chemokine Receptor 5 (CXCR5) on T cells $[65,159]$. Depending on the prevailing cytokine environment, OX40 signalling promotes the expansion of different $\mathrm{T}$ helper cell subsets (Th1, Th2, Th9 and Th17) and supports the production of their associated cytokines [110, 138, 160]. Equally, the existing cytokine milieu, together with the distribution of OX40 molecules on different $\mathrm{T}$ cell subsets and its extent of expression, determines the course of the $\mathrm{T}$ cell response and the preservation of homeostasis. On the one hand, under the influence of IL-4 and IFN $\gamma$, OX40 binding promotes an effector phenotype of $\mathrm{CD}^{+}$cells, which is less susceptible to Treg-mediated suppression [161]. This implies the upregulation of surface molecules like IL-12R $\beta 2$ receptor chain [162] and the downregulation of regulatory elements such as Transforming Growth Factor $\beta$ (TGF- $\beta$ ), Forkhead box protein P3 (FoxP3) [163], IL-10 [164] and

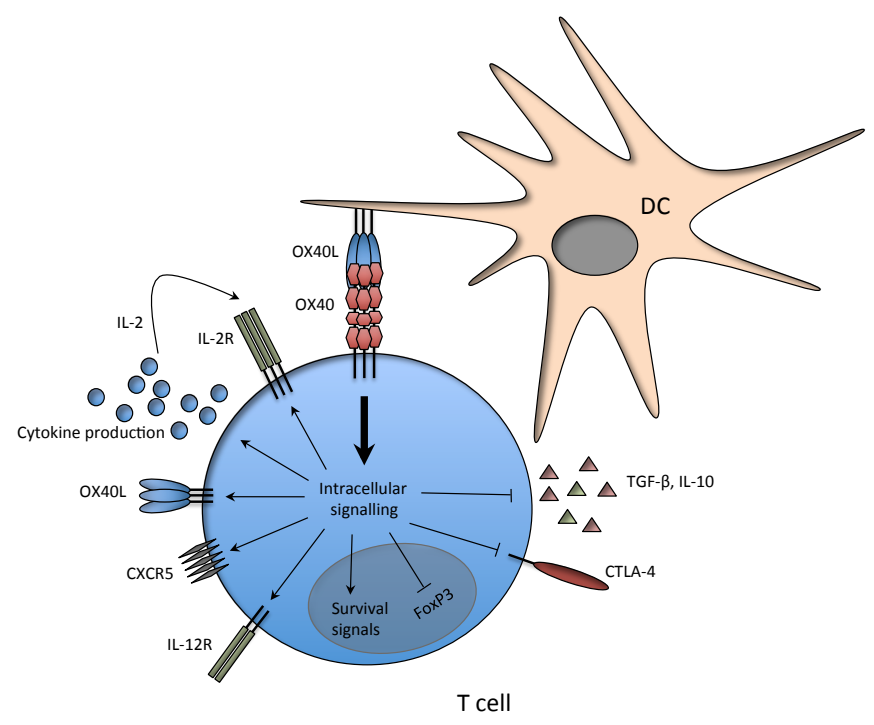

Figure 9: Effects of OX40 signals for $\mathrm{T}$ cells.

OX40 signalling on T cells adds to the expression of IL-2R, IL-12R and OX40L, as well as of CXCR5. It further promotes cytokine production and survival signals, thus favouring the effector phenotype (positive effects indicated by arrows). By inhibiting the expression of FoxP3, CTLA-4, TGF- $\beta$ and IL-10 (indicated by barred lines), it restrains the differentiation into a regulatory phenotype. 
Cytotoxic T Lymphocyte-Associated protein 4 (CTLA-4) [165].

On the other hand, signals by the costimulatory receptor OX40 are necessary to assure the abatement of the immune response and the restoration of the original state. As Takeda et al. demonstrated [161], OX40 also plays a role in the development and proliferation of Treg, as their number is diminished in OX40 knockout animals and increases in animals, which constitutively express OX40L. In addition, signals via this TNFRSF member account for a fully effective decimation of superplus effector cells by Treg [161]. Analogous to its effects on CD4 ${ }^{+} \mathrm{T}$ cells, OX40 signalling also ensures the expansion, the longevity and the memory generation of $\mathrm{CD} 8^{+} \mathrm{T}$ cells [127, 166-168]. Furthermore, it is reported to support the activity of NK and NKT cells and their secretion of IFN $\gamma$, thus further boosting T cell activation upon antigen encounter [136, 137]. Besides professional APC, other cell types like endothelial and muscle cells as well as mast cells are able to provide the OX40L molecule at the sites of infection and inflammation to activated T cells expressing OX40 in order to sustain and further increase the $\mathrm{T}$ cell response [115].

With binding of OX40 to OX40L, not only $\mathrm{T}$ cells receive costimulatory signals via the OX40 molecule, but also the OX40L-expressing cells seem to activate intracellular cascades altering their metabolism, cytokine production and differentiation by reverse signalling [115]. Even though this process of bidirectional interaction between OX40 and its ligand remains to be further investigated, different studies hint at its important role in preparing a local proinflammatory milieu to additionally strengthen the host defence [115]. The impacts of OX40-OX40L interactions on OX40L-expressing cells are illustrated in Figure 10.

In dendritic cells, OX40L signalling was reported to assist their activation and maturation, which is represented by the upregulation of CD83. Furthermore, signals via OX40L stimulate cytokine production (TNF $\alpha$, IL-1 $\beta$, IL-6 and IL-12) and support the upregulation of costimulatory molecules such as CD40, CD54, CD80 and CD86 [169].

OX40L binding on B cells promotes their differentiation into plasma cells and augments the level of secreted antibodies, adding to the crucial effects of CD40-CD40L interactions [129, 170].

As already mentioned above, the interaction between OX40L-expressing endothelia and OX40-bearing $\mathrm{T}$ cells supports the increased adhesion of $\mathrm{T}$ cells to the endothelial cells and their subsequent transmigration. On the side of $\mathrm{T}$ cells, this OX40-OX40L interaction induces the migration-associated molecule CXCR5. By 
A

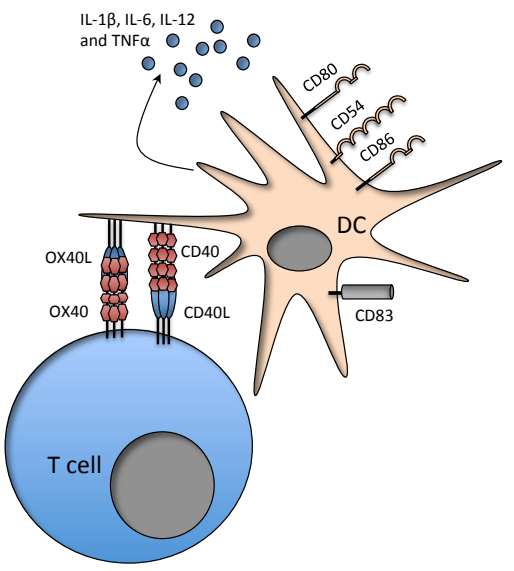

$\mathrm{C}$

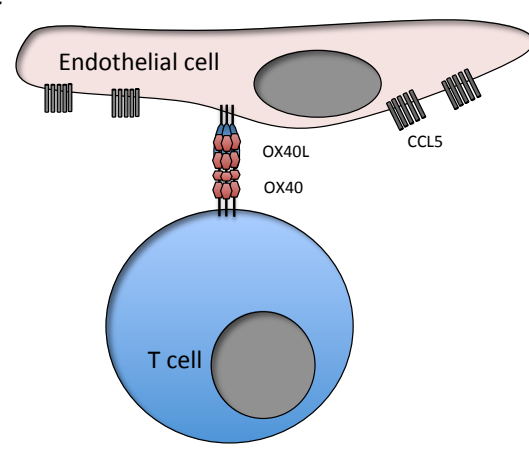

B
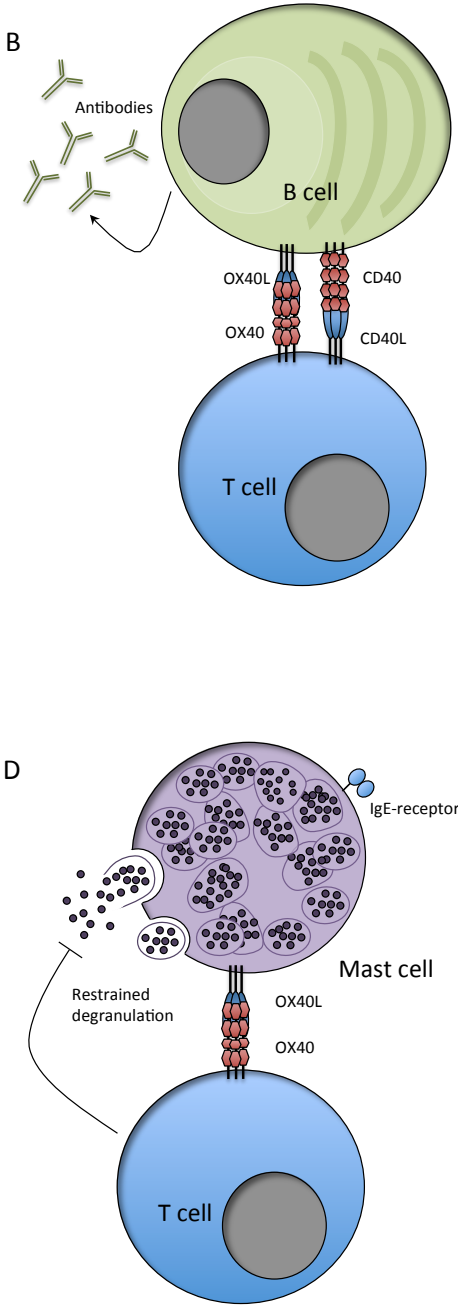

Figure 10: Effects of reverse signalling via OX40L for OX40L-expressing cells.

A, OX40L binding on DC promotes their differentiation and maturation, which is represented by the upregulation of the CD83 molecule. Additionally, it augments the production of IL-1 $\beta$, IL- 6 , IL-12 and TNF $\alpha$, as well as the expression of costimulatory molecules like CD40, CD54, CD80 and CD86. B, In B cells, reverse signalling via OX40L promotes their differentiation into plasma cells and increases the production of antibodies. C, Endothelial cells express CCL5 upon OX40L signals, thereby promoting the transmigration of activated $\mathrm{T}$ cells. D, OX40L signals inhibit the degranulation of mast cells. 
reverse signalling through the OX40L protein, endothelial cells also facilitate the migration of $\mathrm{T}$ cells to germinal centres by upregulating the C-C chemokine Ligand 5 (CCL5), also known as RANTES (Regulated on Activation Normal T cell Expressed and Secreted) [171].

Mast cells expressing OX40L were also reported to assist $\mathrm{T}$ cell activation and proliferation [147, 148]. Moreover, they have a great impact on both effector and regulatory $\mathrm{T}$ cell pools, restraining the suppression of Treg in autoimmune diseases [172]. However, bone marrow-derived mast cells constitutively expressing OX40L can also be affected by bidirectional signalling through OX40L upon binding of OX40 on Treg. As demonstrated by Piconese et al. [172] and Gri et al. [173], signalling through the TNF ligand resulted in a decreased histamine degranulation mediated by the high affinity Immunoglobulin E receptor. This finding suggests a prominent role of the OX40-OX40L system in the direct regulation of the acute phase during allergy via mast cell-Treg interactions.

In summary, the occurrence of reverse signalling within the OX40-OX40L system highlights its involvement during host defence and emphasises its crucial impact in the formation of an immune response. 



\section{Objective}

Within the TNF superfamily of costimulatory molecules, which are involved in $\mathrm{T}$ cell activation, OX40 and its ligand OX40L are reported to be indispensable for the longevity of the evolving T cell response. In mammals, the OX40-OX40L system adopts a pivotal role by providing survival signals as well as by promoting cell proliferation, differentiation and cytokine production. However in chickens, information on the process of $\mathrm{T}$ cell costimulation remains scarce.

The aim of this study was to characterise the chicken homologues of mammalian OX40 and OX40L and to confirm their involvement in the process of chicken $\mathrm{T}$ cell activation.

The characterisation comprised three consecutive steps. The genomic identification and correct attribution of the chicken molecules OX40 and OX40L was a prerequisite to analyse their phylogenetic and structural relation to their mammalian homologues. As a second step, cloning and recombinant expression of soluble and cellbound variants allowed for the investigation of additional properties of the chicken molecules, such as their ability of mutual interaction and the tendency of the soluble forms to dimerise. In the third part of the study, we demonstrated the involvement of the OX40-OX40L system in chicken $\mathrm{T}$ cell activation by proving the existence of OX40L on activated chicken $\alpha \beta$ and $\gamma \delta$ T cells. The recombinant variants of chicken OX40 and OX40L, which were generated within this study, may serve as tools for further studies of chicken $\mathrm{T}$ cell activation. 



\title{
4 Publication
}

\section{Characterisation of chicken OX40 and OX40L}

\author{
Stephanie Scherer, Thomas W. Göbel
}

Institute for Animal Physiology, Department of Veterinary Sciences, University of Munich, Veterinärstrasse 13, 80539 Munich, Germany

A R T I C L E I N F O

\section{Article history:}

Received 8 December 2017

Received in revised form

19 January 2018

Accepted 19 January 2018

\section{Keywords:}

OX40

OX40L

OX40L

$\gamma \delta$ T cells

\begin{abstract}
A B S T R A C T
The Tumour Necrosis Factor superfamilies of receptors and ligands play a crucial role in the regulation of effective immune responses against pathogens and malignant cells. In chickens, only few members have been identified. Here, we characterise the chicken homologues for mammalian costimulatory molecules OX40 and OX40L, which are involved in sustaining T cell responses. Both genes were identified by virtue of their genomic localisation close to highly conserved genes and their structural relationship to their mammalian homologues. Following cloning and expression of soluble and cell-associated chicken OX40 and OX40L, we confirmed their mutual interaction via ELISA and flow cytometric analyses. In addition, we showed the application of soluble OX40-Fc in staining of chicken cells. Whereas non-activated cells did not express OX40L, activation by IL-2 and IL-12 resulted in upregulation of OX40L on $\alpha \beta$ and $\gamma \delta$ T cell populations. Our results demonstrate the existence of the costimulatory OX40-OX40L system in the chicken and provide the basis for further investigations of chicken $\mathrm{T}$ cell responses.
\end{abstract}

(1) 2018 Elsevier Ltd. All rights reserved.

\section{Introduction}

T cell activation is a complex process involving various forms of signals and receptors. Besides TCR triggering, binding of costimulatory molecules is pivotal to obtain a complete activation state in terms of cell differentiation, proliferation, longevity and cytokine production.

The classic costimulatory receptors belong to three superfamilies: the Immunoglobulin (Ig) superfamily (e.g. CD28 or CD2), the family of cytokine receptors (e.g. IL-2R or IL-7R) and the Tumour Necrosis Factor Receptor Superfamily (Croft, 2003). In the pas decades, the focus of research of the $T$ cell activation process was dominated by the investigation of $\mathrm{CD} 28$ signals. Only more recently the Tumour Necrosis Factor (TNF) superfamily, comprising receptors (TNFRSF) and their respective ligands (Tumour Necrosis Factor Superfamily, TNFSF), was studied more intensively (Croft, 2003). The family of TNFRSF receptors comprises 30 members (Gaur and Aggarwal, 2003), which can be divided into three functional groups depending on their intracellular signalling pathways (Ward-Kavanagh et al., 2016): so called decoy receptors without a

Abbreviations: TNF, Tumour Necrosis Factor; TNFRSF, Tumour Necrosis Factor Receptor Superfamily; TNFSF, Tumour Necrosis Factor Superfamily.

मे Supported by DFG Grant 489/5-2.

* Corresponding author.

E-mail address: goebel@Imu.de (T.W. Göbel). cytoplasmic domain are distinguished from receptors containing a death domain (DD) in their cytoplasmic region which induces apoptosis. The third group comprises family members, which contain an intracellular motif for binding to adaptor molecules of the signalling cascade, called TRAFs (TNF Receptor-Associated Factors), promoting activation, survival and differentiation. Several TNF family members play major roles in sustaining $\mathrm{T}$ cell activation subsequent to the primary costimulatory effect of the CD28-B7 system. Among these receptors (CD27, CD30, GITR, 4-1BB, HVEM) (Watts, 2005), OX40 (CD134) and its ligand OX40L (CD252) hold a prominent position, as they ensure the longevity of $\mathrm{T}$ cell response by supplying anti-apoptotic signals (Rogers et al., 2001). During an immune response, the OX40-OX40L system regulates the functions of $\mathrm{CD}^{+}$and $\mathrm{CD}^{+}$T cells, regulatory T cells, Natural Killer (NK) and Natural Killer T (NKT) cells and interacts with Antigen Presenting cells (APCs) and tissue cells like endothelial or smooth muscle cells (Croft, 2010).

The receptor OX40 is a TRAF binding receptor and is reported to be a key mediator of costimulatory signals in mammalian $\mathrm{T}$ cells (Croft, 2010). OX40 belongs to the group of type I transmembrane proteins exhibiting an extracellular $\mathrm{N}$ terminus and an intracellular C terminus (Bodmer et al., 2002). Its extracellular domain comprises four Cysteine-Rich Domains (CRDs) which are the characteristic feature of TNFRSF receptors, but whose number may differ between family members (Ware, 2003). Due to these cysteine residues, the ectodomain of OX40 exhibits a stretched shape which allows for ligand binding (Banner et al., 1993). 
In mouse and human, the OX40 molecule is absent on naïve T cells, but is upregulated during the activation process as early as $12 \mathrm{~h}$ up to 5-6 days after antigen contact and TCR stimulation (Croft, 2010; Latza et al., 1994; Rogers et al., 2001). It can be detected on activated CD4 ${ }^{+}$(Latza et al., 1994; Mallett et al., 1990) and on $\mathrm{CD}^{+}$T cells (Bansal-Pakala et al., 2004), as well as on Th1, Th2, Th17 subsets of T helper cells and on regulatory T cells (Croft, 2010; Redmond et al., 2009). In addition, NK cells (Liu et al., 2008), NKT cells (Zaini et al., 2007) and neutrophils (Baumann et al., 2004) express the receptor at lower densities. The time course of OX40 expression depends on different factors like the nature of the antigen, its persistence, the evolving proinflammatory milieu and the affected T cell subset (Rogers and Croft, 2000). The involvement of other costimulatory molecules such as CD28, IL-2R or the presence of cytokines like IL-1, IL-4 and TNF also contributes to an optimal and prolonged expression (Croft, 2010; Redmond et al., 2009).

OX40L, like the other ligands of this family, is a type II transmembrane protein which exhibits an intracellular $\mathrm{N}$ terminus and an extracellular C terminus with a TNF Homology Domain (THD) (Ware, 2003). The THD is formed by two antiparallel $\beta$ sheets which rejoin with the respective THDs of two other protomers to form non-covalent homotrimers. To date, the OX40 receptor is known only to bind its ligand OX40L (Croft, 2010) while other members of the TNFRSF family can interact with different ligands (Idriss and Naismith, 2000). As reported for other ligands like TNF, BAFF or FasL, OX40L also exists as a soluble variant, cleaved from the cell surface probably after the interaction with its receptor (Croft, 2010).

Human and murine OX40L molecules are expressed by a broader range of cell types, particularly on different kinds of activated APCs comprising B cells (Linton et al., 2003), macrophages (Karulf et al., 2010), dendritic cells (Jenkins et al., 2007) and Langerhans cells (Sato et al., 2002). OX40L expression is promoted by various stimuli like signalling through Toll-like receptors, the B cell receptor and the CD40 molecule or the presence of IL-18, TSLP (Thymic Stromal Lymphopoietin), IFN $\gamma$ or prostaglandin E2 (Croft, 2010; Ito et al., 2005; Krause et al., 2009; Kurche et al., 2012; Maxwell et al., 2006). Furthermore, OX40L was observed on activated $\mathrm{CD}^{+}$and $\mathrm{CD}^{+} \mathrm{T}$ cells, suggesting an additional way of sustaining $T$ cell response via T cell-T cell interactions (Mendel and Shevach, 2006). The expression of OX40 and OX40L in such a wide range of cell types affirms the manifold and extensive influence of the OX40-OX40L costimulatory system in mammals.

In chickens and other birds, information about representatives of the TNF superfamily, particularly about OX40 and OX40L, remains scarce. Although the genomic location of several members of the TNF superfamily has already been identified, the trace of others remains obscure, partly due to the incomplete annotation of the chicken genome (Kaiser, 2012). To date, chicken CD30 (Burgess et al., 2004) and CD30L (Abdalla et al., 2004) are the only TNF members involved in T cell activation, which were characterised in chickens. In our study, we describe the molecular cloning and expression of the chicken TNF receptor-ligand pair OX40-OX40L, characterise their structural properties, their ability of mutual recognition and their possible application in the cell staining of primary chicken cells. As OX40 and OX40L represent key costimulatory molecules in the activation process of T cells, our results will advance the understanding of the $\mathrm{T}$ cell response in chickens.

\section{Materials and methods}

\subsection{Animals}

Chicken line M11 was kindly provided by S. Weigend (Federal Research Institute for Animal Health, Mariensee, Germany). Fertilised eggs were incubated and hatched at the Institute for Animal
Physiology, University of Munich, Germany. The chickens were reared under conventional conditions and they were eight weeks old when experiments were performed.

\subsection{Cell culture and cell preparations}

Human Embryonic Kidney cells (HEK) 293 were cultured in Roswell Park Memorial Institute (RPMI) 1640 medium (Invitrogen life technologies, Carlsbad, CA, USA) containing 10\% Fetal Bovine Serum (FBS) (Biochrom GmbH, Berlin, Germany) in a $5 \% \mathrm{CO}_{2}$ incubator at $37^{\circ} \mathrm{C}$. To obtain chicken splenocytes, a single cell suspension was prepared by passing the spleen through a stainless steel mesh and mononuclear cells were segregated by consecutive density centrifugation on Biocoll Separating Solution (Biochrom $\mathrm{GmbH}$ ). For stimulation, chicken splenocytes were plated at a density of $10^{6}$ cells per well in a 96-well flat bottom plate and maintained at $40{ }^{\circ} \mathrm{C}$ and $5 \% \mathrm{CO}_{2}$ in RPMI 1640 medium supplemented with 10\% FBS, 1\% Penicillin/Streptomycin (Biochrom $\mathrm{GmbH}$ ) and a combination of recombinant chicken IL-2 and IL-12. Chicken cytokines were obtained as previously described (Fenzl et al., 2017). Every second day, cultures were diluted by the substitution of $50 \%$ of the volume per well for fresh stimulation medium.

\subsection{Database search and sequence analysis}

ChOX40 and chOX40L were identified by keyword search using the gene database of NCBI (https://www.ncbi.nlm.nih.gov/) and the Ensembl database (https://www.ensembl.org/index.html). To confirm their correct annotation, mRNA and protein sequences of chOX40 and chOX40L were compared to their mammalian equivalents in the database using the Basic Local Alignment Search Tool (BLAST). Presumed protein sequences were structurally analysed by SMART (smart.embl-heidelberg.de). Protein sequences were aligned using the Clustal Omega method in the DNASTAR Lasergene Software package. Phylogenetic analysis was performed using the software MEGA5 (Tamura et al., 2011). Sequences of human, mouse and turkey equivalents of OX40, CD30 and their ligands OX40L, CD30L and of chicken TACI and BAFF were obtained by keyword search in the database mentioned above. The amino acid sequences of receptors or ligands were separately aligned by Muscle and Maximum Likelihood trees were generated using the following settings. For the data set of receptors, the JTT $+\mathrm{G}$ substitution model was used, whereas the sequences of ligands were analysed via the JTT model. To account for gaps in sequence alignment, the partial deletion option was selected and the tree was constructed with 1000 bootstrap replicates.

\subsection{Cloning procedures}

The sequences of chOX40 (accession no. NM_001354724.1) and chOX40L (accession no. XM_430147.4) were used for primer design. All oligonucleotides were obtained from Eurofins, Ebersberg, Germany. Primer sequences for the generation of the different constructs are displayed in Table 1 . All constructs were verified by sequencing (GATC, Konstanz, Germany). To generate soluble forms of the ectodomains of OX40 and OX40L, either tagged by a C-terminal human IgG1-Fc domain (henceforth "OX40-Fc") or by an Nterminal FLAG-tag (henceforth "OX40L-FLAG"), we applied the following cloning strategy. We employed vectors derived from variants of the pCR3 (Invitrogen life technologies) provided by P. Schneider (University of Lausanne, Epalinges, Switzerland). They either encoded an Ig signal peptide followed by a thrombin cleavage site and the human IgG1-Fc domain at 3' (vector PS229) or a signal peptide of Hemagglutinin of Influenza A virus (HA) and a 
Table 1
Sequences of oligonucleotides.

\begin{tabular}{|c|c|c|c|}
\hline Number & Construct & Orientation $^{\mathrm{a}}$ & Sequence $^{\mathrm{b}}$ \\
\hline 2093 & OX40L-FLAG & $\mathrm{f}$ & GACAGGTGCAGCTGCAGACAGATTCTCTGCAACTC \\
\hline 2094 & OX40L-FLAG & $\mathrm{r}$ & $\overline{\text { GGTGACACTATAGAATAGGAATTCTATGGGTTGCAAAAGACGG }}$ \\
\hline 2101 & OX40-Fc & $\mathrm{f}$ & AGCTGGTGCCACGCGGATCCTCGAAATGCAAAGAACATG \\
\hline \multirow[t]{2}{*}{2133} & HA-SP-Myc & & $\begin{array}{l}\text { CCCAAGCTGGCCTCTGATGGCTATCATCTACCTCATCCTCCTG } \\
\text { TTCACCGCTGTGCGGGGCgaacaaaaactcatctcagaagaggatctaCGCGTA }\end{array}$ \\
\hline & & & GGCCAAGCTTGGGGA \\
\hline 2137 & OX40-Мyс & $\mathrm{r}$ & TCCCCAAGCTTGGCCTATCAGTTTTTTATGAGACTGG \\
\hline 2145 & OX40L-V5 & $\mathrm{r}$ & TGGGTTGCAAAAGACGGGAT \\
\hline
\end{tabular}

a Orientation: $\mathrm{f}$ = forward, $\mathrm{r}=$ reverse.
b Sequence: Bold letters mark nucleotides encoding the signal peptide of Hemagglutinin of Influenza A virus. Lower case letters indicate nucleotides encoding the c-Myc tag. Underlined sequences display overlapping sites with vector arms.

FLAG epitope at 5' (vector PS167). For both constructs, PCR primers were designed for direct use with the Gibson Assembly ${ }^{\mathbb{B}}$ Master Mix (New England Biolabs GmbH, Frankfurt am Main, Germany). In brief, primers spanned the extracellular domains of OX40 or OX40L, respectively, and also contained complementary sequences to the $5^{\prime}$ and $3^{\prime}$ of the corresponding cloning vectors (Table 1 underlined sequences), hence creating overlapping ends. The sequences of OX40 and OX40L were amplified by PCR on CDNA of concanavalin A stimulated T cells using primers 2101 and 2102 (for OX40) and primers 2093 and 2094 (for OX40L) and cloned via Gibson Assembly into their designated vectors. For the construction of full length sequences of OX40 tagged by a c-Myc-tag (henceforth solely "Myc-tag"), we performed two consecutive cloning steps via Gibson Assembly. The oligonucleotide 2133 was synthesised, encoding the HA signal peptide linked to the Myc-epitope and containing overlaps with the designated vector arms. As first step the 2133 oligonucleotide was cloned into the pSBbi-GP vector, comprising a gene for a Green Fluorescent Protein (GFP) (Kowarz et al., 2015). The sequence of OX40 was obtained by PCR on CDNA of concanavalin A stimulated T cells with primers 2137 and 2141 creating overlaps with the vector arms and, as a second step, cloned into the Myc-encoding pSBbi-GP vector. To obtain the OX40L-V5 construct, we performed a PCR with the primers 2144 and 2145 on CDNA of long-term stimulated splenocytes (IL-2 and IL-12) yielding the OX40L sequence. Subsequently, it was cloned into the pEF6/V5-His TOPO ${ }^{\circledR}$ vector using the pEF6/V5-His TOPO ${ }^{\circledR} \mathrm{TA}$ Expression Kit (Invitrogen life technologies).

\subsection{Recombinant protein expression and purification}

Stable HEK 293 cell lines expressing soluble forms of either human Fc-tagged receptor or FLAG-tagged ligand were established by transfecting cells with $0.7 \mu \mathrm{g}$ of the respective constructs using Metafectene $^{\mathbb{Q}}$ (Biontex Laboratories $\mathrm{GmbH}$, Munich, Germany). Transfected cells were subsequently selected with $0.8 \mathrm{mg} / \mathrm{ml} \mathrm{G418}$ (Biochrom $\mathrm{GmbH}$ ) for plasmid uptake. Supernatant of the transfected cell clones was screened after seven days either by an antihuman-IgG Sandwich ELISA or an anti-FLAG-M2 Sandwich ELISA for the presence of fusion proteins. The OX40-Fc supernatant was affinity-purified on Protein-G-coupled agarose (Merck KGaA Darmstadt, Germany), whereas an anti-FLAG ${ }^{\mathbb{R}}$ M2 Affinity Gel (Sigma Aldrich St. Louis, MO, USA) was used to purify OX40L-FLAG. For the generation of stable cell lines expressing the Myc-tagged OX40 receptor (293-OX40-Myc) or the V5-tagged OX40L ligand (293-OX40L-V5) on their cell surface, HEK 293 cells were transfected with the corresponding vectors using $0.7 \mu \mathrm{g}$ plasmid and Metafectene ${ }^{\circledR}$. In detail, for the OX40-Myc transfection, cells were co-transfected with the OX40-Myc encoding SB vector $(0.665 \mu \mathrm{g})$ and a transposase encoding vector $(0.035 \mu \mathrm{g})$. According to the vectors' resistance, cells were selected with puromycin $(1 \mu \mathrm{g} / \mathrm{ml}$, OX40-Myc construct) (Merck KGaA) or blasticidin $(10 \mu \mathrm{g} / \mathrm{ml}$, OX40L-V5 construct) (Thermo Fisher Scientific, Waltham, MA, USA). After ten days, cell clones were screened for their respective tag-surface-expression by flow cytometry (FACS Canto II, Becton Dickinson, Heidelberg, Germany).

\subsection{ELISA}

Wells of a Nunc Immuno ${ }^{\mathrm{TM}}$ MicroWell ${ }^{\mathrm{TM}} 96$ well solid plate (Sigma Aldrich) were coated overnight at $4{ }^{\circ} \mathrm{C}$ with $3.9 \mu \mathrm{g} / \mathrm{ml}$ of donkey anti-human $\operatorname{IgG}(\mathrm{H}+\mathrm{L})$ (Jackson ImmunoResearch Laboratories Inc., West Grove, PA, USA). All incubation steps were performed at $37^{\circ} \mathrm{C}$ for one hour and preceded by washing with PBS buffer containing 0,05\% Tween (PanReac AppliChem ITW Reagents, Darmstadt, Germany) (PBS-T) according to standard procedures. The plate was blocked with 5\% skim milk (PanReac AppliChem ITW Reagents) and afterwards incubated with chOX $40-\mathrm{Fc}(5 \mu \mathrm{g} / \mathrm{ml})$. An unrelated Fc-tagged chicken protein served as a negative control (CD30-Fc). Subsequently, a twofold serial dilution of chOX40L-FLAG in PBS-T was added. All titration steps were performed as triplicates. Control wells contained the highest concentration of chOX40L-FLAG. The interaction between receptor and ligand was identified by a murine anti-FLAG ${ }^{\mathbb{R}}$ M2-HRP mab (Sigma Aldrich). Subsequently, specifically bound mab was detected using the 3,3'5,5'-tetramethylbenzidine-substrate and absorbance was measured at $450 \mathrm{~nm}$ and analysed via X-Read Plus using TECAN. Sunrise $^{\mathrm{TM}}$ (Tecan Deutschland GmbH, Crailsheim, Germany).

\subsection{Western blot}

Samples of chOX40-Fc and chOX40L-FLAG were prepared under reducing (with 1M dithiothreitol) (DTT) (PanReac Applichem ITW Reagents) and non-reducing conditions (without DTT), separated by a $7.5 \%(\mathrm{OX} 40-\mathrm{Fc})$ or a $12 \%$ (OX40L-Flag) SDS polyacrylamide gel, and electroblotted onto a Polyvinylidene Difluoride (PVDF) membrane (GE Healthcare Life Sciences, Chalfont St Giles, Buckinghamshire, UK). The molecular weight marker PageRulerTM Prestained Protein Ladder (Thermo Fisher Scientific) served as protein standard. After blocking with $5 \%$ skim milk, membranes were washed and incubated with mabs for one hour at room temperature. For detection of OX40-Fc, a goat anti-human IgG-HRP (Southern Biotech, Birmingham, AL, USA) was used, whereas OX40L-FLAG was identified by a murine anti-FLAG ${ }^{\mathbb{R}}$ M2-HRP mab. After repeated washing with PBS-T, protein bands were visualised 
via chemiluminescense using the MicroChemi 4.2 (DNR BioImaging Systems, Jerusalem, Israel).

\subsection{Staining procedures}

Stably transfected 293-OX40-Myc cells were stained with OX40L-FLAG, followed by a murine anti-FLAG ${ }^{\circledR}$ M2 mab (Sigma Aldrich) and by a goat anti-mouse IgG1 human ads-APC mab (Southern Biotech). As negative controls, cells were either stained with an unrelated FLAG-tagged chicken protein (CD30L-FLAG) followed by secondary mabs or solely stained with the secondary mabs to exclude any unspecific binding to the Myc-tagged receptor. To verify surface expression of the chOX40-Myc receptor, transfected cells were stained with the mab 9E10 specifically recognising the c-Myc tag (Invitrogen life technologies), followed by a goat antimouse IgG1 human ads-APC mab. 293-OX40L-V5 cells were stained with OX40-Fc and the AF647-conjugated goat anti-human IgG Fc specific $\mathrm{F}(\mathrm{ab})_{2}$ fragment (Jackson ImmunoResearch Laboratories Inc.). As negative control, cells were either stained with an unrelated Fc-tagged chicken protein (CD30-Fc) followed by the secondary mab or solely with the secondary mab. For the affirmation of OX40L-V5 surface expression, transfected cells were stained with a murine anti-V5-FITC mab (Invitrogen life technologies). To acquire the kinetics of chOX40-Fc staining upon activation, chicken splenocytes were stained at days $0,2,4,6,8$ and 10 with chOX40-Fc followed by the AF647-conjugated goat anti-human IgG Fc $\gamma$ specific $\mathrm{F}(\mathrm{ab})_{2}$ fragment. Double immunofluorescence analysis was performed with OX40-Fc, followed by mabs specifically recognising chicken TCR1 ( $\gamma \delta$ T cells, murine IgG1) (Sowder et al., 1988), TCR2 ( $\alpha$ V $\beta 1$ T cells, murine IgG1) (Chiak et al., 1988), TCR3 ( $\alpha$ V $\beta 2$ T cells, murine IgG1) (Chen et al., 1989), and CD8 $\alpha$ (3-298, murine IgG2b) homologues (Luhtala et al., 1997). Subsequently, cells were incubated with a mixture of the AF647-conjugated goat anti-human IgG $\mathrm{Fc}_{\gamma}$ specific $\mathrm{F}\left(\mathrm{ab}^{\prime}\right)_{2}$ fragment and depending on the isotype of the primary mab, either with a goat anti-mouse IgG1 human ads-PE or goat anti-mouse-IgG2b human ads-PE (both Southern Biotech). For each staining appropriate isotype matched controls were used. For life-death staining, either Propidiumiodid (PI) (Sigma Aldrich) or Fixable Viability Dye eFluor780 (eBioscience GmbH, Frankfurt am Main, Germany) were used. The population of living cells was subsequently analysed by flow cytometry (FACS Canto II, Becton Dickinson) using BD FACS DIVA 6.1.3 software.

\section{Results}

\subsection{Identification of chicken $\mathrm{OX} 40$ and $\mathrm{OX} 40 \mathrm{~L}$}

We searched the chicken genome assembly Gallus_gallus-5.0 for the keywords OX40 and OX40L and obtained the genomic location for these TNF family members. The chicken OX40 gene was not discretely listed, but annotated in the database together with another gene as TNFRSF18. In order to ascertain the identity of the presumed OX40 gene, so far annotated as TNFRSF18, we screened the genomic regions containing the supposed OX40 in chicken for shared synteny with the human and murine genome and ran BLAST searches with the predicted coding sequences of the presumed OX40 gene on chicken genome assembly 5.0. The BLAST search revealed a hit on chicken chromosome 21 , flanked by the two genes SDF4 and TNFRSF18. Together with OX40, we identified these two sequences as highly conserved and co-localised genes also on human chromosome 1 and on murine chromosome 4 (Fig. $1 \mathrm{~A}$ ). The OX40L gene is located on chromosome 8 and shares genetic linkage to the gene of PRDX6. It is also clustered to FasL as a screening of genomic regions flanking $\mathrm{OX} 40 \mathrm{~L}$ in human and mouse (both chromosome 1) revealed (Fig. 1 B).
3.2. Chicken OX40 and OX40L share characteristic sequence features with their mammalian homologues

The predicted coding sequences of chicken OX40 and OX40L genes were further compared to their equivalents in other species. Transcription analysis demonstrated that the DNA sequences encode for chains of 287 (chOX40) and 204 (chOX40L) amino acids, respectively. The analysis of OX 40 revealed the typical structure of a type I transmembrane protein with an extracellular domain of 225 amino acids (signal peptide of 28 residues), a transmembrane region of 23 amino acids and a cytoplasmic domain of 39 amino acids (Fig. 2). The entire OX40 molecules of the depicted species comprise 287 (chicken), 286 (turkey), 277 (human) and 272 (mouse) residues. Chicken OX40 displays an overall identity of about $30 \%$ to its human counterpart. The ectodomain of chOX40 exhibits CRDs, representing the characteristic feature of the TNFRSF family members. Like its homologues, chOX40 contains three complete (CRD 1, 2, 4) and one truncated (CRD 3) CRDs (Willoughby et al., 2017). The structure of human OX40 CRDs can be further characterised and divided into submodules according to the system established by Naismith and Sprang (1998). The two avian receptors display the same sequential arrangement of submodules, thus forming the same disulphide bonds. Their CRD 1 and 2 show classical A1-B2 modules, their CRD 3 is truncated and only possesses an A1 module, whereas their CRD 4 contains A1-B1 modules (Willoughby et al., 2017). Another similarity among the species is the major conserved TRAF2 binding motif $(\mathrm{P} / \mathrm{S} / \mathrm{A} / \mathrm{T}) \mathrm{x}(\mathrm{Q} / \mathrm{E}) \mathrm{E}$ in their cytoplasmic domain, which suggests conserved signalling pathways (Ye et al., 1999).

The chicken OX40L molecule displays the structural organisation of a type II protein with its amino-terminal cytoplasmic domain of 41 amino acids, its transmembrane region comprising 23 amino acids and its carboxyl-terminal extracellular domain of 140 residues (Fig. 3). The full length sequences of OX40L of chicken, turkey, human and mouse consist of 204, 204, 183 and 198 amino acids, respectively. Even though the displayed sequences show an overall sequence identity of only $19 \%$, the TNF homology domain ( $\beta$-strands indicated for huOX40L) with its hydrophobic residues, assumed to be important for the trimerisation, is well conserved (Compaan and Hymowitz, 2006). Regarding the intracellular domain of OX40L, the chicken sequence seems to be longer with an extra 31 amino acids (MMVCASASTKQARPAGDCGPPVLLVPALLVE). This may not be the transcriptional start site due to an extra methionine further 3' that is exactly in the same position as in mammals.

\subsection{Phylogenetic relation between depicted TNFRSF and TNFSF} family members

Given the low overall sequence identity, we additionally performed phylogenetic analyses to further validate the homology of the identified genes to their mammalian counterparts using Maximum Likelihood trees (Fig. 4). Sequences of turkey, human and mouse were used as far as identified in the database for the receptor CD30 and its ligand CD30L. Chicken sequences of TACI and BAFF were included as internal tests for tree construction representing outliers. The analysis of the receptors (Fig. 4A) shows that the chicken OX40 is closely related to its species equivalents forming one cluster, whereas the CD30 receptor molecules are clustered and chicken TACI exhibits a more distant relation to these two receptor families. The same phenomenon can be seen for the phylogenetic analysis of the TNFSF ligands OX40L, CD30L and BAFF (Fig. 4B). The molecules belonging to the OX40L family are clustered, while the CD30L family forms an individual branch and chBAFF is only distantly related. Both OX40L and CD30L molecules 


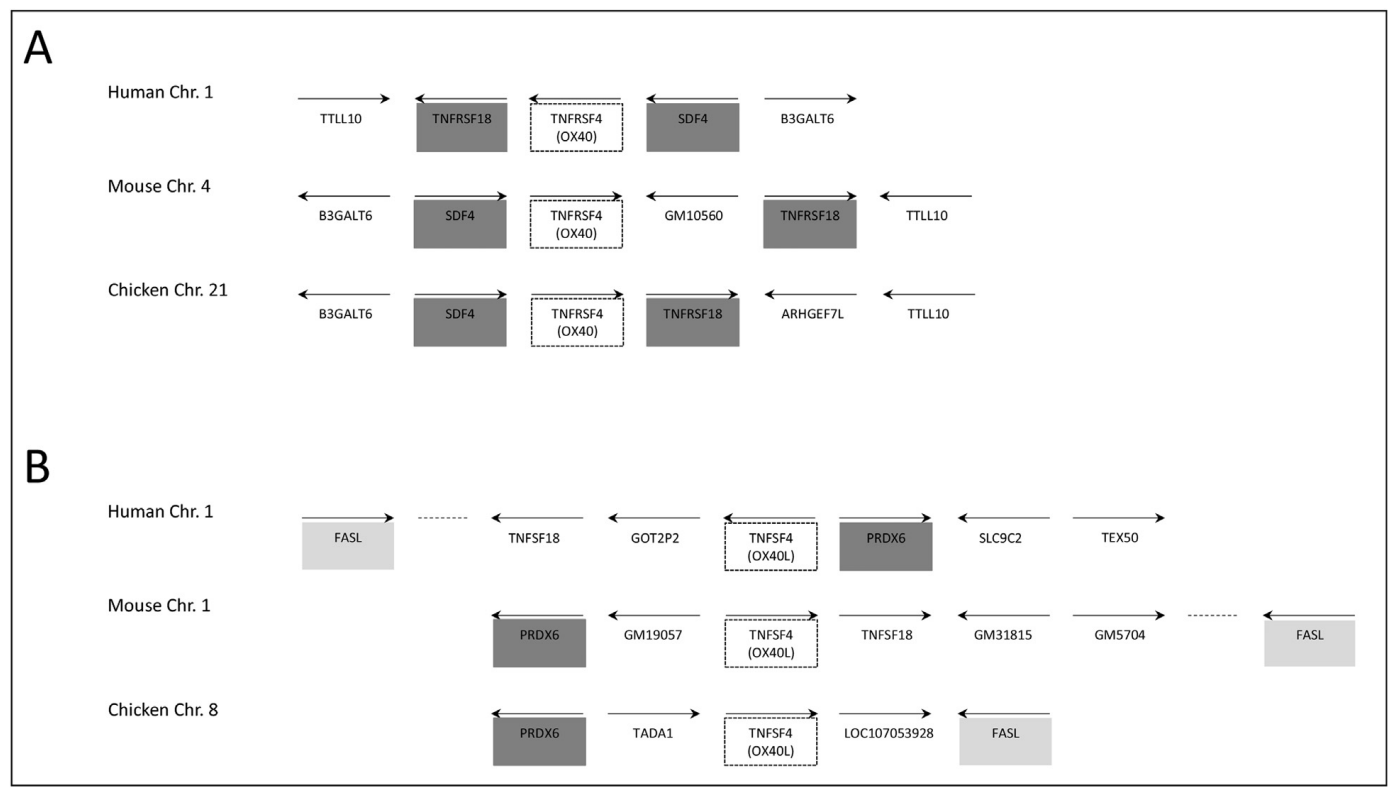

Fig. 1. Comparative chromosomal organisation of OX40 and OX40L. Sequential arrangement of genomic regions flanking the OX40 (A) or the OX40L (B) gene in human, mouse and chicken on the respective chromosomes as indicated. Transcriptional orientation of the genes is marked by an arrow. TNFRSF4 (OX40) and TNFSF4 (OX40L) genes are boxed with a dashed line. Highly conserved flanking genes to OX40 or OX40L are shaded in dark-grey. Gene lengths and distances between individual genes are not drawn to scale. Gaps in gene order, omitting genes up to the localisation of the FasL gene, are marked by a dashed line. The gene of FasL is shaded in light grey. The entire gene denotations according to NCBI: TTLL10: tubulin tyrosine ligase like 10, TNFRSF18: TNF receptor superfamily member 18, SDF4: stromal cell derived factor 4, B3GALT6: beta-13-galactosyltransferase 6, ARHGEF7L: rho

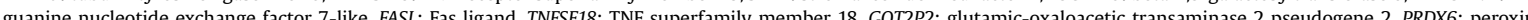

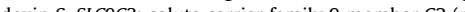
edoxin 6, SLC9C2: solute carrier family 9 member C2 (putative), TEX50: testis expressed 50, TADA1: transcriptional adaptor 1. Putative additional genes are shown following NCBI
nomenclature: Mouse: GM10560, GM19057, GM31815, GM5704; Chicken: LOC107053928.

belong to the divergent group of TNFSF ligands and hence share only weak similarities with each other and with the EF-disulphide group (e.g. BAFF) (Compaan and Hymowitz, 2006).

\subsection{Soluble ectodomains of recombinant chOX40-Fc and chOX40L- FLAG}

We next generated different variants of the chOX40 and of its ligand chOX40L to assess their mutual binding capabilities and to investigate their application in the staining of primary chicken cells. OX40 was generated as soluble Fc-tagged (OX40-Fc) version and the ligand as FLAG-tagged soluble protein (OX40L-FLAG). Purified OX40-Fc and OX40L-FLAG were separated by SDS-PAGE under reducing and non-reducing conditions, subsequently electroblotted and detected by western blot analysis (Fig. 5). ChOX40-Fc shared an apparent molecular weight of approximately $80 \mathrm{kDa}$ under reducing and $160 \mathrm{kDa}$ under non-reducing conditions, thus arguing in favour of homodimerisation (Fig. 5A). In case of chOX40L-FLAG the reduced sample revealed an apparent molecular weight of about $30 \mathrm{kDa}$ and the non-reduced sample of about $60 \mathrm{kDa}$, hence as well suggesting homodimerisation (Fig. 5B).

\subsection{Interaction between recombinant chicken OX40 and OX40L}

To assess the interaction of OX40 and OX40L, we applied ELISA and flow cytometric analyses. To confirm the interaction between the soluble forms of chOX40-Fc and chOX40L-FLAG, we performed an ELISA titration assay (Fig. 6). OX40-Fc was immobilised on a plate and OX40L-FLAG was added in twofold dilutions. The binding capability of the soluble OX40L to its receptor declined with higher dilutions of the ligand. The binding of the OX40L-FLAG-ectodomain to the ectodomain of its Fc-tagged receptor was specific, as the ligand showed no significant interaction with an unrelated chicken Fc-tagged protein (CD30-Fc), even at the highest concentrations.

In order to verify the binding capability of the cell-bound receptor to the ectodomain of its soluble ligand, we established a stable cell line of 293 cells expressing the full length, Myc-tagged OX40 receptor on its cell surface (293-OX40-Myc). Since the vector also comprised a GFP cassette under a second promotor, the efficiency of the transfection could be measured. To exclude any unspecific binding, we included two negative controls using transfected cells with the secondary mabs, or an unrelated FLAGtagged chicken protein (CD30L-FLAG) in combination with the secondary mabs (Fig. 7). Cells were stained with the mab 9E10 and screened for their c-Myc expression via flow cytometry. Simultaneous screening for their GFP signal revealed that almost all cells were double positive for 9E10 and GFP expression. Staining with OX40L-FLAG demonstrated that virtually all cells bearing an OX40Myc receptor on their cell surface could be recognised by their soluble ligand.

Additionally, we tested whether the chOX40-Fc protein was able to detect cell-associated OX40L. For this purpose, we established a cell line stably expressing the entire OX40L ligand (293-OX40L-V5). Virtually all transfected cells exhibited cell-bound OX40L-V5 (Fig. 8), whereas isotype matched controls showed no positive signal. Staining with chOX40-Fc yielded a very similar population of positive cells, compared to the staining with the anti-V5-FITC mab. Negative controls, either with secondary mab only or in 


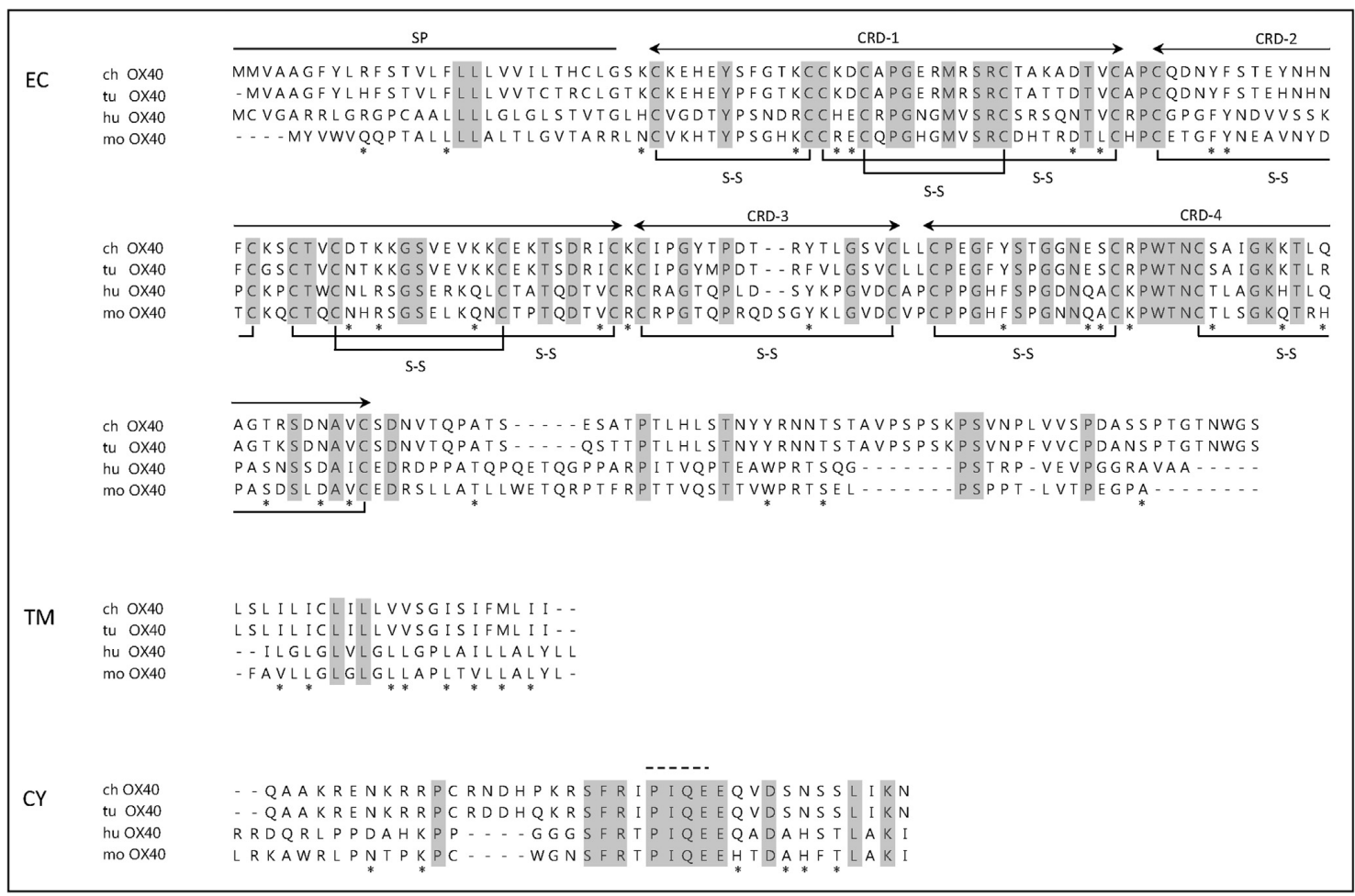

Fig. 2. Amino acid sequence alignment of OX40. Extracellular (EC), transmembrane (TM) and cytoplasmic (CY) domains are indicated and species are denoted as ch, chicken; tu, turkey; hu, human; mo, mouse. Conserved residues are shaded in grey, asterisks $\left(^{*}\right)$ indicate residues sharing similar properties. The signal peptide (SP) is marked by a line and CRDs by arrows above the sequences. Note that the SP of moOX40 solely comprises amino acids $1-22$. Disulphide bridges of CRD submodules are displayed as S-S beneath the sequences. The dashed line indicates the major conserved TRAF2 binding motif. Accession numbers: chOX40 NP_001341653.1, tuOX40 XP_010721084.1, huOX40 XP_016857721.1, moOX40 NP_035789.1.

\begin{tabular}{|c|c|c|}
\hline $\mathrm{CY}$ & $\begin{array}{l}\text { ch } O \times 40 L \\
\text { tu } O \times 40 L \\
\text { hu } O \times 40 L \\
\text { mo OX40L }\end{array}$ & 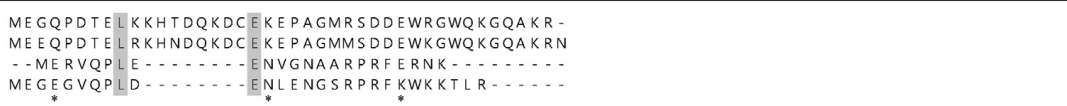 \\
\hline \multirow[t]{2}{*}{ TM } & $\begin{array}{l}\text { ch } O X 40 L \\
\text { tu } O X 40 L \\
\text { hu } O X 40 L \\
\text { mo } O X 40 L\end{array}$ & 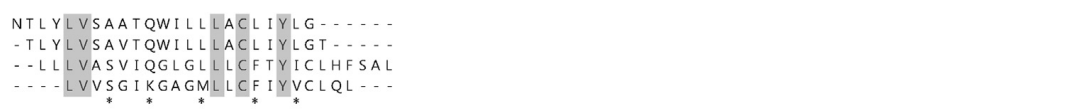 \\
\hline & & $\mathrm{A} \longrightarrow \stackrel{\mathrm{A}^{\prime \prime}}{\longrightarrow} \quad \mathrm{B}^{\prime} \mathrm{B} \quad \mathrm{C} \quad \mathrm{D}$ \\
\hline \multirow[t]{6}{*}{ EC } & $\begin{array}{l}\text { ch } O \times 40 L \\
\text { tu } O X 40 L \\
\text { hu } O X 40 L \\
\text { mo } O \times 40 L\end{array}$ & 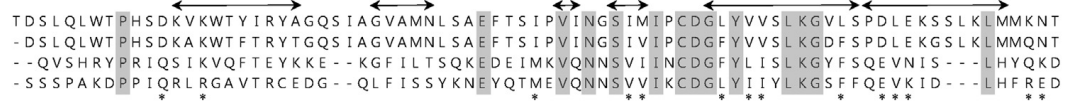 \\
\hline & & G \\
\hline & ch $0 \times 401$ & 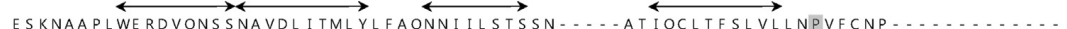 \\
\hline & tu $0 \times 40 \mathrm{~L}$ & ENKNVATLWERDVQNSSSKVDLITILYLFAENNIILSTSSN - A ATIQNLTFSLVLLNPIFCNS \\
\hline & hu OX40L & E - . EPLFQ - LKKVRSVNSLMVASLTYKDKVYLLNVTIDNTSLDDFHVNGGELILIHQNPGEFCVL $\ldots \ldots$ \\
\hline & mo Ox40L & H-..- -NP I SIPML NDGRRIVFT VVASLAFKDKVYLTVNAPDTLCEHLQINDGE L IVVQLTPGYCAPEGSYHSTVNQVPL \\
\hline
\end{tabular}

Fig. 3. Amino acid sequence alignment of OX40L. Cytoplasmic (CY), transmembrane (TM) and extracellular (EC) domains are indicated and species are denoted as ch, chicken; tu, turkey; hu, human; mo, mouse. Conserved residues are shaded in grey, asterisks $\left(^{*}\right)$ indicate residues sharing similar properties. The $\beta$ strands of huOX40L are labelled and their respective residues are marked by arrows above the sequences. Accession numbers: chOX40L XP_430147.2, tuOX40L XP_010714012.1, huOX40L NP_003317.1, moOX40L NP_033478.1. 


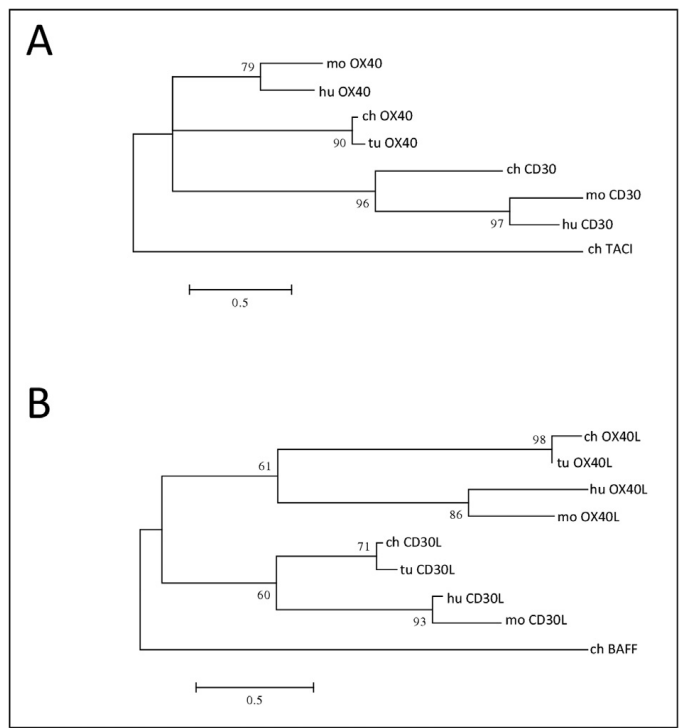

Fig. 4. Phylogenetic comparison of TNFRSF and TNFSF family members. The external nodes are denoted with the receptor (A) or ligand (B) name and the respective external nodes are denoted with the receptor (A) or ligand (B) name and the respective key; hu, human; mo, mouse. The numbers beside the branches indicate the percentage of trees in the bootstrap analysis in which the associated species formed a cluster. The tree is drawn to scale and branch lengths represent the number of substitutions per site. Accession numbers: chOX40 NP_001341653.1, tuOX40 XP_010721084.1, huOX40 XP_016857721.1, moOX40 NP_035789.1, chCD30 XP_015152299.1, huCD30 NP_001234.3, moCD30 NP_033427.1, chTACI XP_015149738.1, chOX40L XP_430147.2, tuOX40L XP_010714012.1, huOX40L NP_003317.1, moOX40L NP_033478.1, chCD30L NP_989740.1, tuCD30L XP_010719103.1, huCD30L NP_001235.1, moCD30L NP_033429.1, chBAFF XP_015129632.1.

combination with an unrelated Fc-tagged chicken protein (CD30Fc), showed no positive staining of transfected cells, thus confirming the specificity of the observed interaction between OX40Fc and its cell-associated ligand. In conclusion, three different assays employing soluble and cell-bound forms of OX40 and its ligand confirmed their interaction.
3.6. Frequency of chOX40-Fc positive splenocytes increases after stimulation with IL-2 and IL-12

In order to test the staining capability of the recombinant chOX40-Fc on primary chicken cells (Fig. 9), chicken splenocytes were stimulated in vitro by a combination of the cytokines IL-2 and IL-12, favouring the selective expansion of $\gamma \delta$ T cells (unpublished observation). Splenocytes were stained directly after preparation to measure the fraction of OX40- $\mathrm{Fc}^{+}$cells in native cells. On day 0 , we observed no significant staining of native chicken splenocytes by OX40-Fc. In the course of stimulation with IL-2 and IL-12, the number of cells positively stained increased and reached its peak after a ten-day stimulation $(10,2 \%)$. We further characterised the population of $\mathrm{OX} 40-\mathrm{Fc}^{+}$cells by additionally applying different lymphocyte markers. The results of double staining with OX40-Fc and mabs specifically recognising chicken TCR1, TCR2, TCR3 and CD8 are shown in Fig. 9B. On day 10 of the stimulation with IL-2 and IL-12, $\gamma \delta$ T cells bearing the TCR1 receptor, dominated the cell population. The TCR $1^{+}$cells exhibited a subpopulation of cells being $\mathrm{OX} 40-\mathrm{Fc}^{+}(9,6 \%)$, whereas a small percentage of cells were OX40- $\mathrm{Fc}^{+}$, but belonged to the subpopulations of $\alpha \beta$ T cells (TCR2 double positive $1,6 \%$, TCR3 double positive $0,9 \%$ ). Also the population of $\mathrm{CD}^{+}$cells was subdivided into a double positive $(6,1 \%)$ and a negative $(47,1 \%)$ subpopulation on the basis of OX40-Fc staining. We hence showed the applicability of recombinant chOX40-Fc for the staining of primary chicken cells and confirmed the presence of OX $40-\mathrm{Fc}^{+}$cells upon stimulation with IL-2 and IL-12.

\section{Discussion}

Besides the CD28-B7 system of costimulatory signals, the TNF superfamily has proven to provide key mediators for $\mathrm{T}$ cell activation in mammals. Even though the functional relationship among these different TNFRSF receptors or their association to CD28 in the complex process of $\mathrm{T}$ cell activation needs to be further investigated, past studies indicate that the effects of TNF family members operate at different times during activation, thus enabling a sustained T cell response (Croft, 2003). Especially OX40 and its ligand OX40L play a major role to ensure the longevity of activated T cells in mammals.

Various members of the TNF superfamily conserved their

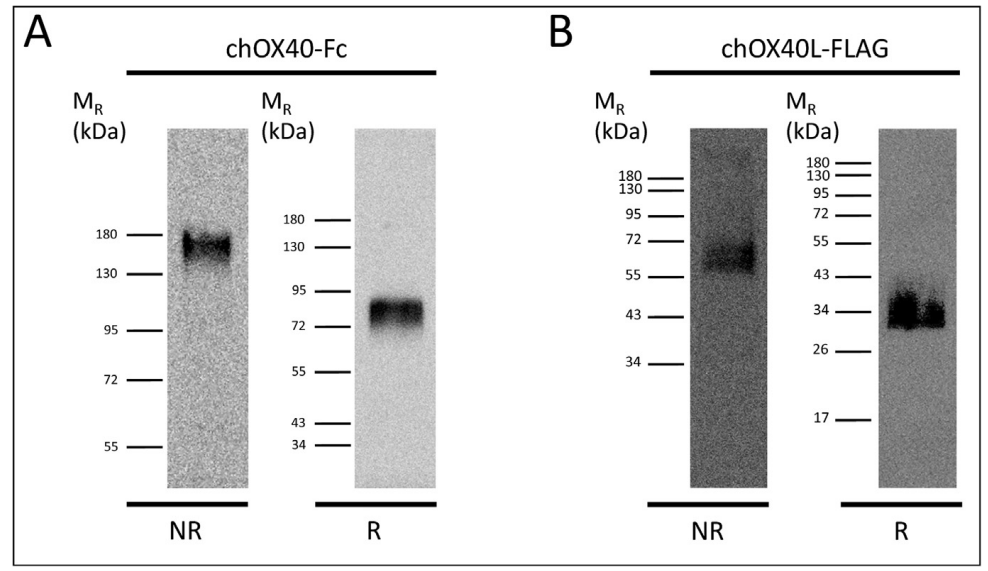

Fig. 5. Western blot of OX40-Fc and OX40L-FLAG. Reduced (R) and non-reduced (NR) samples were separated by SDS-PAGE, blotted and recombinant proteins were detected either by an HRP-coupled goat anti-human-IgG antibody (for OX40-Fc) (A) or by an HRP-coupled mouse anti-FLAG antibody (for OX40L-FLAG) (B). 


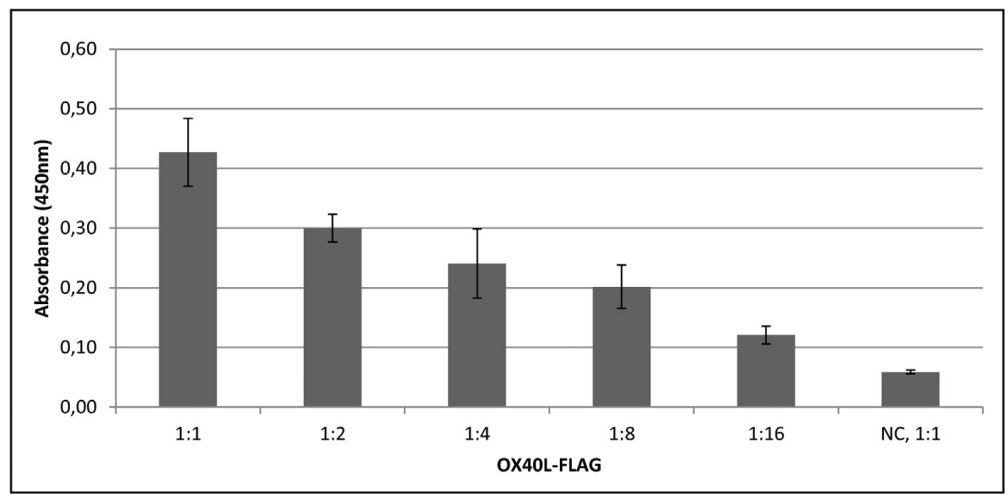

Fig. 6. ELISA titration assay of OX40L-FLAG on immobilised OX40-Fc. OX40L was applied in consecutive twofold dilutions ( $\mathrm{x}$-axis). The resulting absorbance values are indicated on the y-axis. As negative control, OX40L-FLAG was applied at the highest concentration on an irrelevant Fc-tagged receptor (CD30-Fc). The error bars display the standard deviations of triplicates.

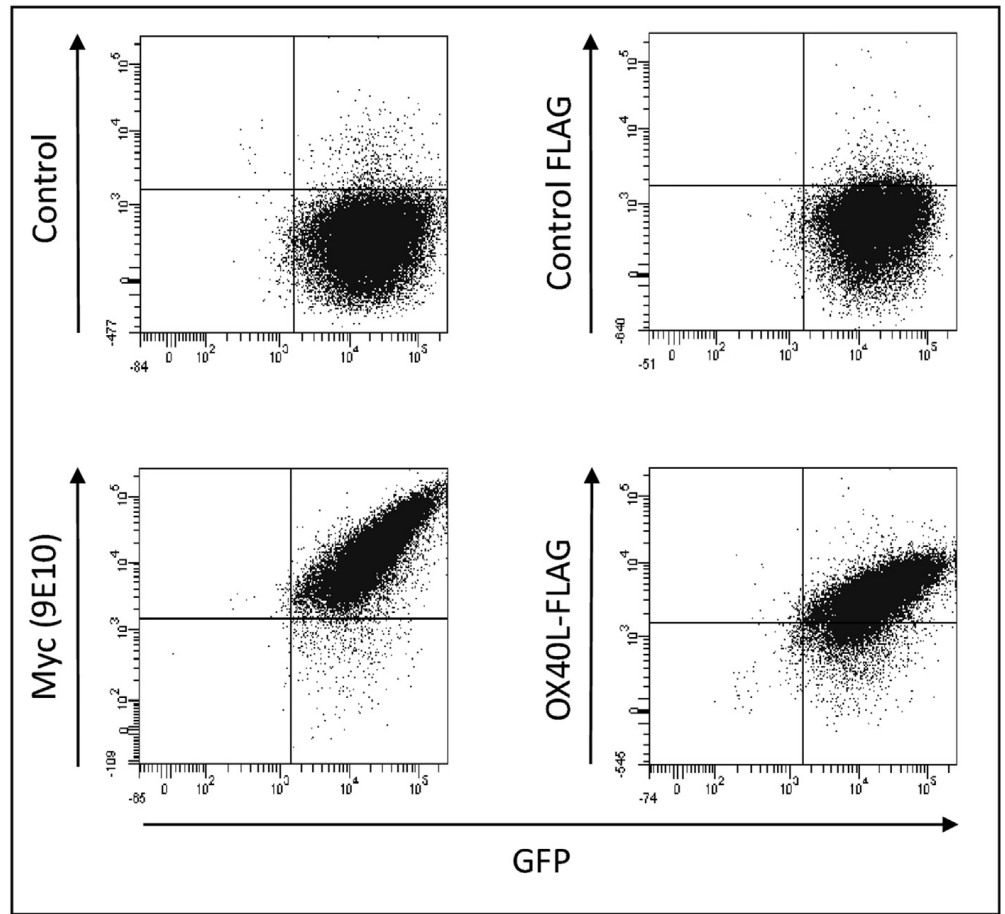

Fig. 7. Flow cytometric analysis of OX40L-FLAG interaction with cell bound OX40-Myc receptor. Top row: staining control of OX40-Myc, GFP ${ }^{+}$transfected cells (only secondary mabs applied) and staining control comprising an unrelated FLAG-tagged chicken protein (CD30L-FLAG) and secondary mabs; bottom row: recognition of the Myc-tag of OX40-Myc, $\mathrm{GFP}^{+}$transfected cells by 9E10 mab; OX40-Myc cells screened for their interaction with soluble OX40L-FLAG in combination with GFP signal.

genomic collocation during the evolutionary process and thus can be found in direct proximity to each other in the genome of different species. According to Ware (2003), this sequential arrangement of several TNF members is probably due to duplication and translocation of particular gene loci in a vertebral ancestor. As their mammalian homologues, the genes of chicken OX40 and OX40L are clustered with other members of the TNF superfamily (e.g. OX40 - GITR, OX40L - FasL) within the genomic sequence. Beyond conserved genomic localisation, chicken OX40 and OX40L proteins exhibit the typical structural features of their respective families. Phylogenetic analyses affirm a stronger relation of the chOX40 and the chOX40L proteins to their respective subfamily in comparison to other chicken molecules such as CD30, TACI or CD30L and BAFF. Even though all representatives of the TNFRSF or the TNFSF share basic, characteristic features across vertebrates, i.e. the existence of CRDs or a THD domain, the structural specialities of OX40 or OX40L persist beyond species boundaries, which is reflected in the cluster formation in the phylogenetic trees. The poor 

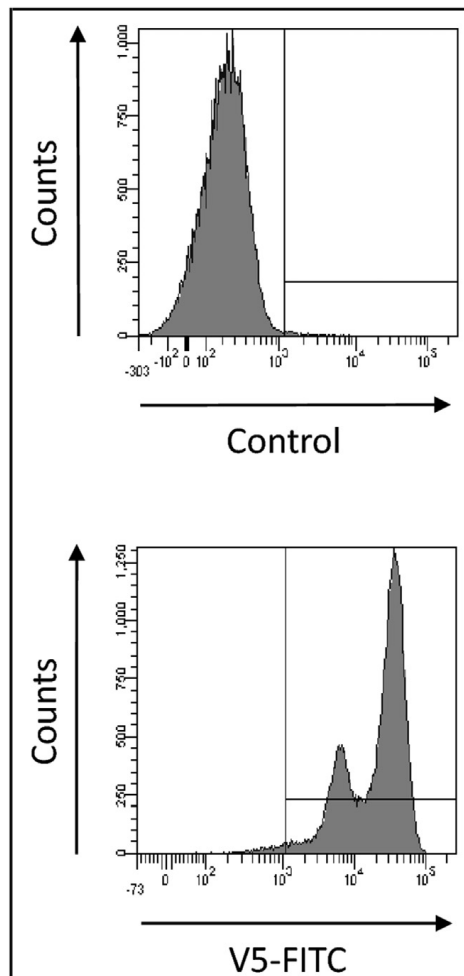

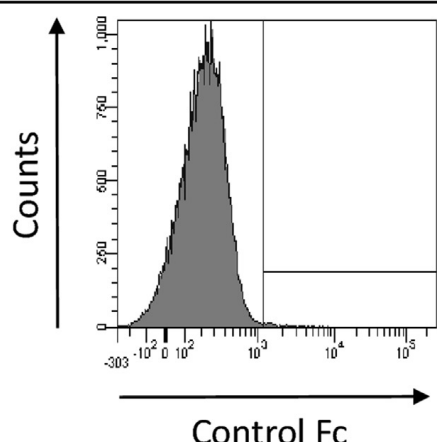

Control Fc

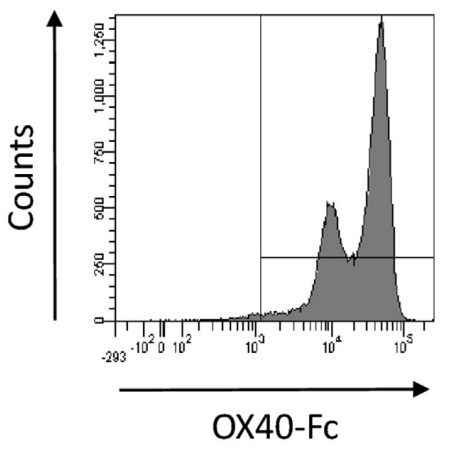

Fig. 8. Flow cytometric analysis of OX40-Fc interaction with cell bound OX40L-V5 ligand. Top row: staining control of OX40L-V5 transfected cells (only secondary mab applied) and staining control comprising an unrelated Fc-tagged chicken protein (CD30-Fc) and the secondary mab; bottom row: recognition of the V5-tag of OX40L-V5 transfected cells by an anti-V5-FITC mab; OX40L-V5 cells stained with soluble OX40-Fc and secondary mab.

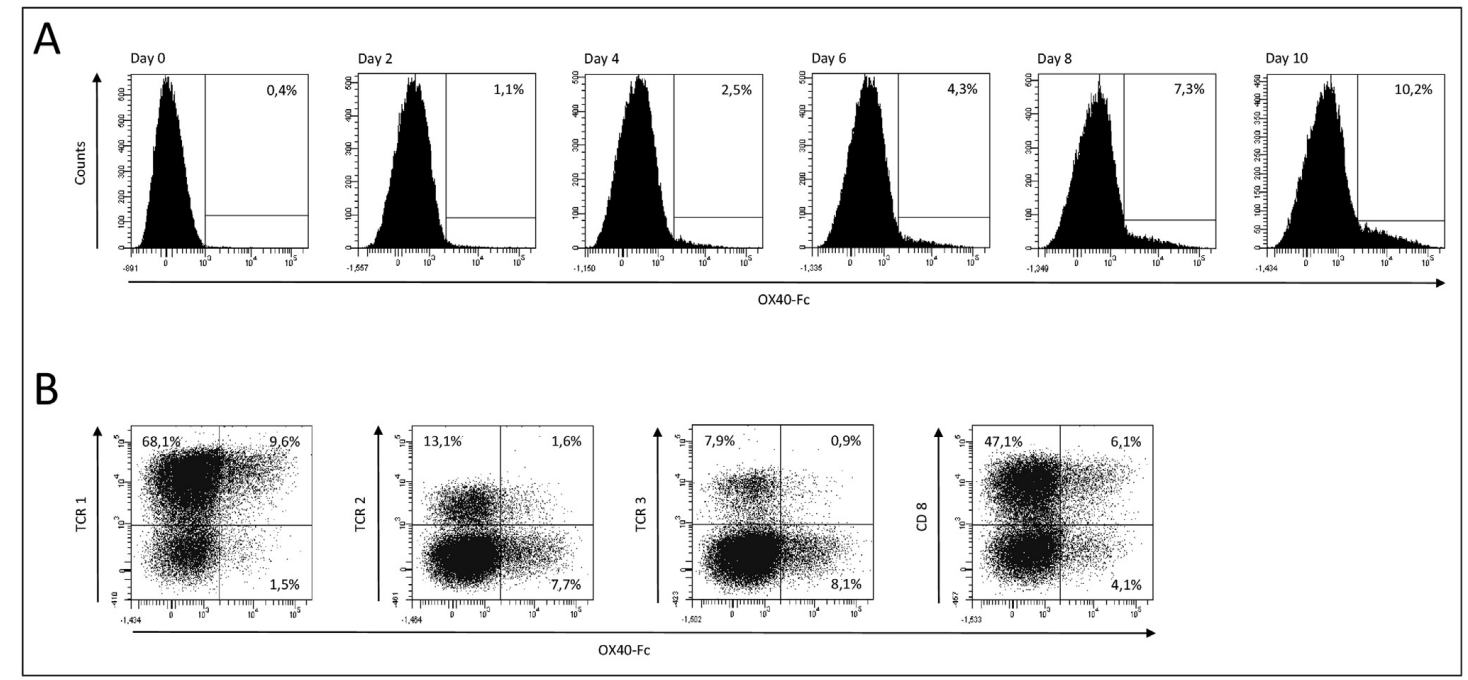

Fig. 9. OX40-Fc staining on stimulated chicken splenocytes. Kinetics of chOX40-Fc staining upon activation on chicken splenocytes (A). Splenocytes, stimulated with IL-2 and IL12 (in long-term culture) were analysed for their interaction with recombinant chOX40-Fc by flow cytometry at different times as indicated. Percentages indicate the fraction of cells, which were positively stained with OX40-Fc. Double staining of splenocytes at day 10 in culture with IL-2 and IL-12 (B). Cells were analysed for their interaction with OX40-Fc in combination with different mabs as indicated. Percentages display the fraction of positive cells in the respective quadrants. All markers were based on isotype-matched controls. 
overall identity (30\%) between human and chicken OX40 amino acid sequences is not surprising, as chicken molecules frequently share poor sequence homology with their mammalian equivalents (Abdalla et al., 2004). Conserved residues among the species are especially concentrated to the $\mathrm{N}$ terminus, which is also evident for the chicken CD30 molecule (Burgess et al., 2004). The ectodomain of the chicken receptor exhibits three complete and one truncated CRD, which is characteristic for the OX40 molecule and causal for its elongated shape (Naismith and Sprang, 1998; Willoughby et al. 2017). Complying with the structural requirements, it is likely that the chicken OX40 interacts with its ligand in a 3:3 ratio as it is reported for mammals (Compaan and Hymowitz, 2006). Binding of chOX40 probably results in anti-apoptotic signals similar to those of mammalian OX40, as it shares the TRAF2 binding motif which is important for the intracellular signal cascade (Ye et al., 1999).

In comparison to the chOX40 molecule, chOX40L protein shares even less sequence identity (19\%) with its human equivalent. Murine and human molecules also display only $40 \%$ sequence homology, which is considerably less compared to the homologies among other TNFSF ligands of these species (Willoughby et al., 2017). However, the existing structural similarities between mammalian and chicken ligand argue for a similar functional behaviour. As in mammals, the hydrophobic properties of the chicken OX40L THD probably allow for trimerisation (Compaan and Hymowitz, 2006). Mammalian OX40 and OX40L are reported to solely bind to each other showing no interaction with other members of the TNF superfamily. In mammals, TNF was demonstrated to bind TNFR-1 and TNFR-2 (Idriss and Naismith, 2000) whereas BAFF was reported to interact with three receptors, namely BAFFR, TACI and BCMA in mammals and with BAFFR and TACI in chickens (Reddy et al., 2008). The exclusive binding of OX40L to OX40 receptor in mammals probably is the result of the atypical assembly of the OX40-OX40L complex in comparison to other TNF members (Compaan and Hymowitz, 2006). To investigate the mutual binding capabilities of chicken OX40 and its ligand OX40L, we pursued three different approaches. In an ELISA titration assay, we demonstrated the specific binding capability of the soluble ectodomains of the receptor and its ligand. To further support these results, we verified their interaction via flow cytometric analyses and showed that cell-bound receptors were recognised by their soluble ligands and vice versa. Since the chicken CD30 and CD30L molecules, applied as negative controls in these assays, revealed no interaction with OX40 and OX40L, respectively, it is possible that also chOX40 and chOX40L exclusively interact with each other.

By western blot analyses, we further characterised the soluble chicken proteins under reducing and non-reducing conditions. Due to four glycosylation sites within the ectodomains of OX40 and OX40L, and one site in the Fc-tag, the observed molecular masses of reduced samples exceeded the calculated values for monomers (47 kDa for OX40-Fc and $17 \mathrm{kDa}$ for OX40L). As expected, the extracellular domain of OX40 formed dimers because of the dimerising Fc domain of human IgG1. Likewise, the OX40L-FLAG molecule revealed bands arguing for the dimerisation of the molecule. This is in line with studies in mammals, revealing that the trimerisation rate of recombinant, tagged THDs of some TNF ligands, e.g. GITRL, is rather low (Wyzgol et al., 2009)

Since only few mabs are available to characterise cell populations in the chicken (Kaiser, 2012), we finally tested the application of recombinant OX40-Fc protein in the staining of primary chicken cells. Screening of native chicken splenocytes, bursal cells, thymocytes, PBL, PBMC, as well as in vitro cultured macrophages and HD11 cells yielded no positive cell population for OX40-FC (data not shown). This finding agrees with reports in human and mouse that OX40L expression is restricted to activated APCs and activated T cells (Watts, 2005)

Besides their involvement in ensuring the longevity of $\alpha \beta$ T cells, OX40-OX40L signalling is probably an important way of activation also in $\gamma \delta$ T cells (Brandes et al., 2003). T cell-T cell interactions via OX40L expressed on activated $\gamma \delta$ T cells may occur in a similar way as observed for $\alpha \beta$ T cells (Mendel and Shevach, 2006). In contrast to humans and mice, which are categorised as $\gamma \delta$ low species, chickens represent one of the species (among sheep, cattle, pigs and rabbits) which displays high levels of $\gamma \delta$ T cells (Su et al.,1999). Therefore, we selected chicken $\gamma \delta$ T cells to assess the involvement of OX40-OX40L system in the process of $\mathrm{T}$ cell activation in the chicken. We demonstrated that in the course of stimulation with IL2 and IL-12, chicken $\gamma \delta \mathrm{T}$ cells, including a $\mathrm{CD}^{+}$subset, upregulate OX40L, probably in order to sustain an activated state via T cell-T cell interactions, as reported for mammalian T cells (Mendel and Shevach, 2006).

In conclusion, our results argue for an important role of the OX40-OX40L system in the process of $\mathrm{T}$ cell activation in the chicken. We demonstrated the tight phylogenetic and structural relationship of chicken molecules to their mammalian homologues, suggesting similar anti-apoptotic functions. Furthermore, we confirmed the interaction of chicken proteins in three different assays and displayed the application of recombinant chOX40-Fc in the staining of primary chicken cells. The cell-bound variants of chicken OX40 and OX40L represent suitable tools to generate mabs to further characterise the expression pattern of the chicken molecules, e.g. on activated $\mathrm{CD} 4^{+}$cells and to generally enlighten the role of chOX40 and its ligand OX40L in the chicken T cell response.

\section{Acknowledgements}

We thank Prof. P. Schneider (University of Lausanne, Epalinges, Switzerland) for kindly providing the variants of pCR3 vector.

\section{Appendix A. Supplementary data}

Supplementary data related to this article can be found at https://doi.org/10.1016/j.dci.2018.01.014.

\section{References}

Abdalla, S., Horiuchi, H., Furusawa, S., Matsuda, H., 2004. Molecular cloning and characterization of chicken tumor necrosis factor (TNF)-superfamily ligands, CD30L and TNF-related apoptosis inducing ligand (TRAIL). J. Vet. Med. Sci. 66, 643-650.

Banner, D.W., D'Arcy, A., Janes, W., Gentz, R., Schoenfeld, H.J., Broger, C., Loetscher, H., Lesslauer, W., 1993. Crystal structure of the soluble human $55 \mathrm{kd}$ TNF rece He, Lessla TNF receptor-human T
tion, Cell $73,431-445$.

Bansal-Pakala, P., Halteman, B.S., Cheng, M., Croft, M., 2004. Costimulation of CD8 T cell responses by OX40. J. Immunol. 172, 4821-4825.

cell responses by OX40. J. Immunol. 172, 4821-4825.
Baumann, R., Yousefi, S., Simon, D., Russmann, S., Mueller, C., Simon, H.U., 2004.

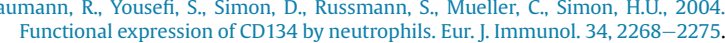
Functional expression of CD134 by neutrophils. Eur. J. Immunol. 34, $2268-2275$.
Bodmer, J.-L., Schneider, P., Tschopp, J., 2002. The molecular architecture of the TNF superfamily. Trends Biochem. Sci. 27, 19-26.

Brandes, M.. Willimann, K., Lang, A.B., Nam, K.H., Jin, C., Brenner, M.B., Morita, C.T. Moser, B., 2003. Flexible migration program regulates gamma delta T-cell nvolven, in hos

Burgess, S.C., Young, J.R., Baaten, B.J.G., Hunt, L., Ross, L.N.J., Parcells, M.S, Kumar, P.M., Tregaskes, C.A., Lee, L.F., Davison, T.F., 2004. Marek's disease is a natural model for lymphomas overexpressing Hodgkin's disease antigen (CD30). P. Natl. Acad. Sci. USA 101, 13879-13884.

Chen, C.H., Sowder, J.T., Lahti, J.M., Cihak, J., Lösch, U., Cooper, M.D., 1989. TCR3: a third T-cell receptor in the chicken. P. Natl. Acad. Sci. USA 86, 2351-2355.

Chiak, J., Löms Ziegler-Heitbrock, H.W., Trainer, H., Schranner, I., Merkenschlager, M., Lösch, U., 1988. Characterization and functional properties of a novel monoclonal antibody which identifies a T cell receptor in chickens. Eur. J. Immunol. 18, 533-537.

Compaan, D.M., Hymowitz, S.G., 2006. The crystal structure of the costimulatory OX40-OX40L complex. Structure 14, 1321-1330.

Croft, M., 2003. Costimulation of T cells by OX40, 4-1BB, and CD27. Cytokine Growth Factor Rev. 14, 265-273. 
Croft, M., 2010. Control of immunity by the TNFR-related molecule OX40 (CD134). Annu. Rev. Immunol. 28, 57-78.

Fenzl, L., Göbel, T.W., Neulen, M.-L.L., 2017. $\gamma \delta$ T cells represent a major spontaneously cytotoxic cell population in the chicken. Dev. Comp. Immunol. 73, ously cyto $175-183$.

Gaur, U., Aggarwal, B.B., 2003. Regulation of proliferation, survival and apoptosis by members of the TNF superfamily. Biochem. Pharmacol 66, 1403-1408.

Idriss, H.T., Naismith, J.H., 2000. TNFa and the TNF receptor superfamily: structurefunction relationship(s). Microsc. Res. Tech. 50, 184-195.

Ito, T., Wang, Y.-H., Duramad, O., Hori, T., Delespesse, G.J., Watanabe, N., Qin, X.-F.F. Yao, Z., Cao, W., Liu, Y.-J., 2005. TSLP-activated dendritic cells induce an inflammatory Thelper type 2 cell response through OX40 ligand. J. Exp. Med. 202, $1213-1223$

Jenkins, S.J., Perona-Wright, G., Worsley, A.G., Ishii, N., MacDonald, A.S., 2007. Dendritic cell expression of OX40 ligand acts as a costimulatory, not polarizing signal for optimal Th2 priming and memory induction in vivo. J. Immunol. 179, 3515-3523.

Kaiser, P., 2012. The long view: a bright past, a brighter future? Forty years of chicken immunology pre- and post-genome. Avian Pathol. 41, 511-518.

Karulf, M., Kelly, A., Weinberg, A.D., Gold, J.A., 2010. OX40 ligand regulate inflammation and mortality in the innate immune response to sepsis. J. Immunol. 185, 4856-4862.

Kowarz, E., Loscher, D., Marschalek, R., 2015. Optimized sleeping beauty transposons rapidly generate stable transgenic cell lines. Biotechnol. J. 10, 647-653.

Krause, P., Bruckner, M., Uermösi, C., Singer, E., Groettrup, M., Legler, D.F., 2009. Prostaglandin E2 enhances T-cell proliferation by inducing the costimulatory molecules OX40L, CD70, and 4-1BBL on dendritic cells. Blood 113, 2451-2460.

Kurche, J.S., Haluszczak, C., McWilliams, J.A., Sanchez, P.J., Kedl, R.M., 2012 Type IFN-dependent T cell activation is mediated by IFN-dependent dendritic cell OX40 ligand expression and is independent of T Cell IFNR expression. J. Immunol. 188, 585-593.

Latza, U., Dürkop, H., Schnittger, S., Ringeling, J., Eitelbach, F., Hummel, M. Fonatsch, C Stein, He 1994. The human OX40 homolog: cDNA structure, Fonatsch, C., Stein, $\mathrm{H}_{\mathrm{g}}$ 1994, She human OX40 homolog. "DNA structure, $24,677-683$.

Linton, P.J. Bautista, B., Biederman, E. Bradley, E. S., Harbertson, J., Kondrack, R.M Padrick, R.C., Bradley, L.M., 2003. Costimulation via OX40L expressed by B cells Padrick, R.C., Bradley, L.M., 2003. Costimulation via OX40L expressed by B cells is sufficient to determine the extent of primary CD4
cytokine secretion in vivo. J. Exp. Med. 197, 875-883.

Liu, C., Lou, Y., Lizée, G., Qin, H., Liu, S., Rabinovich, B., Kim, G.J., Wang, Y.-H., Ye, Y Sikora, A.G., Overwijk, W.W., Liu, Y.-J., Wang, G., Hwu, P., 2008. Plasmacytoid Sikora, A.G., Overwijk, W.W., Liu, Y.-J., Wang, G., Hwu, P., 2008. Plasmacytoid priming and tumor regression in mice. J. Clin. Invest. 118, 1165-1175.

priming and tumor regression in mice. J. Clin. Invest. 118, 1165-1175.
Luhtala, M., Lassila, O., Toivanen, P., Vainio, O., 1997. A novel peripheral CD4+CD8

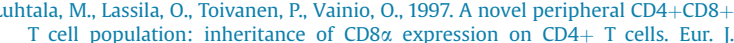
T cell population: inh

Mallett, S., Fossum, S., Barclay, A.N., 1990. Characterization of the MRC OX40 antigen of activated CD4 positive T lymphocytes - a molecule related to nerve growt factor receptor. EMBOJ 9, 1063-1068.

Maxwell, J.R., Yadav, R., Rossi, R.J., Ruby, C.E., Weinberg, A.D., Aguila, H.L., Vella, A.T.
2006. IL-18 bridges innate and adaptive immunity through IFN-gamma and the CD134 pathway. J. Immunol. 177, 234-245.

Mendel, I., Shevach, E.M. 2006. Activated T cells express the OX40 ligand: requirements for induction and costimulatory function. Immunology 117, 196-204.

Naismith, J.H., Sprang, S.R., 1998. Modularity in the TNF-receptor family. TrendsBiochem.Sci. 23, 74-79.

Reddy, S.K., Hu, T., Gudivada, R., Staines, K.A., Wright, K.E., Vickerstaff, L. Kothlow, S., Hunt, L.G., Butter, C., Kaspers, B., Young, J.R., 2008. The BAFFInteracting receptors of chickens. Dev. Comp. Immunol. 32, 1076-1087.

Redmond, W.L., Ruby, C.E., Weinberg, A.D., 2009. The role of OX40-mediated costimulation in T-cell activation and survival. Crit. Rev. Immunol. 29, 187-201. Rogers, P.R., Croft, M., 2000. CD28, Ox-40, LFA-1, and CD4 modulation of Th1/Th2 differentiation is directly dependent on the dose of antigen. J. Immunol. 164 $2955-2963$.

Rogers, P.R., Song, J., Gramaglia, I., Killeen, N., Croft, M., 2001. OX40 promotes Bcl-xL and Bcl-2 expression and is essential for long-term survival of CD4 T cells. Immunity $15,445-455$.

Sato, T., Ishii, N., Murata, K., Kikuchi, K., Nakagawa, S., Ndhlovu, L.C., Sugamura, K. 2002. Consequences of OX40-OX40 ligand interactions in Langerhans cell function: enhanced contact hypersensitivity responses in OX40L-ransgenic mice. Eur. J. Immunol. 32, 3326-3335.

Sowder, J.T., Chen, C.L., Ager, L.L., Chan, M.M., Cooper, M.D., 1988. A large subpopulation of avian $\mathrm{T}$ cells express a homologue of the mammalian $\mathrm{T}$ gamma/delta receptor. J. Exp. Med. 167, 315-322.

Su, C., Jakobsen, I., Gu, X., Nei, M., 1999. Diversity and evolution of T-cell receptor variable region genes in mammals and birds. Immunogenetics 50, 301-308.

Tamura, K., Peterson, D., Peterson, N., Stecher, G. Nei, M., Kumar, S., 2011. MEGA5: molecular evolutionary genetics analysis using maximum likelihood, evolutionary distance, and maximum parsimony methods. Mol. Biol. Evol. 28 2731-2739.

Ward-Kavanagh, L.K. Lin, W., Šedý, J.R., Ware, C.F., 2016. The TNF receptor superfamily in Co-stimulating and Co-inhibitory responses. Immunity 44 1005-1019.

Ware, C.F., 2003. The TNF superfamily. Cytokine Growth Factor Rev. 14, 181-184. Watts, T.H., 2005. TNF/TNFR family members in costimulation of T cell responses. Annu. Rev. Immunol. 23, 23-68.

Willoughby, J., Griffiths, J., Tews, I., Cragg, M.S., 2017. OX40: structure and functionwhat questions remain? Mol. Immunol. 83, 13-22.

Wyzgol, A., Müller, N., Fick, A., Munkel, S., Grigoleit, G., Pfizenmaier, K., Wajant, H. 2009. Trimer stabilization, oligomerization, and antibody-mediated cell surface immobilization improve the activity of soluble trimers of CD27L, CD40L, 41BBL, and glucocorticoid-induced TNF receptor ligand. J. Immunol. 183, 1851-1861. e, H., Park, Y., Kreishman, M., Kieff, E., Wu, H., 1999. The structural basis for the recognition of diverse receptor sequences by TRAF2. Mol. Cell 4, 321-330.

Zaini, J., Andarini, S., Tahara, M., Saijo, Y., Ishii, N., Kawakami, K., Taniguchi, M., Sugamura, K., Nukiwa, T., Kikuchi, T., 2007. OX40 ligand expressed by DCs costimulates NKT and CD4+ Th cell antitumor immunity in mice. J. Clin. Invest 117, 3330-3338. 



\section{Discussion}

\subsection{Costimulatory signals in $\mathrm{T}$ cell activation in chickens}

Secondary signals via different types of costimulatory molecules, accompanying TCR triggering, are essential for the generation of a fully effective $T$ cell response in mammals as well as in chickens. Regarding mammals, many studies so far have investigated the process of $\mathrm{T}$ cell costimulation. They focussed on central aspects, such as the identity of the involved molecules, their mutual interactions, downstream signalling events and their functional implication in $\mathrm{T}$ cell activation.

Even though the avian and mammalian lineages split approximately 310 million years ago in the evolutionary process, chickens and mammals share many mechanisms and properties of an effective $\mathrm{T}$ cell response $[5,10]$. Chickens generally display the major biomolecules involved in the generation of a potent, but equally balanced $\mathrm{T}$ cell response, which are described for mammals. The main three superfamilies of costimulatory molecules for $\mathrm{T}$ cells, namely the immunoglobulin superfamily, the family of cytokine receptors and the tumour necrosis factor receptor superfamily, exist in both chickens and mammals and seem to fulfil similar functions.

The most prominent members of the immunoglobulin family, CD28 molecule and its ligands CD80 and CD86, were identified in the genomes of chicken, turkey and zebra finch [10] and CD28 was characterised for the chicken. Its expression on $\alpha \beta$ and $\gamma \delta \mathrm{T}$ cells, as well as its ability to stimulate $\mathrm{T}$ cell proliferation and IFN $\gamma$ production seems to be conserved among chickens and mammals [34, 174]. With ICOS and CD2 [10, 23], two other important costimulatory molecules of the IGSF have been identified in chickens.

Similarly, different chicken cytokines (e.g. IL-2, IL-12 and IL-15) have been described and were reported to function as major $\mathrm{T}$ cell growth factors $[175,176]$. The ability of chicken IL-2 and IL-12 to favour cell proliferation was demonstrated in our culturing system of $\gamma \delta \mathrm{T}$ cells.

Since the decoding of the chicken genome [177], different members of the TNF superfamily were genomically identified for the chicken, where their number seems to be restricted in comparison to the known repertoire in mammals [178]. Both mammals and chickens display TNF genes in certain sub-groups of collocated genes [178]. Some of these sub-groups could not be identified via shared synteny yet, as 
the regions in the chicken genome are strongly rearranged compared to the mammalian genome [178]. It is still not clear whether some of the missing subfamilies can be tracked in the future or whether further genomic and functional analyses will confirm their absence in the chicken. Compared to the 19 ligands and 29 receptors noted for the human genome, up to now, 15 receptors and 10 ligands have been identified for the chicken genome [179]. Only few of them have been further characterised yet, like the ligand BAFF [180] and its receptors Transmembrane Activator and Calcium Modulating Ligand Interactor (TACI) and BAFFR [181], CD40L [182] and CD40 [183], Receptor Activator of Nuclear factor $\chi B$ Ligand (RANKL) and its receptors Receptor Activator of Nuclear factor $\chi \mathrm{B}$ (RANK) and OPG $[179,184]$ or CD30L [185] and its receptor CD30 [186].

However, CD30 and its ligand CD30L, have remained the only representatives of the chicken TNF superfamily whose involvement in $\mathrm{T}$ cell costimulation has been described so far. Even though their respective expression patterns generally appear similar to those in mammals $[185,186]$, their functional implication is still unknown. As both molecules were characterised independently, no information is available concerning their ability of mutual binding and consequential effects of their interaction. For this work, CD30 and CD30L were cloned from chicken complementary DNA (cDNA) of Concanavalin A (ConA) stimulated T cells and constructs were generated based on the recombinant soluble variants of OX40 and OX40L to serve as controls within the demonstrated experiments.

As OX40 and OX40L adopt a major role in the process of $\mathrm{T}$ cell activation in mammals, this study focussed on their identification and characterisation in chickens. This work compares chicken OX40 and OX40L with their mammalian counterparts and illustrates their tight structural and phylogenetic relation. It further demonstrates their mutual interaction as soluble and cell-bound molecules and proves the expression of OX40L on chicken $\alpha \beta$ and $\gamma \delta$ T cells.

\subsection{Genomic identification of chicken OX40 and OX40L}

Both chicken molecules were identified by keyword search in the genome assembly Gallus_gallus-5.0 and correctly assigned to their mammalian homologues by virtue of shared synteny with collocated genes and homology search using murine and human sequences. In this process, the chicken homologues for the costimulatory molecule GITR (chromosome 21) and its ligand GITRL (chromosome 8) were also identified 
and equally allocated to their mammalian counterparts. The genes for Stromal Cell Derived Factor 4 (SDF4) and GITR, also annotated as TNFRSF18, flanked the gene of OX40 within the human (chromosome 1), murine (chromosome 4) and chicken (chromosome 21) genome. Analogously, the gene of OX40L was linked to the gene of Peroxiredoxin 6 (PRDX6) and clustered to the genes of GITRL (TNFSF18) and FasL in all three species (chicken chromosome 8, human and murine chromosome 1). The genes of TNF ligands and TNF receptors probably originated from gene duplication and translocation of specific gene loci in a former vertebral ancestor and retained their respective collocation during the evolution of vertebrates [76]. This phenomenon was also confirmed for OX40 and OX40L molecules and can help to identify further TNF family members in the chicken.

\subsection{Phylogenetic and structural analyses of OX40 and OX40L}

Besides conserved genomic localisation, we demonstrated the conservation of the overall structure and molecular topology between avian and mammalian OX40 and OX40L molecules via amino acid sequence alignments. Both chicken proteins exhibit characteristic features of the TNF receptor and the TNF ligand families and share the structural specialities of their mammalian equivalents.

Chicken and turkey OX40, as type I transmembrane proteins, exhibit the characteristic CRD in the N-terminal, extracellular domain. Like their mammalian counterparts, chicken and turkey OX40 possess three complete (CRD1, CRD2, CRD4) and one truncated CRD (CRD3), which argue for an elongated shape as it is reported for mammals $[78,90]$. According to the system established by Naismith and Sprang [73], these CRD are further divided into submodules, based on the number of cysteine residues and the topology of disulphide bonds. The arrangement of submodules of the chicken OX40 molecule is also similar to the human protein [78], as illustrated in Fig. 4. While CRD1 and 2 display A1-B2 modules, CRD3 is truncated with only an A1 module and CRD4 shows A1-B1 modules. Conserved residues among the depicted species concentrate in this N-terminal, extracellular region, which was also reported for chicken CD30 [186], BAFFR and TACI [181]. As shown for OX40 in this study, also chicken BAFFR and TACI exhibit the same number of CRD like their mammalian homologues [181]. In contrast, the transmembrane and the intracellular region of chicken OX40 display only minor levels of homology. However, poor sequence similarities are not unusual for chicken proteins 
$[6,185]$, which reflects in the overall low identity of $30 \%$ of chicken OX40 with its human counterpart. Frequently, the high sequence identity seems to be dispensable, as long as functionally relevant motifs are preserved among species. The conservation of characteristic features was already shown for other chicken equivalents of the TNFRSF. The cytoplasmic domain of the CD30 protein e.g. harbours a sequence of 22 amino acids highly conserved among chickens, mice and humans [186]. Even though its functional impact remains unclear, its importance is emphasised by the otherwise prevailing low sequence similarity within the $\mathrm{C}$ terminus. Other motifs, which are conserved beyond species boundaries within the generally variable intracellular domains of chicken CD30 [186], BAFFR, TACI [181] and OX40 receptors, are the binding motifs for TRAF adaptor proteins. Preservation of these motifs in chicken molecules argues for conserved signalling pathways and consequently for similar functions. The TRAF2-binding motif, present in the chicken OX40 intracellular domain, potentially allows for anti-apoptotic signals, mediated through TRAF2 and other associated TRAF proteins, which is described for mammalian OX40 $[104,108]$. It is likely that chicken OX40 also sustains T cell activation by providing survival signals and enhances cell proliferation, differentiation and cytokine production. Some signalling components of the TNFRSF, like TRAF3 [187] and TRAF5 [188] have already been characterised for the chicken, as well as for other birds like pigeons (TRAF3) [189] and ducks (TRAF6) [190]. In addition to structural similarities of mammalian and avian receptor molecules, the conservation of downstream signalling molecules, exhibiting strong homology levels, renders similar effector functions of avian TNFRSF most likely. The chicken molecules OX40, BAFFR and TACI therefore exemplify the preservation of molecular topology and probably of functionality since the divergence of mammals and birds about 310 million years ago. Phylogenetic analyses also confirm the tight relation of chicken OX40 and OX40L to their respective receptor or ligand subfamilies within the superfamily of TNF receptors and TNF ligands. Even though all depicted receptors and their respective ligands share the common features of their superfamilies (CRD or THD), the topological specialities of OX40 and OX40L molecules persist beyond species boundaries. This also reflects in the cluster formation in the phylogenetic diagrams: OX40L and CD30L molecules e.g. are part of the divergent group of TNF ligands and thus exhibit only poor homology levels among each other and with BAFF from the EF-disulphide group.

Compared to its receptor, the chicken OX40L exhibits an even poorer sequence 
identity to its human equivalent, namely 19\%. A comparatively poor homology level of $40 \%$ was described for human and mouse molecules, two species, which normally share considerably higher sequence identities [78]. These very low identity values among species seem to be molecule-specific and cannot be extrapolated to other TNFSF members, as e.g. other chicken ligands share normal (CD30L, 36\%) or even high (TNF-Related Apoptosis-Inducing Ligand, TRAIL, 56\%; BAFF, 76\%) sequence identity with their respective human counterparts $[180,185]$. Despite its low homology levels, chicken OX40L displays the characteristic structural features of the mammalian protein, suggesting similar functional properties. The chicken protein is a type II transmembrane protein with an N-terminal intracellular domain and a C-terminal extracellular THD, similar to other chicken TNF ligands (CD30L, TRAIL, BAFF and RANKL) [180, 184, 185]. With regard to the intracellular domain of OX40L, the original chicken sequence obtained from cDNA was N-terminally elongated by 31 amino acids (MMVCASASTKQARPAGDCGPPVLLVPALLVE) compared to the version depicted in the publication [191]. Alignments with and without this additional sequence however revealed that the first methionine residue of the elongated chicken sequence probably does not represent the actual transcriptional start site. The DNA sequence further 3' exhibits an additional start codon, which exactly matches the position in mammals and generates the shorter, only 41 amino acid long version of the chicken cytoplasmic domain. Both chicken and turkey OX40L molecules share the overall compactness and the short linker between the extra- and the transmembrane region with their mammalian counterparts [90]. In contrast, mammalian and chicken CD30L for instance, display an elongated connection between the transmembrane domain and THD, evident in the amino acid sequence alignment of Abdalla et al. [185] and in accordance with the prediction by the Simple Modular Architecture Research Tool (SMART) [192].

Even though generally only few residues are conserved between chicken and mammalian molecules, the extracellular region of chicken OX40L forming the THD shares important properties with the other species. It comprises hydrophobic residues, which are assumed to be necessary for trimerisation of the protomers in human and mouse. It additionally displays residues sharing very similar biochemical properties with the sites involved in $\beta$-strand formation in human OX40L [90], further supporting its general capability to trimerise. 


\subsection{Dimerisation of recombinant soluble OX40 and OX40L variants}

Western blot analyses of the extracellular FLAG-tagged chicken OX40L domain however revealed bands arguing for the dimerisation of the molecule, as it was estimated and observed for the Fragment crystallisable (Fc)-tagged extracellular domain of its receptor. Wyzgol et al. [193] also described the propensity of some recombinant, tagged TNF ligands, e.g. GITRL, to dimerise, instead of forming the predicted trimers. Likewise, Corti et al. [194] reported the dissociation of ligandtrimers at low concentrations. This behaviour possibly represents a way to modulate their functional impact by altering the quaternary structure in vivo. To favour trimerisation by recombinant proteins in vitro and to stabilise their oligomeric state for therapeutic applications, different trimerisation domains can be linked to the THD: a Tenascin C (TNC) domain [195], a leucine zipper motif [196], as well as an isoleucine zipper motif [197]. For instance, the linkage of a TNC domain to the chicken OX40L THD domain would probably ensure its trimerisation, as it is reported for other mammalian TNF ligands [193]. The generation of recombinant OX40L trimers may be advantageous for the staining of chicken cells or for investigating its activation potential upon OX40 binding.

\subsection{Interaction of chicken OX40 and OX40L}

Meeting the topological requirements, chicken OX40 and OX40L are likely to interact in a 3:3 stoichiometry in vivo, as it is reported for their mammalian homologues [90] and TNF superfamily members in general. For humans and mice, Compaan et al. [90] demonstrated that binding of OX40L to its receptor differs from the interaction between other ligand-receptor pairs. Murine and human OX40 and OX40L molecules display a special way of assembling into a complex of 3:3 proteins, compared to other molecules like CD40 and CD40L. Upon interaction, the angle between OX40L protomers and the trimer axis differs from other TNF members by $15^{\circ}$ and the size of the trimer interface of the OX40L complex is smaller [78, 90]. Probably due to this atypical way of interaction between mammalian OX40 and OX40L, both molecules are reported to exclusively bind each other [115]. In contrast, other members of the TNF superfamily interact with several distinct partners in mammals as well as in chickens. The range of interaction may be conserved beyond species boundaries or may differ between mammals and chickens. The interaction 
between RANKL and its receptors RANK and OPG constitutes an example for the former case, as their mutual binding and their functional effects are conserved between chickens and mammals [179]. Chicken BAFF on the contrary, seems to lack one of its binding partners in comparison to mammalian BAFF. In human and mouse, BAFF interacts with three receptors, namely BCMA, TACI and BAFFR. In chickens, only TACI and BAFFR were identified and characterised, whereas the chicken BCMA gene is disrupted by a termination codon, therefore representing only a remnant of the mammalian gene [181].

In this work, we used three different approaches to verify the mutual binding capabilities of chicken OX40 and OX40L. The generation of differently tagged receptor and ligand variants, either soluble or cell-bound forms, helped to independently confirm their specific interaction via ELISA (Enzyme-Linked Immunosorbent Assay) and via flow cytometric analyses. Suitable variants of chicken CD30 and CD30L molecules showed no interaction with the OX40 or the OX40L molecules. Only recently, we acquired data (unpublished), which suggest that chicken OX40 may have an additional binding partner. To further characterise the activation process of chicken $\mathrm{T}$ cells, we generated soluble and cell-bound variants of two other chicken TNF family members, GITR and GITRL, based on the recombinant proteins of OX40 and OX40L. In flow cytometric experiments, the soluble variant of chicken FLAG-tagged GITRL was able to bind the stably expressed, c-Myc-tagged chicken OX40 receptor. It even displayed a higher binding capability to OX40 than the FLAG-tagged OX40L. The latter was also able to recognise the c-Myc-tagged GITR receptor, but to a much lesser extent. As GITRL is also reported to solely interact with its designated receptor GITR in mammals [68], the interaction between chicken GITRL-OX40 and OX40L-GITR would imply an unknown link between these two costimulatory systems. Since GITR and GITRL likewise function as costimulators for T cells and for APC in mammals [198, 199], their functional connection to the OX40-OX40L system in chickens appears plausible. GITR is detected on naïve $\mathrm{T}$ cells at low levels [198] and is also constitutively expressed on Treg [200]. As reported for OX40, the GITR expression on $\mathrm{CD} 4^{+}$and $\mathrm{CD} 8^{+} \mathrm{T}$ cells is vigorously induced upon T cell activation for several days [201]. Both OX40 and GITR interact with the intracellular adaptor protein TRAF2 in T cells and promote CD4 ${ }^{+}$ and $\mathrm{CD}^{+} \mathrm{T}$ cell proliferation and cytokine production [198, 201]. GITR however, is also reported to induce apoptosis, depending on the level of $\mathrm{T}$ cell stimulation [202]. GITRL was demonstrated to be expressed by B cells, macrophages and den- 
dritic cells, which upregulated the ligand upon lipopolysaccharide stimulation only for a brief period [202]. Moreover, GITRL expression was reported for endothelial cells and for activated $\mathrm{CD} 4^{+}$and $\mathrm{CD} 8^{+} \mathrm{T}$ cells, but not for naïve $\mathrm{T}$ cell subsets [201-203]. Perhaps, the overlapping interaction between the two systems OX40OX40L and GITR-GITRL in chickens serves as a way to modulate costimulatory signals in a dose-dependent, temporal or spatial manner, as GITRL expression in mammals seems to be more restricted than OX40L expression. Despite these interesting findings, additional experiments, based on different approaches such as ELISA or further flow cytometric analyses, have to verify this special link between the OX40-OX40L and GITR-GITRL systems in chickens.

\subsection{Staining of chicken cells with recombinant OX40-Fc}

After having confirmed the mutual binding capability of the recombinant chicken OX40 and OX40L proteins, we assessed an application of the recombinant molecules. Since only few monoclonal antibodies are available to characterise different cell populations and cell subpopulations in chickens [204], we tested the application of soluble, Fc-tagged OX40 in the staining of primary chicken cells. As expected from studies in mammals, which report the expression of OX40L being restricted to activated APC and activated T cells [62], also here, the screening of native chicken bursal lymphocytes, thymocytes, Peripheral Blood Lymphocytes (PBL), Peripheral Blood Mononuclear Cells (PBMC), splenocytes, HD11 cells and in vitro cultured macrophages yielded no OX40-Fc positive $\left(\mathrm{OX} 40-\mathrm{Fc}^{+}\right)$cells. In mammals, the OX40-OX40L system is not only assumed to provide important costimulatory signals to $\alpha \beta \mathrm{T}$ cells, but also to $\gamma \delta \mathrm{T}$ cells [28]. The OX40L molecule may also be upregulated on activated $\gamma \delta \mathrm{T}$ cells to provide costimulatory signals via $\mathrm{T}$ cell-T cell contact, as it is described for $\alpha \beta \mathrm{T}$ cells [152]. As chickens naturally display high numbers of $\gamma \delta \mathrm{T}$ cells [13] in contrast to humans and mice, we selected chicken ro T cells to investigate the involvement of OX40 and OX40L in the process of chicken $\mathrm{T}$ cell activation. In the course of stimulation with the chicken cytokines IL-2 and IL-12, which selectively favours the expansion of $\gamma \delta \mathrm{T}$ cells in cultures of native chicken splenocytes, we demonstrated that $\gamma \delta \mathrm{T}$ cells upregulate OX40L. While native splenocytes exhibited no $\mathrm{OX} 40-\mathrm{Fc}^{+}$cells on day zero of stimulation, the number of activated T cells expressing OX40L increased up to 10,2\% on day ten of culture. We further characterised the population of OX40L-expressing cells by us- 
ing additional lymphocyte markers, namely TCR1 (for $\gamma \delta$ T cells) [205], TCR2 (for T cells exhibiting the variable (V) chains $\alpha$ and $\beta 1, \mathrm{~V} \alpha \mathrm{V} \beta 1$ ) [206], TCR3 (for V $\alpha \mathrm{V} \beta 2$ T cells) [207] and CD8 (for cytotoxic T lymphocytes) [208]. Due to the culturing conditions with IL-2 and IL-12, the population of T cells, further investigated by double staining, mainly consisted of $\gamma \delta \mathrm{T}$ cells $\left(\mathrm{TCR} 1^{+}\right)$and harboured only a low percentage of $\alpha \beta \mathrm{T}$ cells $\left(\mathrm{TCR} 2^{+}\right.$or $\mathrm{TCR} 3^{+}$). Nevertheless, some of the remnant $\alpha \beta$ T cells expressed OX40L upon stimulation, as it is reported for mammals [152]. Surely, additional experiments, selectively stimulating the expansion of chicken $\alpha \beta$ $\mathrm{T}$ cells, e.g. by the application of anti-TCR 2 antibodies, are necessary to verify these initial indications and to investigate the role of $\mathrm{T}$ cell- $\mathrm{T}$ cell interactions via the OX40-OX40L system in chicken $\alpha \beta \mathrm{T}$ cells, including $\mathrm{CD}^{+}$as well as $\mathrm{CD} 8^{+}$ subsets. As both subpopulations seem to be affected by costimulatory signals via OX40 and OX40L molecules in mammals [125, 127], the prevailing ratio of these cells in chickens would be of great interest. However, as the culture with IL-2 and IL-12 practically yielded no CD4 ${ }^{+}$cells, we confined our analysis of OX40L expression to the $\mathrm{CD}^{+}$cell subset and demonstrated that a fraction of $\mathrm{CD} 8^{+}$cells was also OX40-Fc ${ }^{+}$. Besides the small subpopulation of $\alpha \beta \mathrm{T}$ cells and the fraction of $\mathrm{CD} 8^{+}$cells, also a portion of $\gamma \delta \mathrm{T}$ cells were $\mathrm{OX} 40-\mathrm{Fc}^{+}$, suggesting that also chicken ro T cells upregulate OX40L in the process of activation to support the longevity of the activation state by $\mathrm{T}$ cell-T cell interactions. For human $\gamma \delta \mathrm{T}$ cells, it was already shown that they upregulate OX40 upon activation with phosphor-antigen, as well as other costimulatory TNF family members, like 4-1BBL and CD27L [28, 209]. As $\mathrm{CD} 8^{+} \mathrm{TCR}^{+}$cells constitute the cell population in the chicken spleen with major cytolytic activity [210], costimulatory signals via OX40-OX40L interactions could represent one important way to increase or sustain their effector functions.

Besides OX40L expression, the expression pattern of the OX40 molecule in chickens is another interesting topic, as the period of cell surface expression upon stimulation in mammals is rather narrow $[63,115,125]$. Differences in the extent of OX40 and OX40L upregulation on activated $\mathrm{T}$ cells could be estimated under the influence of different stimulants such as ConA or activating antibodies like the anti-CD3 antibody. In this context, OX40- and OX40L-bearing cells could be further characterised by different markers via flow cytometry, as it was demonstrated in this work for OX40L in the $\gamma \delta \mathrm{T}$ cell culture with IL-2 and IL-12. 


\subsection{Outlook}

In addition to the use of recombinant proteins, the generation of antibodies specifically recognising chicken OX40 receptor or its ligand OX40L, would be advantageous to characterise the impacts of the OX40-OX40L system in the chicken in more detail. As already mentioned above for non-altered, recombinant ligands, a certain portion of the recombinantly expressed protein may dissociate and thereby lose its ability to bind its counterpart on primary chicken cells. Surely, this possibly reduced interaction represents a limit of staining with recombinant protein. Especially if the expression of the targeted molecule is rather low, the staining with recombinant protein may then fail to detect it. In contrast, molecule-specific antibodies can detect the target molecule more precisely. Moreover, monoclonal antibodies can facilitate the screening of different chicken cell populations and allow for their characterisation by multicolour staining. Antibodies with activating or inhibiting properties specifically binding OX40 and OX40L can furthermore shed light on their effects concerning cell proliferation, differentiation and cytokine production in both the receptor- and the ligand-expressing cells. After stimulation via OX40-binding antibodies, flow cytometric analyses could potentially help to phenotypically characterise the evolving effector $\mathrm{T}$ cell subsets and to estimate their cytotoxic potential via cytotoxicity assays. In addition, quantitative Polymerase Chain Reaction (qPCR) analysis or cytoplasmic cytokine staining via flow cytometry could inform about the production of different cytokines following OX40 stimulation. The cell lines generated within this study, stably expressing OX40 and OX40L, respectively, can be used as tools to generate such monoclonal antibodies or to screen existing antibodies with unknown specificity for OX40 and OX40L recognition.

Similarly, screening of uncharacterised monoclonal antibodies derived from a fusion with chicken $\gamma \delta \mathrm{T}$ cells, already yielded the antibody 9C5, which specifically recognises GITR-Myc-expressing cells (unpublished data). The latter were generated in the course of establishing the OX40-Myc-expressing cells during this study, as mentioned above. The specificity of 9C5 to the GITR molecule was verified by isotype-matched controls. First experiments with this antibody revealed an expression of GITR on activated $\gamma \delta$ T cells, which were cultured with IL-2 and IL-12 and co-expressed OX40L. Activated $\gamma \delta \mathrm{T}$ cells apparently express the GITR molecule to a great extent, whereas native chicken splenocytes exhibited only a minute expression. Further experiments will be necessary to describe its expression pattern, to 
estimate its functional role in $\mathrm{T}$ cell costimulation and its link to the OX40-OX40L system in chickens. In summary, our results prove the existence of the OX40-OX40L system in chickens and provide the recombinant variants of OX40 and OX40L as useful tools to further characterise the involvement of the OX40-OX40L system in chicken immune response. 



\section{Summary}

\section{Characterisation of chicken OX40 and OX40L}

Among the costimulatory members of the tumour necrosis factor superfamily, the OX40 molecule and its ligand OX40L play a decisive role in the formation and the regulation of an efficient immune response upon antigen encounter. In mammals, their interaction allows for a sustained $\mathrm{T}$ cell response by providing anti-apoptotic signals as well as by promoting cytokine production, cell proliferation and differentiation. In chickens, however, the information on costimulatory signals accompanying TCR stimulation remains scarce.

This study aimed at the characterisation of chicken OX40 and OX40L to gain more information about the complex process of $\mathrm{T}$ cell activation in chickens.

We identified the genes of chicken OX40 and OX40L in the chicken genome and confirmed their correct annotation by virtue of shared synteny with respective flanking genes in the genomes of human and mouse. The obtained sequences were further analysed for their phylogenetic and structural relationship to other members of the TNF family in birds and mammals. The analyses revealed a tight topological relation of chicken OX40 and OX40L to their respective homologues in other species. The conservation of a functionally relevant motif among species suggests that the OX40-OX40L system preserved its functions during evolution. After the cloning and the recombinant expression of soluble and cell-associated variants, we verified the mutual interaction of chicken OX40 and OX40L via ELISA and flow cytometric analyses and demonstrated that both soluble recombinant proteins tend to dimerise. As only few antibodies are available to characterise chicken cell types, we proved the application of recombinant OX40-Fc in staining of chicken cells. While OX40L could not be detected on non-activated cells, OX40L was upregulated on $\alpha \beta$ and $\gamma \delta$ $\mathrm{T}$ cells upon activation by IL-2 and IL-12. These findings confirm the existence of the OX40-OX40L system in chickens and suggest their involvement in the activation process of chicken $\mathrm{T}$ cells.

Eventually, soluble and cell-bound variants of OX40 and OX40L, generated within this study, may serve as new tools to further characterise the involvement of the OX40-OX40L system in chicken $\mathrm{T}$ cell response. 



\section{Zusammenfassung}

\section{Charakterisierung von OX40 und OX40L beim Haushuhn}

Innerhalb der Gruppe der kostimulatorischen Moleküle der Tumor-Nekrose-Faktor Superfamilie nehmen OX40 und sein Ligand OX40L eine besondere Rolle ein, da sie maßgeblich zur Entstehung einer Immunantwort nach Antigenkontakt beziehungsweise zu deren Regulation beitragen. Bei Säugetieren erhält die Interaktion von OX40 und OX40L den Aktivierungszustand von T-Zellen aufrecht, indem sowohl Überlebenssignale und Zytokinproduktion, als auch Zelldifferenzierung und -proliferation gefördert werden. Beim Haushuhn ist jedoch bisher bezüglich der kostimulatorischen Signale, die mit der Stimulation des T-Zell-Rezeptors einhergehen, wenig bekannt.

Ziel dieser Arbeit war es deshalb, die kostimulatorisch wirksamen Moleküle OX40 und OX40L beim Haushuhn zu charakterisieren, um mehr über den Aktivierungsprozess von T-Zellen beim Haushuhn zu erfahren.

Der erste Teil dieser Arbeit beschäftigt sich mit der Identifizierung der OX40und OX40L-Gene im Hühnergenom. Dank der Konservierung der Genabfolge innerhalb relevanter Genomabschnitte bei Mensch, Maus und Huhn, konnten die Gene für OX40 und OX40L beim Huhn identifiziert und richtig zugeordnet werden. Nachfolgende Sequenzanalysen schlossen die Proteinsequenzen anderer Mitglieder der TNF-Familie mit ein. Sie verdeutlichten die phylogenetisch enge Verwandtschaft der aviären Moleküle zu ihren Homologen beim Säuger. Ebenso offenbarten die Analysen der Proteinsequenzen strukturelle Gemeinsamkeiten zwischen den Molekülen von Vögeln und Säugern, sowie die Konservierung eines Sequenzmotivs mit funktioneller Bedeutung. Der Erhalt dieses Motivs und des charakteristischen Molekülaufbaus lässt vermuten, dass OX40 und OX40L beim Huhn ähnliche Aufgaben wie beim Säugetier erfüllen. Die Klonierung und rekombinante Expression von löslichen und zell-gebundenen Formen der OX40- und OX40L-Moleküle ermöglichte eine nähere Untersuchung dieser Proteine beim Huhn. So konnte mittels ELISA und Durchflusszytometrie die Interaktion zwischen Rezeptor und Ligand in drei unabhängigen Versuchen bestätigt werden. Darüberhinaus konnte gezeigt werden, dass die löslichen, rekombinant hergestellten Proteine Dimere bilden. Da zur näheren Charakterisierung von Zellen beim Huhn nur eine begrenzte Anzahl an Antikörpern zur Verfügung steht, wurde in dieser Arbeit gezeigt, dass die lösliche, 
rekombinante Form OX40-Fc geeignet ist, Hühnerzellen für die Durchflusszytometrie anzufärben. In diesem Zusammenhang konnte nachgewiesen werden, dass OX40L, nach Aktivierung durch IL-2 und IL-12, sowohl auf $\alpha \beta-$ als auch auf $\gamma \delta$ T-Zellen des Huhns zu finden ist, wohingegen verschiedene naive Hühnerzellen OX40L nicht exprimierten. Diese Ergebnisse bestätigen die Existenz des OX40OX40L-Systems für das Haushuhn und legen nahe, dass es an der T-Zell-Aktivierung beteiligt ist.

Darüber hinaus bieten die im Zuge dieser Arbeit hergestellten rekombinanten OX40und OX40L-Proteine des Huhns neue Möglichkeiten, den Einfluss des OX40-OX40LSystems in der T-Zell-Aktivierung beim Haushuhn näher zu untersuchen. 


\section{References}

1. Lowenthal, J., Bean, A. \& Kogut, M. What's so special about chicken immunology? Developmental $\&$ Comparative Immunology 41, 307-309 (2013).

2. Glick, B., Chang, T. \& Jaap, R. The bursa of Fabricius and antibody production. Poultry Science 35, 224-225 (1956).

3. Cooper, M., Peterson, R. \& Good, R. Delineation of the thymic and bursal lymphoid systems in the chicken. Nature 205, 143-146 (1965).

4. Isaacs, A. \& Lindenmann, J. Virus interference. I. The interferon. Proceedings of the Royal Society of London Series B (Biological Sciences) 147, 258-267 (1957).

5. Furlong, R. Insights into vertebrate evolution from the chicken genome sequence. Genome Biology 6, 207 (2005).

6. Kaiser, P. The avian immune genome - a glass half-full or half-empty? Cytogenetic and Genome Research 117, 221-230 (2007).

7. Straub, C. et al. Chicken NK cell receptors. Developmental \& Comparative Immunology 41, 324-333 (2013).

8. Barjesteh, N. et al. TLR Ligands Induce Antiviral Responses in Chicken Macrophages. Plos One 9, e105713 (2014).

9. Ratcliffe, M. \& Härtle, S. Avian Immunology 2nd Edition, Chap. 4: B Cells, the Bursa of Fabricius and the Generation of Antibody Repertoires, p. 65-89 (eds Schat, K., Kaspers, B. \& Kaiser, P.) (Academic Press, Elsevier, London, UK, 2014).

10. Smith, A. \& Göbel, T. Avian Immunology 2nd Edition, Chap. 5: Avian T Cells: Antigen Recognition and Lineages, p. 91-102 (eds Schat, K., Kaspers, B. \& Kaiser, P.) (Academic Press, Elsevier, London, UK, 2014).

11. Allison, J., McIntyre, B. \& Bloch, D. Tumor-specific antigen of murine Tlymphoma defined with monoclonal antibody. The Journal of Immunology 129, 2293-2300 (1982).

12. Brenner, M. et al. Identification of a putative second T-cell receptor. Nature 322, 145-149 (1986). 
13. Su, C., Jakobsen, I., Gu, X. \& Nei, M. Diversity and evolution of T-cell receptor variable region genes in mammals and birds. Immunogenetics 50, 301-308 (1999).

14. Tolkamp, B., Wall, E., Roehe, R., Newbold, J. \& Zaralis, K. Review of nutrient efficiency in different breeds of farm livestock. Report prepared for Department of Environment, Food and Rural Affairs, London, UK. Available at: http://sciencesearch.defra.gov.uk/Document.aspx?Document=Final ReportIF0183.doc [accessed 13th February 2018], 1-105 (2010).

15. Stewart, C., Keyburn, A., Deffrasnes, C. \& Tompkins, S. Potential directions for chicken immunology research. Developmental $\&$ Comparative Immunology 41, 463-468 (2013).

16. Murphy, K. Janeway's Immunobiology 8th Edition, Chap. 1: Basic Concepts in Immunology, p. 1-36 (ed Lawrence, E.) (Garland Science, Taylor \& Francis Group, LLC, New York, USA, 2012).

17. Murphy, K. Janeway's Immunobiology 8th Edition, Chap. 9: T Cell-Mediated Immunity, p. 335-386 (ed Lawrence, E.) (Garland Science, Taylor \& Francis Group, LLC, New York, USA, 2012).

18. Rink, L., Kruse, A. \& Haase, H. Immunologie für Einsteiger 1st Edition, Chap. 5: Die Immunantwort durch Lymphocyten, p. 75-104 (Spektrum Akademischer Verlag, Heidelberg, Germany, 2012).

19. Ribot, J., deBarros, A. \& Silva-Santos, B. Searching for "signal 2": costimulation requirements of $\gamma \delta \mathrm{T}$ cells. Cellular and Molecular Life Sciences 68, 2345-2355 (2011).

20. Murphy, K. Janeway's Immunobiology 8th Edition, Chap. 7: Signaling Through Immune-System Receptors, p. 239-274 (ed Lawrence, E.) (Garland Science, Taylor \& Francis Group, LLC, New York, USA, 2012).

21. Lenschow, D., Walunas, T. \& Bluestone, J. CD28/B7 system of T cell costimulation. Annual Review of Immunology 14, 233-258 (1996).

22. Ribeiro, S., Ribot, J. \& Silva-Santos, B. Five layers of receptor signaling in $\gamma \delta$ T-cell differentiation and activation. Frontiers in Immunology 6, 1-9 (2015).

23. Vainio, O., Riwar, B., Brown, M. \& Lassila, O. Characterization of the putative avian CD2 homologue. The Journal of Immunology 147, 1593-1599 (1991). 
24. Croft, M. Costimulation of T cells by OX40, 4-1BB, and CD27. Cytokine 85 Growth Factor Reviews 14, 265-273 (2003).

25. Tibaldi, E., Salgia, R. \& Reinherz, E. CD2 molecules redistribute to the uropod during $\mathrm{T}$ cell scanning: Implications for cellular activation and immune surveillance. Proceedings of the National Academy of Sciences of the Unites States of America 99, 7582-7587 (2002).

26. Espagnolle, N. et al. CD2 and TCR synergize for the activation of phospholipase $\mathrm{C} \gamma 1 /$ calcium pathway at the immunological synapse. International Immunology 19, 239-248 (2007).

27. Meuer, S. et al. An alternative pathway of T-cell activation: a functional role for the $50 \mathrm{kd}$ T11 sheep erythrocyte receptor protein. Cell 36, 897-906 (1984).

28. Brandes, M. et al. Flexible migration program regulates $\curlyvee \delta$ T-cell involvement in humoral immunity. Blood 102, 3693-3701 (2003).

29. Simpson, T., Quezada, S. \& Allison, J. Regulation of CD4 T cell activation and effector function by inducible costimulator (ICOS). Current Opinion in Immunology 22, 326-332 (2010).

30. Hansen, J., Martin, P. \& Nowinski, R. Monoclonal antibodies identifying a novel T-cell antigen and Ia antigens of human lymphocytes. Immunogenetics 10, 247-260 (1980).

31. Gross, J., Callas, E. \& Allison, J. Identification and distribution of the costimulatory receptor CD28 in the mouse. The Journal of Immunology 149, 380-388 (1992).

32. Young, J., Davison, T., Tregaskes, C., Rennie, M. \& Vainio, O. Monomeric homologue of mammalian CD28 is expressed on chicken T cells. The Journal of Immunology 152, 3848-3851 (1994).

33. Testi, R. \& Lanier, L. Functional expression of CD28 on T cell antigen receptor $\gamma / \delta$ bearing $\mathrm{T}$ lymphocytes. European Journal of Immunology 19, 185188 (1989).

34. Koskela, K., Arstila, T. \& Lassila, O. Costimulatory function of CD28 in avian ro T cells is evolutionarily conserved. Scandinavian Journal of Immunology 48, 635-641 (1998). 
35. Sperling, A., Linsley, P., Barrett, T. \& Bluestone, J. CD28-mediated costimulation is necessary for the activation of $\mathrm{T}$ cell receptor-gamma delta $+\mathrm{T}$ lymphocytes. The Journal of Immunology 151, 6043-6050 (1993).

36. Boise, L. et al. CD28 costimulation can promote $\mathrm{T}$ cell survival by enhancing the expression of Bcl-xL. Immunity 3, 87-98 (1995).

37. Fraser, J., Irving, B., Crabtree, G. \& Weiss, A. Regulation of interleukin-2 gene enhancer activity by the T cell accessory molecule CD28. Science $\mathbf{2 5 1}$, 313-316 (1991).

38. Lindstein, T., June, C., Ledbetter, J., Stella, G. \& Thompson, C. Regulation of lymphokine messenger RNA stability by a surface-mediated $\mathrm{T}$ cell activation pathway. Science 244, 339-343 (1989).

39. Ma, A., Koka, R. \& Burkett, P. Diverse functions of IL-2, IL-15, and IL-7 in lymphoid homeostasis. Annual Review of Immunology 24, 657-679 (2006).

40. Waldmann, T. et al. Expression of interleukin 2 receptors on activated human B cells. Journal of Experimental Medicine 160, 1450-1466 (1984).

41. Benveniste, E. \& Merrill, J. Stimulation of oligodendroglial proliferation and maturation by interleukin-2. Nature 321, 610-613 (1986).

42. Henney, C., Kuribayashi, K., Kern, D. \& Gillis, S. Interleukin-2 augments natural killer cell activity. Nature 291, 335-338 (1981).

43. Morgan, D., Ruscetti, F. \& Gallo, R. Selective in vitro growth of T lymphocytes from normal human bone marrows. Science 193, 1007-1008 (1976).

44. Casetti, R. et al. Drug-induced expansion and differentiation of V $\curlyvee 9 \mathrm{~V} \delta 2 \mathrm{~T}$ cells in Vivo: The Role of Exogenous IL-2. The Journal of Immunology 175, 1593-1598 (2005).

45. Leonard, W. et al. Molecular cloning and expression of cDNAs for the human interleukin-2 receptor. Nature 311, 626-631 (1984).

46. Sharon, M., Klausner, R., Cullen, B., Chizzonite, R. \& Leonard, W. Novel interleukin-2 receptor subunit detected by cross-linking under high-affinity conditions. Science 234, 859-863 (1986).

47. Takeshita, T. et al. Cloning of the gamma chain of the human IL-2 receptor. Science 257, 379-382 (1992). 
48. Leonard, W. Fundamental Immunology 7th Edition, Chap. 25: Type I Cytokines and Interferons, and Their Receptors, p. 601-638 (ed Paul, W.) (Lippincott Williams \& Wilkins, a Wolters Kluwer business, Philadelphia, USA, 2013).

49. Liao, W., Lin, J., Wang, L., Li, P. \& Leonard, W. Modulation of cytokine receptors by IL-2 broadly regulates differentiation into helper T cell lineages. Nature Immunology 12, 551-559 (2011).

50. Liao, W. et al. Priming for $\mathrm{T}$ helper type 2 differentiation by interleukin 2 -mediated induction of interleukin 4 receptor $\alpha$-chain expression. Nature Immunology 9, 1288-1296 (2008).

51. Cote-Sierra, J. et al. Interleukin 2 plays a central role in Th2 differentiation. Proceedings of the National Academy of Sciences of the Unites States of America 101, 3880-3885 (2004).

52. Williams, M., Tyznik, A. \& Bevan, M. Interleukin-2 signals during priming are required for secondary expansion of CD8+ memory T cells. Nature $\mathbf{4 4 1}$, 890-893 (2006).

53. Laurence, A. et al. Interleukin-2 Signaling via STAT5 Constrains T Helper 17 Cell Generation. Immunity 26, 371-381 (2007).

54. Yu, A., Zhu, L., Altman, N. \& Malek, T. A Low Interleukin-2 Receptor Signaling Threshold Supports the Development and Homeostasis of T Regulatory Cells. Immunity 30, 204-217 (2009).

55. Lenardo, M. Interleukin-2 programs mouse $\alpha \beta \mathrm{T}$ lymphocytes for apoptosis. Nature 353, 858-861 (1991).

56. Desai, B. et al. IL-12 receptor. II. Distribution and regulation of receptor expression. The Journal of Immunology 148, 3125-3132 (1992).

57. Yin, Z. et al. Dominance of IL-12 over IL-4 in $\gamma \delta \mathrm{T}$ cell differentiation leads to default production of IFN- $\gamma$ : failure to down-regulate IL-12 receptor $\beta 2$-chain expression. The Journal of Immunology 164, 3056-3064 (2000).

58. Zou, J., Presky, D., Wu, C. \& Gubler, U. Differential Associations between the Cytoplasmic Regions of the Interleukin-12 Receptor Subunits $\beta 1$ and $\beta 2$ and JAK Kinases. Journal of Biological Chemistry 272, 6073-6077 (1997). 
59. Gately, M. et al. The interleukin-12/interleukin-12-receptor system: role in normal and pathologic immune responses. Annual Review of Immunology 16, 495-521 (1998).

60. Szabo, S., Dighe, A., Gubler, U. \& Murphy, K. Regulation of the Interleukin (IL)-12R $\beta 2$ Subunit Expression in Developing T Helper 1 (Th1) and Th2 Cells. Journal of Experimental Medicine 185, 817-824 (1997).

61. Manetti, R. et al. Natural Killer Cell stimulatory Factor (Interleukin 12 [IL-12]) Induces T Helper Type 1 (Th1)-specific Immune Responses and Inhibits the Development of IL-4-producing Th Cells. Journal of Experimental Medicine 177, 1199-1204 (1993).

62. Watts, T. TNF/TNFR family members in costimulation of $\mathrm{T}$ cell responses. Annual Review of Immunology 23, 23-68 (2005).

63. Rogers, P., Song, J., Gramaglia, I., Killeen, N. \& Croft, M. OX40 promotes Bcl-xL and Bcl-2 expression and is essential for long-term survival of CD4 T cells. Immunity 15, 445-455 (2001).

64. Akiba, H. et al. CD28-independent costimulation of T cells by OX40 ligand and CD70 on activated B cells. The Journal of Immunology 162, 7058-7066 (1999).

65. Walker, L. et al. Compromised OX40 function in CD28-deficient mice is linked with failure to develop CXC chemokine receptor 5-positive CD4 cells and germinal centers. Journal of Experimental Medicine 190, 1115-1122 (1999).

66. Esperón, E., Cordier, G. \& Engel, N. A genomic reservoir for Tnfrsf genes is developmentally regulated and imprinted in the mouse. Epigenetics 7, 626634 (2012).

67. Screaton, G. \& Xu, X. T cell life and death signalling via TNF-receptor family members. Current Opinion in Immunology 12, 316-322 (2000).

68. Bodmer, J., Schneider, P. \& Tschopp, J. The molecular architecture of the TNF superfamily. Trends in Biochemical Sciences 27, 19-26 (2002).

69. Gruss, H. \& Dower, S. Tumor necrosis factor ligand superfamily: involvement in the pathology of malignant lymphomas. Blood 85, 3378-3404 (1995).

70. Goodwin, R. et al. Molecular cloning of a ligand for the inducible T cell gene 4-1BB: a member of an emerging family of cytokines with homology to tumor necrosis factor. European Journal of Immunology 23, 2631-2641 (1993). 
71. Mallett, S. \& Barclay, A. A new superfamily of cell surface proteins related to the nerve growth factor receptor. Immunology Today 12, 220-223 (1991).

72. Idriss, H. \& Naismith, J. TNF $\alpha$ and the TNF receptor superfamily: Structurefunction relationship(s). Microscopy Research and Technique 50, 184-195 (2000).

73. Naismith, J. \& Sprang, S. Modularity in the TNF-receptor family. Trends in Biochemical Sciences 23, 74-79 (1998).

74. Liu, Y. et al. Ligand-receptor binding revealed by the TNF family member TALL-1. Nature 423, 49-56 (2003).

75. Zhang, G. Tumor necrosis factor family ligand-receptor binding. Current Opinion in Structural Biology 14, 154-160 (2004).

76. Ware, C. The TNF Superfamily. Cytokine $\& 3$ Growth Factor Reviews 14, 181$184(2003)$.

77. Banner, D. et al. Crystal structure of the soluble human $55 \mathrm{kd}$ TNF receptorhuman TNF $\beta$ complex: implications for TNF receptor activation. Cell 73, 431-45 (1993).

78. Willoughby, J., Griffiths, J., Tews, I. \& Cragg, M. OX40: Structure and function - What questions remain? Molecular Immunology 83, 13-22 (2017).

79. Chan, F. et al. A Domain in TNF Receptors That Mediates Ligand-Independent Receptor Assembly and Signaling. Science 288, 2351-2354 (2000).

80. Ward-Kavanagh, L., Lin, W., Šedý, J. \& Ware, C. The TNF Receptor Superfamily in Co-stimulating and Co-inhibitory Responses. Immunity 44, 10051019 (2016).

81. Pitti, R. et al. Genomic amplification of a decoy receptor for Fas ligand in lung and colon cancer. Nature 396, 699-703 (1998).

82. Vanamee, É. \& Faustman, D. Structural principles of tumor necrosis factor superfamily signaling. Science Signaling 11, eaao4910 (2018).

83. Chung, J., Park, Y., Ye, H. \& Wu, H. All TRAFs are not created equal: common and distinct molecular mechanisms of TRAF-mediated signal transduction. Journal of Cell Science 115, 679-688 (2002). 
84. O'Malley, W. \& Achinstein, B. Action of Bacterial Polysaccharide on Tumors. II. Damage of Sarcoma 37 by Serum of Mice Treated With Serratia Marcescens Polysaccharide, and Induced Tolerance. Journal of the National Cancer Institute 29, 1169-1175 (1962).

85. Aggarwal, B., Shishodia, S., Ashikawa, K. \& Bharti, A. The role of TNF and its family members in inflammation and cancer: lessons from gene deletion. Current Drug Targets - Inflammation \& Allergy 1, 327-341 (2002).

86. Eck, M. \& Sprang, S. The structure of tumor necrosis factor-alpha at $2.6 \mathrm{~A}$ resolution. Implications for receptor binding. Journal of Biological Chemistry 264, 17595-17605 (1989).

87. Chen, Y. et al. Mutations within a furin consensus sequence block proteolytic release of ectodysplasin-A and cause X-linked hypohidrotic ectodermal dysplasia. Proceedings of the National Academy of Sciences of the Unites States of America 98, 7218-7223 (2001).

88. Schneider, P. et al. Mutations Leading to X-linked Hypohidrotic Ectodermal Dysplasia Affect Three Major Functional Domains in the Tumor Necrosis Factor Family Member Ectodysplasin-A. Journal of Biological Chemistry 276, 18819-18827 (2001).

89. Tanaka, M., Itai, T., Adachi, M. \& Nagata, S. Downregulation of Fas ligand by shedding. Nature Medicine 4, 31-36 (1998).

90. Compaan, D. \& Hymowitz, S. The Crystal Structure of the Costimulatory OX40-OX40L Complex. Structure 14, 1321-1330 (2006).

91. RCSB Protein Data Bank. [Accessed: Jan. 2018]. Available at: <https :// www.rcsb.org/>.

92. Berman, H. et al. The Protein Data Bank. Acta Crystallographica Section D 58, 899-907 (2002).

93. Rose, A. \& Hildebrand, P. NGL Viewer: a web application for molecular visualization. Nucleic Acids Research 43, W576-579 (2015).

94. Rose, A. et al. Web-based molecular graphics for large complexes. Proceedings of the 21st International Conference on Web3D Technology, 185-186 (2016).

95. Karpusas, M. et al. 2 å crystal structure of an extracellular fragment of human CD40 ligand. Structure 3, 1031-1039 (1995). 
96. Karpusas, M. et al. Crystal structure of extracellular human BAFF, a TNF family member that stimulates B lymphocytes. Journal of Molecular Biology 315, 1145-1154 (2002).

97. Hymowitz, S. et al. The Crystal Structures of EDA-A1 and EDA-A2. Structure 11, 1513-1520 (2003).

98. Locksley, R., Killeen, N. \& Lenardo, M. The TNF and TNF Receptor Superfamilies. Cell 104, 487-501 (2001).

99. Papoff, G. et al. Identification and characterization of a ligand-independent oligomerization domain in the extracellular region of the CD95 death receptor. Journal of Biological Chemistry 274, 38241-38250 (1999).

100. Naismith, J., Devine, T., Brandhuber, B. \& Sprang, S. Crystallographic evidence for dimerization of unliganded tumor necrosis factor receptor. Journal of Biological Chemistry 270, 13303-13307 (1995).

101. Siegel, R. et al. Fas Preassociation Required for Apoptosis Signaling and Dominant Inhibition by Pathogenic Mutations. Science 288, 2354-2357 (2000).

102. Yin, Q. et al. E2 interaction and dimerization in the crystal structure of TRAF6. Nature Structural \& Molecular Biology 16, 658-666 (2009).

103. Fu, Q. et al. Structural Basis and Functional Role of Intramembrane Trimerization of the Fas/CD95 Death Receptor. Molecular Cell 61, 602-613 (2016).

104. Ye, H., Park, Y., Kreishman, M., Kieff, E. \& Wu, H. The structural basis for the recognition of diverse receptor sequences by TRAF2. Molecular Cell 4, 321-330 (1999).

105. Takeuchi, M., Rothe, M. \& Goeddel, D. Anatomy of TRAF2 distinct domains for nuclear factor- $\chi \mathrm{B}$ activation and association with tumor necrosis factor signaling proteins. Journal of Biological Chemistry 271, 19935-19942 (1996).

106. Aggarwal, B. Signalling pathways of the TNF superfamily: a double-edged sword. Nature Reviews Immunology 3, 745-756 (2003).

107. Arch, R. \& Thompson, C. 4-1BB and Ox40 are members of a tumor necrosis factor (TNF)-nerve growth factor receptor subfamily that bind TNF receptorassociated factors and activate nuclear factor $\chi \mathrm{B}$. Molecular and Cellular Biology 18, 558-565 (1998). 
108. Kawamata, S., Hori, T., Imura, A., Takaori-Kondo, A. \& Uchiyama, T. Activation of OX40 signal transduction pathways leads to tumor necrosis factor receptor-associated factor (TRAF) 2- and TRAF5-mediated NF- $x \mathrm{~B}$ activation. Journal of Biological Chemistry 273, 5808-5814 (1998).

109. Song, J., So, T. \& Croft, M. Activation of NF- $\chi \mathrm{B} 1$ by OX40 contributes to antigen-driven $\mathrm{T}$ cell expansion and survival. The Journal of Immunology 180, 7240-7248 (2008).

110. Xiao, X. et al. OX40 signaling favors the induction of TH9 cells and airway inflammation. Nature Immunology 13, 981-990 (2012).

111. Song, J. et al. The costimulation-regulated duration of PKB activation controls T cell longevity. Nature Immunology 5, 150-158 (2004).

112. Song, J., So, T., Cheng, M., Tang, X. \& Croft, M. Sustained Survivin Expression from OX40 Costimulatory Signals Drives T Cell Clonal Expansion. Immunity 22, 621-631 (2005).

113. So, T., Song, J., Sugie, K., Altman, A. \& Croft, M. Signals from OX40 regulate nuclear factor of activated $\mathrm{T}$ cells $\mathrm{c} 1$ and $\mathrm{T}$ cell helper 2 lineage commitment. Proceedings of the National Academy of Sciences of the Unites States of America 103, 3740-3745 (2006).

114. Gramaglia, I., Weinberg, A., Lemon, M. \& Croft, M. Ox-40 ligand: a potent costimulatory molecule for sustaining primary CD4 $\mathrm{T}$ cell responses. The Journal of Immunology 161, 6510-6517 (1998).

115. Croft, M. Control of immunity by the TNFR-related molecule OX40 (CD134). Annual Review of Immunology 28, 57-78 (2010).

116. Webb, G., Hirschfield, G. \& Lane, P. OX40, OX40L and autoimmunity: a comprehensive review. Clinical Reviews in Allergy $\&$ Immunology 50, 312332 (2016).

117. Eissner, G., Kolch, W. \& Scheurich, P. Ligands working as receptors: reverse signaling by members of the TNF superfamily enhance the plasticity of the immune system. Cytokine $\&$ Growth Factor Reviews 15, 353-366 (2004).

118. Eissner, G. et al. Reverse signaling through transmembrane TNF confers resistance to lipopolysaccharide in human monocytes and macrophages. The Journal of Immunology 164, 6193-6198 (2000). 
119. Smith, C., Farrah, T. \& Goodwin, R. The TNF receptor superfamily of cellular and viral proteins: activation, costimulation, and death. Cell 76, 959-962 (1994).

120. HGNC - HUGO Gene Nomenclature Committee. OX40. [Accessed: Feb. 2018]. Available at: <https : / / www . genenames .org/cgi-bin/gene _ symbol _ report?hgnc_id=HGNC: $11918>$.

121. Paterson, D. et al. Antigens of activated rat $\mathrm{T}$ lymphocytes including a molecule of 50,000 $\mathrm{Mr}$ detected only on CD4 positive T blasts. Molecular Immunology 24, 1281-1290 (1987).

122. HGNC - HUGO Gene Nomenclature Committee. OX40L. [Accessed: Feb. 2018]. Available at: <https : / / www . genenames . org / cgi-bin / gene _ symbol_report?hgnc_id=HGNC:11934>.

123. Tanaka, Y., Inoi, T., Tozawa, H., Yamamoto, N. \& Hinuma, Y. A glycoprotein antigen detected with new monoclonal antibodies on the surface of human lymphocytes infected with human T-cell leukemia virus type-I (HTLV-I). International Journal of Cancer 36, 549-555 (1985).

124. Baum, P. et al. Molecular characterization of murine and human OX40/OX40 ligand systems: identification of a human OX40 ligand as the HTLV-1-regulated protein gp34. The EMBO Journal 13, 3992-4001 (1994).

125. Latza, U. et al. The human OX40 homolog: cDNA structure, expression and chromosomal assignment of the ACT35 antigen. European Journal of Immunology 24, 677-683 (1994).

126. Mallett, S., Fossum, S. \& Barclay, A. Characterization of the MRC OX40 antigen of activated CD4 positive $\mathrm{T}$ lymphocytes - a molecule related to nerve growth factor receptor. The EMBO Journal 9, 1063-1068 (1990).

127. Bansal-Pakala, P., Halteman, B., Cheng, M. \& Croft, M. Costimulation of CD8 T Cell Responses by OX40. The Journal of Immunology 172, 48214825 (2004).

128. Redmond, W., Ruby, C. \& Weinberg, A. The role of OX40-mediated costimulation in T-cell activation and survival. Critical Reviews in Immunology 29, 187-201 (2009). 
129. Stüber, E. \& Strober, W. The T cell-B cell interaction via OX40-OX40L is necessary for the $\mathrm{T}$ cell-dependent humoral immune response. Journal of Experimental Medicine 183, 979 (1996).

130. Gramaglia, I. et al. The OX40 Costimulatory Receptor Determines the Development of CD4 Memory by Regulating Primary Clonal Expansion. The Journal of Immunology 165, 3043-3050 (2000).

131. Vetto, J. et al. Presence of the T-cell activation marker OX-40 on tumor infiltrating lymphocytes and draining lymph node cells from patients with melanoma and head and neck cancers. The American Journal of Surgery 174, 258-265 (1997).

132. Tittle, T., Weinberg, A., Steinkeler, C. \& Maziarz, R. Expression of the T-cell activation antigen, OX-40, identifies alloreactive $\mathrm{T}$ cells in acute graft-versushost disease. Blood 89, 4652-4658 (1997).

133. Lamb, L. et al. Expression of CD134 (0X-40) on T cells during the first 100 days following allogeneic bone marrow transplantation as a marker for lymphocyte activation and therapy-resistant graft-versus-host disease. Cytometry 380, 238-243 (1999).

134. Stüber, E. et al. The expression of OX40 in immunologically mediated diseases of the gastrointestinal tract (celiac disease, Crohn's disease, ulcerative colitis). European Journal of Clinical Investigation 30, 594-599 (2000).

135. Baumann, R. et al. Functional expression of CD134 by neutrophils. European Journal of Immunology 34, 2268-2275 (2004).

136. Liu, C. et al. Plasmacytoid dendritic cells induce NK cell-dependent, tumor antigen-specific $\mathrm{T}$ cell cross-priming and tumor regression in mice. The Journal of Clinical Investigation 118, 1165-1175 (2008).

137. Zaini, J. et al. OX40 ligand expressed by DCs costimulates NKT and CD4+ Th cell antitumor immunity in mice. The Journal of Clinical Investigation 117, 3330-3338 (2007).

138. Rogers, P. \& Croft, M. CD28, Ox-40, LFA-1, and CD4 modulation of Th1/Th2 differentiation is directly dependent on the dose of antigen. The Journal of Immunology 164, 2955-2963 (2000). 
139. Jenkins, S., Perona-Wright, G., Worsley, A., Ishii, N. \& MacDonald, A. Dendritic cell expression of OX40 ligand acts as a costimulatory, not polarizing, signal for optimal Th2 priming and memory induction in vivo. The Journal of Immunology 179, 3515-3523 (2007).

140. Linton, P. et al. Costimulation via OX40L expressed by B cells is sufficient to determine the extent of primary CD4 cell expansion and Th2 cytokine secretion in vivo. Journal of Experimental Medicine 197, 875-883 (2003).

141. Karulf, M., Kelly, A., Weinberg, A. \& Gold, J. OX40 ligand regulates inflammation and mortality in the innate immune response to sepsis. The Journal of Immunology 185, 4856-4862 (2010).

142. Sato, T. et al. Consequences of OX40-OX40 ligand interactions in Langerhans cell function: enhanced contact hypersensitivity responses in OX40Ltransgenic mice. European Journal of Immunology 32, 3326-3335 (2002).

143. Maxwell, J. et al. IL-18 bridges innate and adaptive immunity through IFNgamma and the CD134 pathway. The Journal of Immunology 177, 234-245 (2006).

144. Ito, T. et al. TSLP-activated dendritic cells induce an inflammatory T helper type 2 cell response through OX40 ligand. Journal of Experimental Medicine 202, 1213-1223 (2005).

145. Kurche, J., Haluszczak, C., McWilliams, J., Sanchez, P. \& Kedl, R. Type I IFN-Dependent T Cell Activation Is Mediated by IFN-Dependent Dendritic Cell OX40 Ligand Expression and Is Independent of T Cell IFNR Expression. The Journal of Immunology 188, 585-593 (2012).

146. Krause, P. et al. Prostaglandin E2 enhances T-cell proliferation by inducing the costimulatory molecules OX40L, CD70, and 4-1BBL on dendritic cells. Blood 113, 2451-2460 (2009).

147. Kashiwakura, J., Yokoi, H., Saito, H. \& Okayama, Y. T cell proliferation by direct cross-talk between OX40 ligand on human mast cells and OX40 on human $\mathrm{T}$ cells: comparison of gene expression profiles between human tonsillar and lung-cultured mast cells. The Journal of Immunology 173, 52475257 (2004). 
148. Nakae, S. et al. Mast cells enhance T cell activation: importance of mast cell costimulatory molecules and secreted TNF. The Journal of Immunology $\mathbf{1 7 6}$, 2238-2248 (2006).

149. Zingoni, A. et al. Cross-talk Between Activated Human NK Cells and CD4+ $\mathrm{T}$ Cells via OX40-OX40 Ligand Interactions. The Journal of Immunology 173, 3716-3724 (2004).

150. Burgess, J. et al. Detection and characterization of OX40 ligand expression in human airway smooth muscle cells: a possible role in asthma? The Journal of Allergy and Clinical Immunology 113, 683-689 (2004).

151. Imura, A. et al. The human OX40/gp34 system directly mediates adhesion of activated $\mathrm{T}$ cells to vascular endothelial cells. Journal of Experimental Medicine 183, 2185-2195 (1996).

152. Mendel, I. \& Shevach, E. Activated T cells express the OX40 ligand: requirements for induction and costimulatory function. Immunology 117, 196-204 (2006).

153. Akiba, H. et al. Critical Contribution of OX40 Ligand to T Helper Cell Type 2 Differentiation in Experimental Leishmaniasis. Journal of Experimental Medicine 191, 375-380 (2000).

154. Aten, J. et al. Strong and selective glomerular localization of CD134 ligand and TNF receptor-1 in proliferative lupus nephritis. Journal of the American Society of Nephrology 11, 1426-1438 (2000).

155. Godfrey, W., Fagnoni, F., Harara, M., Buck, D. \& Englman, E. Identification of a human OX-40 ligand, a costimulator of CD4+ T cells with homology to tumor necrosis factor. Journal of Experimental Medicine 180, 757-762 (1994).

156. Maxwell, J., Weinberg, A., Prell, R. \& Vella, A. Danger and OX40 receptor signaling synergize to enhance memory $\mathrm{T}$ cell survival by inhibiting peripheral deletion. The Journal of Immunology 164, 107-112 (2000).

157. Williams, C., Murray, S., Weinberg, A. \& Parker, D. OX40-mediated differentiation to effector function requires IL-2 receptor signaling but not CD28, CD40, IL-12Rß2, or T-bet. The Journal of Immunology 178, 7694-7702 (2007). 
158. Soroosh, P., Ine, S., Sugamura, K. \& Ishii, N. OX40-OX40 ligand interaction through $\mathrm{T}$ cell- $\mathrm{T}$ cell contact contributes to CD4 T cell longevity. The Journal of Immunology 176, 5975-5987 (2006).

159. Obermeier, F. et al. OX40/OX40L interaction induces the expression of CXCR5 and contributes to chronic colitis induced by dextran sulfate sodium in mice. European Journal of Immunology 33, 3265-3274 (2003).

160. Zhang, Z. et al. Activation of OX40 Augments Th17 Cytokine Expression and Antigen-Specific Uveitis. The American Journal of Pathology 177, 2912-2920 (2010).

161. Takeda, I. et al. Distinct Roles for the OX40-OX40 Ligand Interaction in Regulatory and Nonregulatory T Cells. The Journal of Immunology 172, 3580-3589 (2004).

162. Ruby, C., Montler, R., Zheng, R., Shu, S. \& Weinberg, A. IL-12 is required for anti-OX40-mediated CD4 T cell survival. The Journal of Immunology 180, 2140-2148 (2008).

163. So, T. \& Croft, M. Cutting edge: OX40 inhibits TGF- $\beta$ - and antigen-driven conversion of naive CD4 T cells into CD25+Foxp3+ T cells. The Journal of Immunology 179, 1427-1430 (2007).

164. Ito, T. et al. OX40 ligand shuts down IL-10-producing regulatory T cells. Proceedings of the National Academy of Sciences of the Unites States of America 103, 13138-13143 (2006).

165. Prell, R. et al. OX40-Mediated Memory T Cell Generation Is TNF ReceptorAssociated Factor 2 Dependent. The Journal of Immunology 171, 5997-6005 (2003).

166. Fujita, T., Ukyo, N., Hori, T. \& Uchiyama, T. Functional characterization of OX40 expressed on human CD8+ T cells. Immunology Letters 106, 27-33 (2006).

167. Lee, S. et al. Functional dichotomy between OX40 and 4-1BB in modulating effector CD8 T cell responses. The Journal of Immunology 177, 4464-4472 (2006).

168. Salek-Ardakani, S., Moutaftsi, M., Crotty, S., Sette, A. \& Croft, M. OX40 drives protective vaccinia virus-specific CD8 T cells. The Journal of Immunology 181, 7969-7976 (2008). 
169. Ohshima, Y., Tanaka, Y., Tozawa, H., Maliszewski, C. \& Delespesse, G. Expression and function of OX40 ligand on human dendritic cells. The Journal of Immunology 159, 3838-3848 (1997).

170. Stüber, E., Neurath, M., Calderhead, D., Fell, H. \& Strober, W. Cross-linking of OX40 ligand, a member of the TNF/NGF cytokine family, induces proliferation and differentiation in murine splenic B cells. Immunity 2, 507-521 (1995).

171. Kotani, A., Hori, T., Matsumura, Y. \& Uchiyama, T. Signaling of gp34 (OX40 ligand) induces vascular endothelial cells to produce a CC chemokine RANTES/CCL5. Immunology Letters 84, 1-7 (2002).

172. Piconese, S. et al. Mast cells counteract regulatory T-cell suppression through interleukin-6 and OX40/OX40L axis toward Th17-cell differentiation. Blood 114, 2639-2648 (2009).

173. Gri, G. et al. CD4+CD25+ Regulatory T Cells Suppress Mast Cell Degranulation and Allergic Responses through OX40-OX40L Interaction. Immunity 29, 771-781 (2008).

174. Arstila, T., Vainio, O. \& Lassila, O. Evolutionarily conserved function of CD28 in $\alpha \beta$ T cell activation. Scandinavian Journal of Immunology 40, 368371 (1994).

175. Lillehoj, H. et al. Molecular, cellular, and functional characterization of chicken cytokines homologous to mammalian IL-15 and IL-2. Veterinary Immunology and Immunopathology 82, 229-244 (2001).

176. Degen, W., van Daal, N., van Zuilekom, H., Burnside, J. \& Schijns, V. Identification and molecular cloning of functional chicken IL-12. The Journal of Immunology 172, 4371-4380 (2004).

177. Wong, G. et al. A genetic variation map for chicken with 2.8 million singlenucleotide polymorphisms. Nature 432, 717-722 (2004).

178. Kaiser, P. et al. A genomic analysis of chicken cytokines and chemokines. Journal of Interferon $\&$ Cytokine Research 25, 467-484 (2005).

179. Sutton, K. et al. The functions of the avian receptor activator of NF- $x \mathrm{~B}$ ligand (RANKL) and its receptors, RANK and osteoprotegerin, are evolutionarily conserved. Developmental \& Comparative Immunology 51, 170-184 (2015). 
180. Schneider, K. et al. Chicken BAFF - a highly conserved cytokine that mediates B cell survival. International Immunology 16, 139-148 (2004).

181. Reddy, S. et al. The BAFF-Interacting receptors of chickens. Developmental 8 Comparative Immunology 32, 1076-1087 (2008).

182. Tregaskes, C., Glansbeek, H., Gill, A. \& Hunt, L. Conservation of biological properties of the CD40 ligand, CD154 in a non-mammalian vertebrate. Developmental \&3 Comparative Immunology 29, 361-374 (2005).

183. Kothlow, S., Morgenroth, I., Tregaskes, C., Kaspers, B. \& Young, J. CD40 ligand supports the long-term maintenance and differentiation of chicken $\mathrm{B}$ cells in culture. Developmental \& Comparative Immunology 32, 1015-1026 (2008).

184. Wang, Y., Hou, J. \& Zhou, Z. Chicken Receptor Activator of Nuclear FactorxB Ligand Induces Formation of Chicken Osteoclasts from Bone Marrow Cells and also Directly Activates Mature Osteoclasts. Poultry Science 87, 23442349 (2008).

185. Abdalla, S., Horiuchi, H., Furusawa, S. \& Matsuda, H. Molecular cloning and characterization of chicken tumor necrosis factor (TNF)-superfamily ligands, CD30L and TNF-related apoptosis inducing ligand (TRAIL). Journal of Veterinary Medical Science 66, 643-650 (2004).

186. Burgess, S. et al. Marek's disease is a natural model for lymphomas overexpressing Hodgkin's disease antigen (CD30). Proceedings of the National Academy of Sciences of the Unites States of America 101, 13879-13884 (2004).

187. Yang, H. et al. Molecular cloning and expression analysis of TRAF3 in chicken. Genetics and Molecular Research 14, 4408-4419 (2015).

188. Abdalla, S., Horiuchi, H., Furusawa, S. \& Matsuda, H. Molecular study on chicken tumor necrosis factor receptor-II and tumor necrosis factor receptorassociated factor-5. Veterinary Immunology and Immunopathology 98, 31-41 (2004).

189. Zhou, Y. et al. Molecular and functional characterization of pigeon (Columba livia) tumor necrosis factor receptor-associated factor 3. Developmental \& Comparative Immunology 69, 51-59 (2017). 
190. Zhai, Y. et al. Molecular characterization and functional analysis of duck TRAF6. Developmental \& Comparative Immunology 49, 1-6 (2015).

191. Scherer, S. \& Göbel, T. Characterisation of chicken OX40 and OX40L. Developmental $\&$ Comparative Immunology 82, 128-138 (2018).

192. SMART - Simple Modular Architecture Research Tool. [Accessed: Feb. 2018]. Available at: <http://smart.embl-heidelberg.de/>.

193. Wyzgol, A. et al. Trimer stabilization, oligomerization, and antibody-mediated cell surface immobilization improve the activity of soluble trimers of CD27L, CD40L, 41BBL, and of Glucocorticoid-induced TNF receptor ligand. The Journal of Immunology 183, 1851-1861 (2009).

194. Corti, A., Fassina, G., Marcucci, F., Barbanti, E. \& Cassani, G. Oligomeric tumour necrosis factor $\alpha$ slowly converts into inactive forms at bioactive levels. Biochemical Journal 284, 905-910 (1992).

195. Berg, D. et al. Enforced covalent trimerization increases the activity of the TNF ligand family members TRAIL and CD95L. Cell Death 83 Differentiation 14, 2021-2034 (2007).

196. Walczak, H. et al. Tumoricidal activity of tumor necrosis factor-related apoptosis-inducing ligand in vivo. Nature Medicine 5, 157-163 (1999).

197. Ganten, T. et al. Preclinical Differentiation between Apparently Safe and Potentially Hepatotoxic Applications of TRAIL Either Alone or in Combination with Chemotherapeutic Drugs. Clinical Cancer Research 12, 2640-2646 (2006).

198. Ronchetti, S. et al. Frontline: GITR, a member of the TNF receptor superfamily, is costimulatory to mouse T lymphocyte subpopulations. European Journal of Immunology 34, 613-622 (2004).

199. Shin, H., Kwon, B. \& Choi, H. Recombinant glucocorticoid induced tumour necrosis factor receptor (rGITR) induced COX-2 activity in murine macrophage Raw 264.7 cells. Cytokine 19, 187-192 (2002).

200. McHugh, R. et al. CD4+CD25+ Immunoregulatory T Cells Gene Expression Analysis Reveals a Functional Role for the Glucocorticoid-Induced TNF Receptor. Immunity 16, 311-323 (2002). 
201. Kwon, B. et al. Identification of a novel activation-inducible protein of the tumor necrosis factor receptor superfamily and its ligand. Journal of Biological Chemistry 274, 6056-6061 (1999).

202. Tone, M. et al. Mouse glucocorticoid-induced tumor necrosis factor receptor ligand is costimulatory for T cells. Proceedings of the National Academy of Sciences of the Unites States of America 100, 15059-15064 (2003).

203. Stephens, G. et al. Engagement of Glucocorticoid-Induced TNFR FamilyRelated Receptor on Effector $\mathrm{T}$ Cells by its Ligand Mediates Resistance to Suppression by CD4+CD25+ T Cells. The Journal of Immunology 173, 5008-5020 (2004).

204. Kaiser, P. The long view: a bright past, a brighter future? Forty years of chicken immunology pre-and post-genome. Avian Pathology 41, 511-518 (2012).

205. Sowder, J., Chen, C., Ager, L., Chan, M. \& Cooper, M. A large subpopulation of avian $\mathrm{T}$ cells express a homologue of the mammalian $\mathrm{T}$ gamma/delta receptor. Journal of Experimental Medicine 167, 315 (1988).

206. Cihak, J., Ziegler-Heitbrock, H., Trainer, H., Merkenschlager, M. \& Lösch, U. Characterization and functional properties of a novel monoclonal antibody which identifies a $\mathrm{T}$ cell receptor in chickens. European Journal of Immunology 18, 533-538 (1988).

207. Chen, C. et al. TCR3: a third T-cell receptor in the chicken. Proceedings of the National Academy of Sciences of the Unites States of America 86, 23512355 (1989).

208. Luhtala, M., Lassila, O., Toivanen, P. \& Vainio, O. A novel peripheral CD4+ CD8 + T cell population: inheritance of CD8 $\alpha$ expression on CD4+ T cells. European Journal of Immunology 27, 189-193 (1997).

209. Maniar, A. et al. Human $\gamma \delta \mathrm{T}$ lymphocytes induce robust NK cell-mediated antitumor cytotoxicity through CD137 engagement. Blood 116, 1726-1733 (2010).

210. Fenzl, L., Göbel, T. \& Neulen, M. Үơ T cells represent a major spontaneously cytotoxic cell population in the chicken. Developmental $\&$ Comparative Immunology 73, 175-183 (2017). 



\section{$9 \quad$ Danksagung}

Mein besonderer Dank gilt Herrn Prof. Dr. Thomas Göbel für die Überlassung des Themas und seine Bereitschaft, mir schon während meines Studiums die Möglichkeit zu bieten, mich mit dem Laboralltag und den Themengebieten der Immunologie vertraut zu machen. Seine fachliche Kompetenz und seine hervorragende Betreuung weckten mein Interesse an der Immunologie und vermittelten mir Freude am wissenschaftlichen Arbeiten. Sein mir entgegengebrachtes Vertrauen und seine stete Bereitschaft zur kritischen Diskussion trugen maßgeblich zum Gelingen dieser Arbeit bei.

Des Weiteren möchte ich mich bei Frau PD Dr. Sonja Härtle, Frau PD Dr. Birgit Viertlböck und Herrn Prof. Dr. Bernd Kaspers für ihre Anregungen und Ratschläge bedanken. Der wissenschaftliche Austausch ermöglichte es mir, mein Thema aus anderen Blickwinkeln zu betrachten und mein Wissen stetig zu erweitern.

Ein herzlicher Dank gilt den Mitgliedern meiner Arbeitsgruppe, Frau Dr. MarieLuise Neulen, Frau Dr. Isabelle Walliser, Frau Dr. Daniela Huhle und Frau Dr. Lisa Fenzl für das nette Arbeitsklima, die gute Zusammenarbeit und für die vielen lustigen Momente, die wir miteinander erlebt haben.

Den Mitarbeitern der Arbeitsgruppen Kaspers und Deeg danke ich für die freundliche und kollegiale Zusammenarbeit. Ein großes Dankeschön gilt Frau Sieglinde Hirmer, Frau Marina Kohn und Frau Beatrice Schaerer für ihre stete Hilfsbereitschaft und Geduld bei größeren und kleineren Problemen. Ebenso möchte ich mich an dieser Stelle bei den ehemaligen Mitarbeitern und Doktoranden der AG Göbel und AG Kaspers bedanken, die mich noch zu meiner Studienzeit freundlich am Lehrstuhl aufgenommen und mich eingearbeitet haben. Ihre Hilfsbereitschaft zu meiner Anfangszeit im Labor erleichterte mir den Start in die Doktorarbeit.

Bei Herrn Fritz Meggendorfer, Herrn Andreas Schöffmann, Frau Daniela Hölle und Herrn Thomas Hoschka möchte ich mich für die Betreuung der Tiere und die gute Zusammenarbeit bedanken. Herrn Franz Schmitt danke ich für seine Hilfe bei anfallenden Reparaturen im Labor. 
Ein herzliches Dankeschön gilt auch meinen Freunden, die mich immer wieder aufgemuntert und mir Mut gemacht haben.

Bei Günther möchte ich mich ganz besonders für seine Bereitschaft bedanken, mir immer zur Seite zu stehen, mich aufzubauen und mir den Rücken zu stärken.

Von Herzen bin ich meinen Eltern dankbar, die mich mein Leben lang vorbehaltlos unterstützt, an mich geglaubt und es mir ermöglicht haben, meinen Weg zu gehen. Meine Großeltern werde ich für ihre liebevolle Unterstützung immer in guter Erinnerung behalten. 